University of Redlands

\title{
A GIS Web Application for Oasis Ranch Management
}

\author{
A Major Individual Project submitted in partial satisfaction of the requirements \\ for the degree of Master of Science in Geographic Information Systems \\ by \\ James Herning \\ Mark Kumler, Ph.D., Committee Chair \\ Ruijin Ma, Ph.D. \\ Russell Weaver, Ph.D.
}

July 2013 
A GIS Web Application for Oasis Ranch Management

Copyright (C) 2013

by

James Herning 
The report of James Herning is approved.
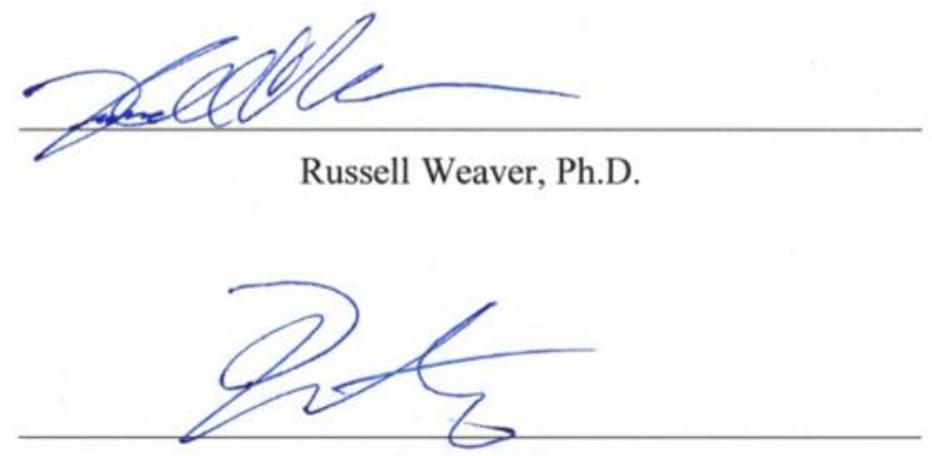

Ruijin Ma, Ph.D.

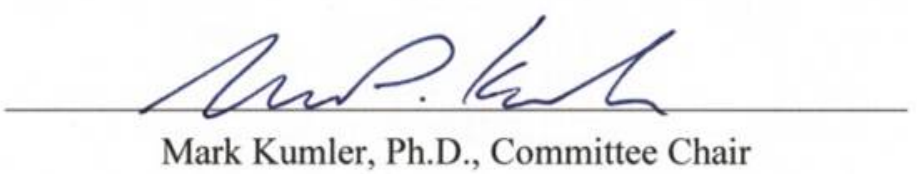

July 2013 



\section{Acknowledgements}

First and foremost I would like to thank my wonderful family: Martha, Felix, and Ayla. Your love and support were essential to my making it through this challenging year. Thank you.

I would like to thank Dr. Mark Kumler, my advisor for this project, for his help and guidance. His advice and suggestions were always helpful and he was always there when I needed him. Thanks for helping me get done-done.

I would also like to express my thanks and appreciation to the faculty and staff that I worked with during my time in Cohort 22. You were all happy to help when needed and I learned a lot.

Finally I would like to thank my project client Mr. Dennis Jensen and the whole Seaview Sales team. I enjoyed working on your project and developing an understanding of the citrus farming business. 


\begin{abstract}
A GIS Web Application for Oasis Ranch Management

by

James Herning

Geographic information systems technologies have been a fundamental component of precision agriculture for many years. However, due to the high costs of entry and the focus on variable rate input application technologies such farming methods have historically been restricted to large scale industrial farms. Oasis Ranch Management, a mid-sized grower of citrus and specialty fruits, was interested in exploring how GIS could be beneficial to their operations by facilitating knowledge capture and spatial yield tracking, and by providing a method for the creation and editing of data from a mobile device while in the field. This project developed a solution built around an ArcGIS
\end{abstract} Online organizational account for the storage and hosting of data and a mobile compatible web application that will help to achieve these goals. 


\section{Table of Contents}

Chapter 1 - Introduction ...................................................................................................... 1

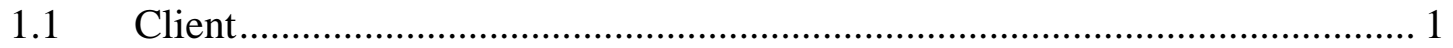

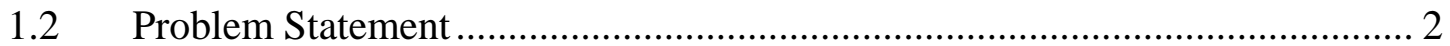

$1.3 \quad$ Proposed Solution .............................................................................. 3

1.3.1 Goals and Objectives ............................................................................... 3

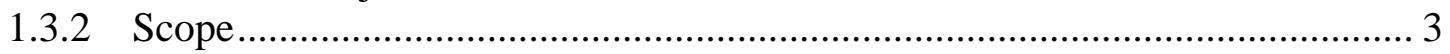

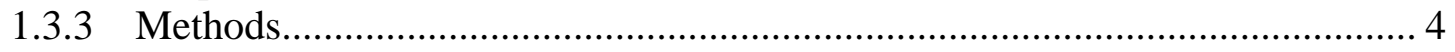

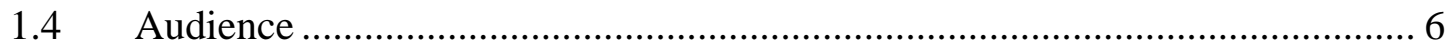

1.5 Overview of the Rest of this Report ............................................................. 6

Chapter 2 - Background and Literature Review ............................................................ 7

$2.1 \quad$ Agricultural Applications of GIS ............................................................ 7

$2.2 \quad$ Mobile GIS in Agriculture ....................................................................... 8

$2.3 \quad$ Mobile GIS Application Development ......................................................... 9

2.4 Summary ............................................................................................... 10

Chapter 3 - Systems Analysis and Design.................................................................. 11

$3.1 \quad$ Problem Statement ................................................................................ 11

3.2 Requirements Analysis ……………………………................................... 11

3.2.1 Data Requirements ..................................................................................... 11

3.2.2 Functional Requirements ......................................................................... 13

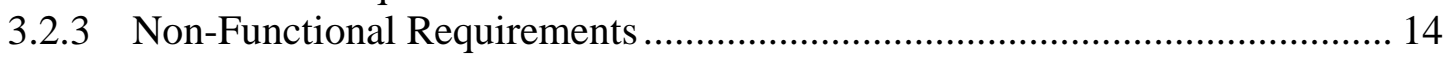

3.3 System Design ........................................................................................ 15

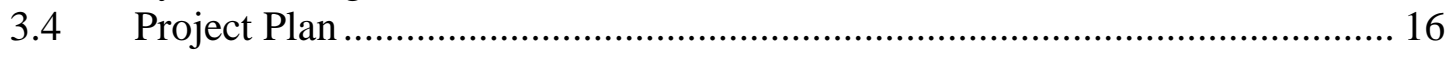

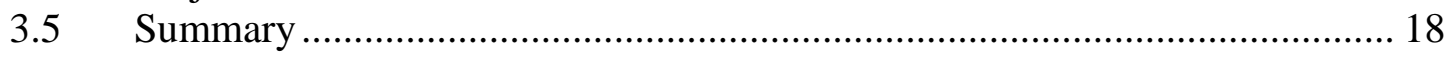

Chapter 4 - Database Design............................................................................................ 19

4.1 Conceptual Data Model ............................................................................. 19

$4.2 \quad$ Logical Data Model ..................................................................................... 20

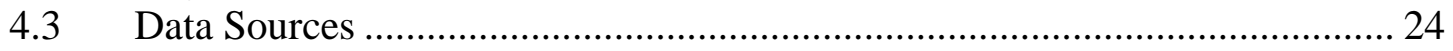

$4.4 \quad$ Data Collection Methods ............................................................................ 24

$4.5 \quad$ Data Scrubbing and Loading ……………………....................................... 26

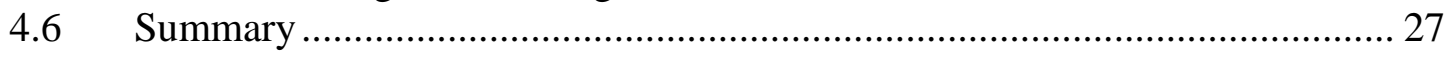

Chapter 5 - Implementation............................................................................ 29

$5.1 \quad$ Map document preparation ....................................................................... 29

$5.2 \quad$ Publishing feature services ....................................................................... 31

5.3 Web application development......................................................................... 33

5.3.1 User Interface Design ...................................................................................... 33

5.3.2 Implementation of the TimeSlider Widget ........................................................ 36

5.3.3 Data Editing Environments.......................................................................... 36

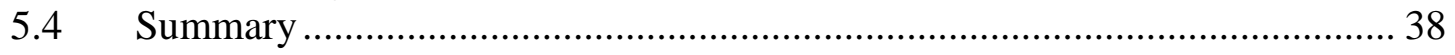

Chapter 6 - Results and Analysis....................................................................................... 41

$6.1 \quad$ Web Maps …………………………………………………………..... 41

6.1.1 The Electrical Distribution System................................................................... 41 


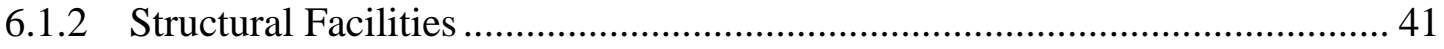

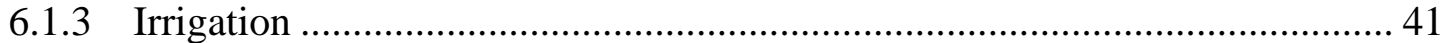

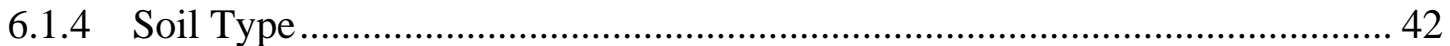

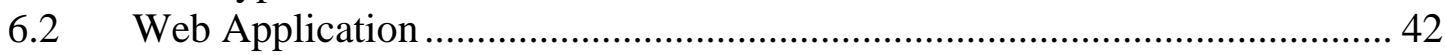

6.2.1 Visualizing Crop Production Units and Temporal Yield Values.................... 42

6.2.2 Visualizing Irrigation System Components ................................................. 44

6.2.3 Editing and Updating Information in the Field ............................................. 44

6.3 Limitations of the Application and ArcGIS Online ...................................... 47

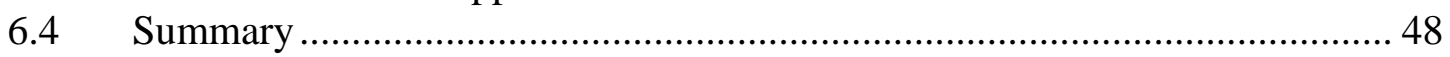

Chapter 7 - Conclusions and Future Work ................................................................ 49

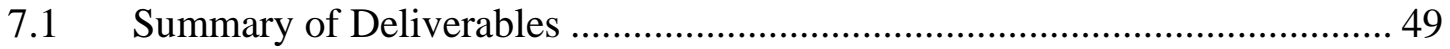

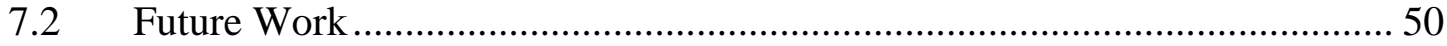

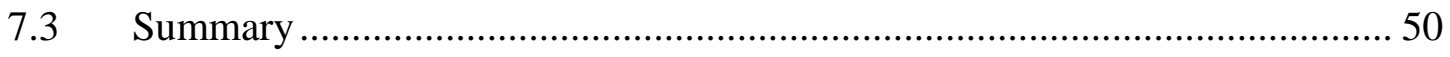

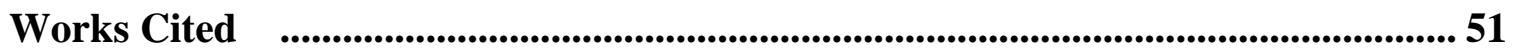

Appendix A. Feature Class Attribute Tables ................................................... 53

Appendix B. Map Documents Prepared For Publication to ArcGIS Online......... 63

Appendix C. Web Application Source Code ....................................................... 67 


\section{Table of Figures}

Figure 1-1 Seaview Ranch..................................................................................... 2

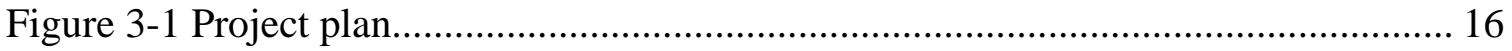

Figure 4-1 Conceptual model of the Seaview Ranch property ..................................... 19

Figure 4-2 A portion of Seaview Ranch with individual block groups selected ............. 20

Figure 4-3 A portion of the logical data model showing the cadastre, soil type, tile

drainage, electrical distribution, and production elements ........................................... 21

Figure 4-4 Logical data model showing the facilities and irrigation elements............... 22

Figure 4-5 The distribution of sampled GPS locations across the property ..................... 25

Figure 5-1 Production feature dataset map document showing the block group layer.... 30

Figure 5-2 Production feature dataset showing the varietal yield layers .......................... 30

Figure 5-3 The ArcGIS Online log in panel accessed through ArcMap......................... 31

Figure 5-4 The ArcGIS Online content panel accessed through ArcMap showing feature

services in the red box with web maps below............................................................ 32

Figure 5-5 The Service Editor showing allowed editing operations for published feature

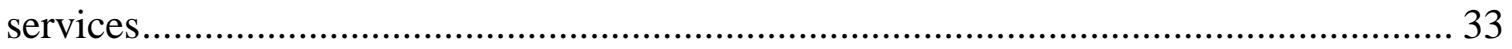

Figure 5-6 Layout of the web application user interface ............................................. 34

Figure 5-7 The default appearance of the Legend tab for each layer group.................... 35

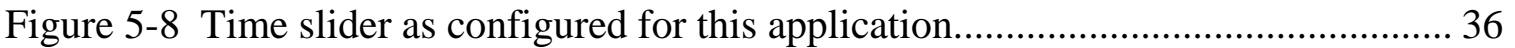

Figure 5-9 The default state of the Editor tab for the production layer group.................. 37

Figure 5-10 Editor tab with editing enabled for the block group layer ........................... 37

Figure 5-11 Edit environment for the irrigation layer group ....................................... 38

Figure 6-1 Accessing information on a specific block group ...................................... 43

Figure 6-2 Accessing temporal information on Ruby Red grapefruit yields for 2008 .... 43

Figure 6-3 Accessing information about a specific irrigation valve.............................. 44

Figure 6-4 Editing the tree count attribute for block group 22 ................................... 45

Figure 6-5 Entering yield estimates for the 2012/2013 season...................................... 46

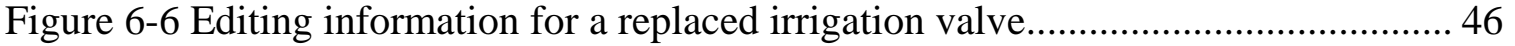

Figure 6-7 Editing yield values in multipage popups .................................................... 48 


\section{List of Tables}

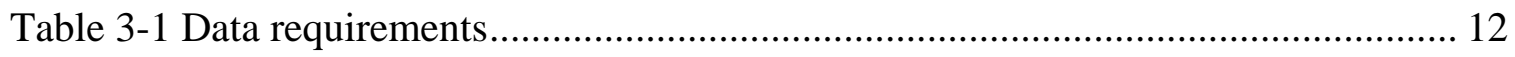

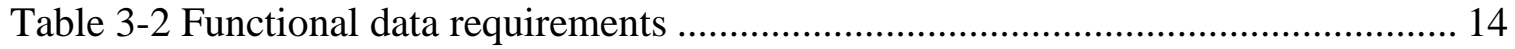

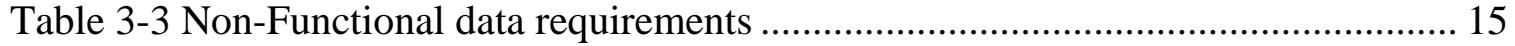

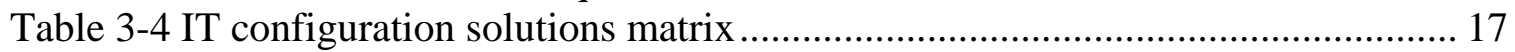

Table 4-1 Data created from field collected GPS data ................................................ 25 


\section{List of Acronyms and Definitions}

$\begin{array}{ll}\text { API } & \text { Application Programming Interface } \\ \text { CAD } & \text { Computer Aided Drafting } \\ \text { CORS } & \text { Continuously Operating Reference Station } \\ \text { CSS } & \text { Cascading Style Sheet } \\ \text { CVWD } & \text { Coachella Valley Water District } \\ \text { GIS } & \text { Geographic Information Systems } \\ \text { GPS } & \text { Global Positioning System } \\ \text { GSD } & \text { Ground Sample Distance } \\ \text { iOS } & \text { Apple’s Mobile Operating System } \\ \text { IT } & \text { Information Technology } \\ \text { HTML } & \text { Hypertext Markup Language } \\ \text { NAD } & \text { North American Datum } \\ \text { NAIP } & \text { National Agricultural Imagery Program } \\ \text { NRCS } & \text { National Resource Conservation Service } \\ \text { SSURGO Soil Survey Geographic Database } \\ \text { TLMA } & \text { Transportation Land Management Agency } \\ \text { UML } & \text { Unified Modeling Language } \\ \text { USDA } & \text { United States Department of Agriculture }\end{array}$




\section{Chapter 1 - Introduction}

Since the dawn of agrarian societies humans have searched for ways to improve the efficiency with which they manage their land and to increase the yield of their harvests. These efforts can be traced from the early development of simple irrigation techniques up through modern mechanized farming. Today large scale farms utilize remote sensing satellites, automated variable-rate technology farm equipment, and spatial decision support systems to achieve these goals (Davis, Casady, \& Massey, 1998). Such farming practices have come to be known as precision agriculture and have traditionally been used primarily by large farms that grow row crops such as rice, corn and soybeans (Shibusawa, 2002). However, thanks to continued technological advances and the rise of high powered mobile computing platforms it is now possible to harness the power of Geographic Information Systems (GIS) to provide spatial farm management solutions that are affordable and tailored to the specific needs of farmers of all types.

\subsection{Client}

The client for this project was Oasis Ranch Management, Inc. The point of contact was Mr. Dennis Jensen, president of the corporation. Oasis Ranch Management is a farm management company that manages over 2,300 acres on 23 properties in Riverside, San Diego, and Imperial Counties in California (Oasis Ranch Management, 2010). Their farms produce a wide variety of citrus and specialty fruits such as dates, kumquats, and jujubes, for both the domestic and international markets. This project focused exclusively on their Seaview Ranch property located in the Coachella Valley at 84700 Johnson Street, Thermal, California (Figure 1-1). Mr. Jensen was interested in using GIS to consolidate documentation on the properties' infrastructure systems and crop production into a single access point that would be available through both desktop and mobile computing technologies. 


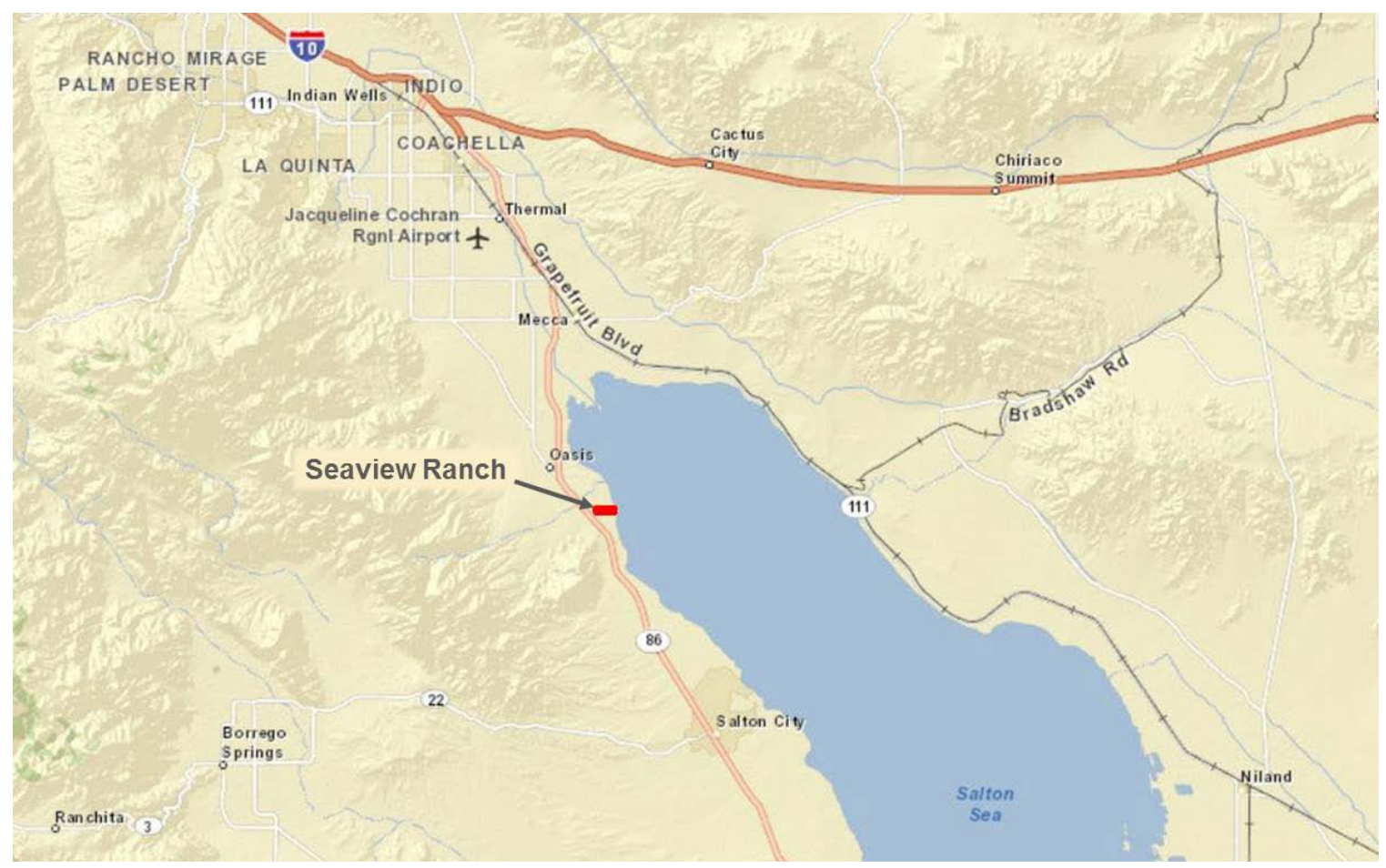

Figure 1-1 Seaview Ranch

\subsection{Problem Statement}

The client traditionally relied on spreadsheets, paper documents, and personal knowledge to manage infrastructure systems and to track estimated and realized harvest yields. While this system functioned acceptably in the past it places a heavy reliance on the institutional knowledge held by the onsite farm manager. Without this individual it would be difficult to manage critical infrastructure elements. Many aspects of these systems were not well documented and this led to inefficiencies in tracking down and dealing with problems when they occurred. It also relied on the timely and accurate transfer of information collected in the field to the appropriate record keeping format back at the office. Through the years this process did not function well. Accurate records on both infrastructure systems and past harvests are incomplete.

The client was looking to take advantage of technological advances in current farming practices by transferring their harvest data and infrastructure documentation into a GIS. They wished to employ a spatial decision support system which they could use and access from both the office and the field to increase the efficiency and accuracy of their record keeping and by so doing increase productivity and maximize their yields.

A major issue for this project was the fact that the client possessed no geospatial data related to the property. All map layers relating to infrastructure systems and crop production had to be created from either field collected GPS data or heads-up digitization using areal imagery.

Another important consideration was the fact that the client did not possess and had no familiarity with commercial GIS software systems. As a result they were looking to 
develop a web based application that would be simple, easy to use, and minimize their investment in a new technology.

\subsection{Proposed Solution}

In order to provide the client with a least cost solution that did not require learning to navigate a new and unfamiliar GIS software package, this project proposed to develop a GIS web application where the required data layers would be hosted through an ArcGIS Online account. The application would be designed to function on both desktop and mobile devices. It would consist of a simple intuitive interface that provides access to selected elements of the farm's infrastructure systems as well as spatio-temporal data on estimated and realized harvest yields. The application would allow for map based queries of the feature attributes and the editing of selected map layers. It would also allow for access to photographs of selected infrastructure elements and attachments containing supplemental information.

\subsubsection{Goals and Objectives}

By capturing the core systems and products of the Seaview Ranch property into a centralized graphically based system the client hopes to increase business efficiency by providing a single point of access for management and staff. By developing a web based application that can be accessed from the field by a mobile device, farm managers can easily access and update information related to maintenance and modifications of infrastructure systems. They will also be able to input harvest estimates directly from the field thus minimizing the risk of such data being lost or forgotten in transit back to the office. Finally, by providing a graphical visualization of the annual production values for specific crops, senior management will have a more intuitive way of tracking the health and productivity of the different tree varieties found on the property.

To facilitate these goals the web application was designed with three main functionalities. The first is referred to as the legend view. In this state the user can view selected layers relating to infrastructure elements and crop production. They can access detailed information on selected features and in some cases view photographs or access supplemental information such as PDF files. The second functionality is the temporal data viewer that allows the user to view a time series animation of the annual production values for different classes of crops. And the third is the data editor that allows the user to update the attribute information, and in some cases the geometry, of selected features.

\subsubsection{Scope}

Four main components were required for the implementation of this project. They included data collection and creation, the design of a database model, publishing map services, and the design and development of the web application.

A major effort in this project involved the collection and creation of the necessary data required to populate the database and build the map layers. The client possessed no spatial data at the start of this project. The information they did possess consisted primarily of hand drawn sketches dating from the 1980s, incomplete harvest records going back to the same time, and a table of values relating to the production block group 
attributes. The client initially requested that the final application include layers relating to soil composition, the irrigation system, underground tile drainage system (used to drain excess water away from the roots of the trees), electrical distribution systems, on- site facilities, and crop production block groups. While all of these data were created a major consideration when designing mobile applications is the speed in loading the source code and accessing and loading the required data. With this in mind, discussions with the client regarding the final form and capabilities of the web application resulted in exclusion of the soils, electrical, and facilities layers from the final design. However, since the client has an ArcGIS Online account for hosting their data these layers were published there and a web map was created that included these layers.

The database design included a cadastral layer, a soils layer, and feature datasets including all aspects of the tile drainage system, irrigation system, electrical distribution system, on site facilities, and crop production units.

The client provided all requested information regarding the infrastructure systems and supplied CAD drawings of the on-site rental units. They allowed unlimited access to the farm property for the collection of the required data and participated in the final testing of the application and gave input on the user interface design.

The final deliverables consisted of the publication of all feature services to the client's ArcGIS Online account and the creation of a web map showing the soils, electrical distribution, and facilities data layers. The final web application was deployed to the client's corporate web server. The client was supplied with a DVD containing the final source code for the application, a file geodatabase containing all of the data created during the project, an instructional video showing how to use the application, and a user's manual. As delivered the application was fully functional and ready for use by the client. However, this application was developed as an initial proof of concept for the client to begin utilizing spatial data as a means for managing their property and its production. As time passes the data sets hosted through ArcGIS Online will likely require maintenance to keep the application functioning smoothly. It is the client's responsibility to plan for and implement such maintenance.

\subsubsection{Methods}

The project development cycle as outlined below was not conceived as a strictly linear workflow. The initial phases of the database design and data collection and creation occurred to some extent in parallel. The same was true for the publishing of the map services and the user interface design. To ensure the timely and successful completion of the project, continued interaction with the client throughout all phases of the process was essential. The project tasks were as follows:

- Requirements analysis and needs assessment,

- Database design,

- Data collection and creation,

- Publishing map services,

- Application development and testing, and

- Product deployment.

The core requirements for this project were well defined through documents supplied by the client during the initial project pitch and through the first meeting with the client. The needs assessment was an ongoing process that continued to evolve as the 
datasets were created and a greater understanding of the limitations and capabilities of developing a web application using data hosted through ArcGIS Online was achieved.

The database design process began with a thorough analysis of the problem domain. The agricultural data model published by Esri in 1997 was used as a conceptual framework (ESRI, 1997). Through the ongoing development of the client's needs assessment and using Esri's model a refined database design was implemented that focused on the data that would be most useful to the client.

The data relating to the farm's infrastructure systems and production units were collected either on the farm property using a Trimble GeoExplorer XH GPS unit or through heads-up digitization using Esri's satellite base map imagery. The Coachella Valley Water District supplied data on the tile drainage system in the form of scanned copies of the original surveyor plats and tables from the initial instillation of the drainage systems. These dated from 1951 through 1972 and contained precise information on the lengths of pipe that were laid at each stage of the installation. This information was used along with the satellite base map imagery to digitize the drainage layers. The remaining required data, consisting of parcel assessor and soil type data, were available from public domain sources.

Publishing the map services was a multistage process. Starting with an initial user interface (UI) design, a small subset of map services was published as they could be used to test the various programming modules that comprised the UI and the core functionality of the application. At this point, however, it was discovered that working with data hosted through ArcGIS Online posed limitations that required a redesign of the production database layers and a different application design for displaying spatiotemporal data. As a result some of the data layers that related to crop production had to be redesigned to work with the time slider widget provided as part the ArcGIS JavaScript API.

The project utilized ArcGIS Desktop v.10.1 for the construction of data layers, the database, and the publishing of the web services. The web application was built using Esri's JavaScript API and dojo mobile for constructing the web application's core functionality. Dojo mobile is designed to furnish the look and feel of native mobile application controls but it renders in desktop browsers just as well. This was an important consideration as the client wanted the application to be available on both mobile and desktop platforms. The user interface was built using HTML5 (Hypertext Markup Language 5) and CSS3 (Cascading Style Sheets 3). These formats are supported by all standard web browsers. While the client only required that the application be compatible with iOS tablets, it was also designed to work with Android tablets.

The proposed project architecture relied on the application data layers being hosted through an ArcGIS Online organizational account. However, to facilitate application development while the client purchased an ArcGIS Online account, and to keep from consuming the client's account credits during the development process, these layers were hosted through the University of Redlands ArcGIS Server. Microsoft's Internet Information Services web server was used to serve the web application during the initial developmental process. Once a beta version of the application was ready, the source code was migrated to the University's developmental web server for further testing. As the final stage in the process the application source code was migrated to the client's commercial web hosting account and all map services were published to the client's 
ArcGIS Online account. The application source code was adjusted to reflect these changes and the final deployment testing was carried out.

\subsection{Audience}

This report is intended for Dennis Jensen and other senior managers at Oasis Ranch Management, Inc., as well as any others who may be interested in the application of GIS technologies to the management of orchard crops. While it is not possible to fully describe the creation of the data products used or the development of web applications without some amount of technical language, every effort has been made to present this material in a manner that should be accessible to the casual reader.

\subsection{Overview of the Rest of this Report}

The remainder of this report consists of six chapters that describe both previous work done and the major developmental stages of this project. Chapter 2 will cover previous work done in the fields of both the general application of GIS to agriculture and the specific application of mobile GIS in this arena. Systems analysis and design as it pertains to this project will be covered in Chapter 3. This will include a discussion of the project requirements, system design, and the comprehensive project plan. Chapter 4 will focus on the database design including the conceptual and logical database models and how the data were created to satisfy this design. Chapter 5 will detail the project implementation. The remaining two chapters (Chapters 6 and 7) will present the project results, conclusions, and further recommendations. 


\section{Chapter 2 - Background and Literature Review}

Three main topics were investigated for this project to ensure that the final system met the needs of Oasis Ranch Management and leveraged the latest advancements in GIS technology. This chapter will cover those research areas in three sections. Traditional agricultural applications of GIS will covered in Section 2.1. The application of mobile GIS technologies to agriculture will be discussed in Section 2.2. Section 2.3 will cover mobile GIS application development.

\subsection{Agricultural Applications of GIS}

The application of GIS to the arena of farm management falls under the umbrella of precision agriculture. As defined by Pierce and Nowak (1999, p. 1), "Precision agriculture is the application of technologies and principles to manage spatial and temporal variability associated with all aspects of agricultural production for the purpose of improving crop performance and environmental quality.”

Historically, due to the heavily automated nature of their production practices, GIS based precision agriculture has largely been employed by the farmers of row crops such as corn and soybeans. The growth cycle of such crops is based upon the application of seed, fertilizer, pesticides, and water that can be precisely controlled in site-specific applications by variable-rate technology farm equipment. This type of equipment utilizes GPS guidance systems and application rate data generated from GIS based analyses of various soil factors such as type, nutrient load, electrical conductivity, and moisture content as well as satellite imagery and historical yield data (Westervelt \& Reetz, Jr., 2000).

Today precision agriculture techniques are being applied in an ever widening array of agricultural settings such as sugar cane, palm oil, and banana production (McBratney, Whelan, \& Ancev, 2005). These techniques are also being employed in vineyards and orchards at both the local and regional scales (Hetzroni, Peeters, \& BenGal, 2012; Smith \& Whigham, 1999). In all such cases the emphasis is focused on sitespecific applications using variable rate technology equipment. Such equipment and the associated costs of soil sampling, remote sensing imagery collection and analysis, along with the necessary expertise to analyze the resultant data, have for the most part left precision agriculture of this type in the domain of large scale producers. The slow rate of adoption of these technologies by small scale farmers is understandable not only from the perspective of entry and maintenance costs but also due to the uncertainties of the profitability of such systems (Lambert \& Lowenberg-Deboer, 2000).

Aside from site-specific applications of inputs, GIS technology has the potential to aid all farmers, large and small, through its application toward whole farm business management (Norvell, 2003). An agricultural operation is a distinctly spatial enterprise regardless of scale and many of the issues that farmers cope with on a daily basis are basic facilities management problems well suited to management through a GIS based interface. The use of GIS for managing facilities aspects such as cadastral information, irrigation, and electrical networks are well established (Arctur \& Zeiler, 2004). These techniques will be employed here and tailored toward the particular needs of this client. 
Traditionally most farmers keep records related to the management of their properties and crops in a field book that may contain property descriptions, crop plans, and records (Norvell, 2003). The client for this project had minimal records pertaining to the property itself. Those that did exist were in the form of distributed paper documents, many of which were hand drawn and lacking in accurate spatial context. All information pertaining to crop plantings and yield were contained in spreadsheets and also lacked any spatial context. This project built on the GIS data model for agriculture developed by Esri (1997) with the primary focus being on the enhancement of record keeping facilitating more efficient management and decision making.

\subsection{Mobile GIS in Agriculture}

The use of mobile devices for the collection and creation of GIS data has been a common practice for some time. Esri's ArcPad is a mobile GIS platform that has been integrated into numerous GPS receiver units and pocket PCs for almost two decades. Using ArcPad it is possible to collect, display, edit, and analyze geographic data while in the field (Esri, 2013a). Through the development of custom tool suites this technology has been applied to precision agriculture to enable basic mapping and record keeping (Koostra, Stombaugh, \& Dowdy, 2003). However, this solution requires that a user manually connects the device to an existing installation of ArcGIS for Desktop to transfer data to and from the device.

The advent of Web 2.0 has played a pivotal role in advancing the possibilities for the use of mobile GIS in the agricultural industry. As described in Web GIS Principles and Applications (Fu \& Sun, 2011), the original Web, Web 1.0, provided read-only content that flowed from the host server to the client in a top-down manner, by contrast, the Web 2.0 format provides a two way flow of information where a user can also generate content. Another feature of the Web 2.0 model that is rapidly increasing the utility of GIS is the concept of the Web as a platform. The new Web now functions not only as a source of information but as a platform for computing and software development (Fu \& Sun, 2011). Web applications such as that developed by Lertsakdadet for his master's thesis Mobile GIS Web Application for Agri-Empire (2012) provide a rich interface and functionality that is tightly focused on the specific needs of the user. Commercial providers such as WebMapSolutions are also developing such applications targeted to the needs of individual agricultural producers

(WebMapSolutions, 2011).

Another crucial component of mobile GIS was the development of 3-G (third generation) cellular communication networks that made it possible to link mobile computing devices to the internet with the speed required to transfer geospatial data. This advance has made it possible to directly connect to and access GIS data resources such as Arc Server or ArcGIS Online while in the field. With this technology it is no longer necessary to physically connect a mobile device to a desktop machine in order to upload and download data. Data collected in the field or edits made to existing data sets are recorded to the master database in real time. This allows for agricultural owners or production managers to make immediate decisions based on current conditions in the field. 


\subsection{Mobile GIS Application Development}

At present there are two main approaches for building mobile applications: native or web. Each of these methods has its pros and cons and it is important to consider these when deciding on which route is the most appropriate for building a solution that meets the desired goals.

Native applications are by far the most prevalent with over 1.7 million apps covering all device platforms (Rende, 2013). This approach requires specialized programming languages such as Objective-C, .NET Mobile, or Java Mobile and the language used is dependent on the device platform, e.g., iOS, Windows, or Android. Thus if an application is to be made available across multiple platforms it must be rewritten in the language used by each device. According to Pinde Fu (personal communication, March 2013) these languages have a much steeper learning curve than those required for web application development. Additionally, native applications written for iOS (Apple) devices must be approved by Apple and this process can take anywhere from one to two weeks and in some cases even longer (Duryee, 2012). The prevalence of this type of application development stems from the fact that the programming languages used can fully integrate with the devices hardware set and are thus able to offer a richer user experience. Native apps also have the advantage of being able to function without a network connection. Of course, this is only true for the functionalities and components that are not relying on distributed data sources accessed over the internet.

Web applications, unlike native apps, are compiled by a web browser and run in a browser tab like a conventional web page. They are designed and built using free open source programming languages such as HTML, CSS, JavaScript, and Dojo. The chief advantage of web applications is that they are not platform dependent and can run on almost any modern web browser (Power, 2011). When they are written using the newer mobile compatible language standards such as HTML5, Dojo Mobile, and CSS3 they can provide a rich user experience that delivers the look and feel of native applications. This does, however, require that they be run in browsers such as Firefox, Chrome, or Safari that support the mobile standards. This can be an issue when such applications are run from desktop or laptop machines with older browsers or those running Internet Explorer. Until recently only native applications could make use of hardware components such as accelerometers, GPS, and cameras. Now, new advancements in the mobile application programming interfaces (APIs) allow developers to make use of these native hardware components (PhoneGap, 2013).

Another advantage of web application development is that the programming languages are comparatively easy to learn. The Dojo Foundation maintains free online documentation on their API which includes numerous examples for every component and is updated on a daily basis (Dojo Foundation, 2013a). Similarly, W3Schools.com provides a free website that maintains current code references, samples, tutorials, and testing to enable individuals to quickly learn current versions of all major open source web application development languages such as HTML, JavaScript, AJAX, and PHP to name just a few (w3Schools.com, 2013). Esri also provides complete online API references and functioning application samples that demonstrate how to use the components of its various web application programming APIs (Esri, 2013e). 


\subsection{Summary}

While GIS is an essential component of precision agriculture many of these techniques are either not relevant or too expensive for adoption by small scale agricultural producers. With the advent of powerful mobile computing devices and readily available high bandwidth wireless communications networks, it is now possible to put the power of GIS in the hands of an average farmer in the form of a mobile application. Given the benefit of cross platform compatibility, ease of development, and the abundance of free online resources, web applications allow for quick development of mobile GIS solutions that are tailored to the needs of the individual farmer. 


\section{Chapter 3 - Systems Analysis and Design}

Proper system analysis and design are fundamental tasks required for the successful completion of any project. This chapter will detail the steps taken in this process as they relate to the project described in this report. The problem that this project solved will be described in Section 3.1. Section 3.2 will detail the requirements analysis that was undertaken identifying both the data required and the functional and non-functional requirements of the system. The overall system design is discussed in Section 3.3 where the major components of the system and their interrelations are described. Section 3.4 will present the project plan that was developed to ensure successful project completion.

\subsection{Problem Statement}

The client for this project was looking to consolidate his records pertaining to critical infrastructure systems and harvest yields into a single access point that could be accessed both from the office and in the field. He wanted an easy and efficient means of keeping track of changes to the infrastructure systems and updating crop estimates and yields that does not rely on waiting to get back to the office to update the relevant records. He also did not want to make a major investment in new and unfamiliar technology.

\subsection{Requirements Analysis}

A critical part of any project is a clear and complete understanding of the elements that are required to satisfy the client's needs. Although the client had no experience with GIS, he did have a solid idea of the data he wanted the system to contain and what he wanted it to do. This section details the results of the analysis undertaken to satisfy these requirements and is divided into three sections covering data requirements and the functional and nonfunctional requirements of the web application.

\subsubsection{Data Requirements}

As all of the data required for this project had to be either collected from public domain sources or created from scratch a thorough and complete understanding of the data requirements was essential. The client provided a list of the data he would like included in the project. In order to keep the application as responsive as possible during mobile use certain layers were not included in the web application design. These layers were used in a separate web map that was published in the client's ArcGIS Online account. Table 3-1 details the data requirements and also indicates whether the data was included as part of the final web application or in the online web map. 
Table 3-1 Data requirements

\begin{tabular}{|c|c|c|}
\hline Data Sets & Web Map & Web Application \\
\hline Parcels & $\checkmark$ & $\checkmark$ \\
\hline Drain Lines & $\checkmark$ & $\checkmark$ \\
\hline Drain Cleanout & $\checkmark$ & $\checkmark$ \\
\hline Drain Sump Pump & $\checkmark$ & $\checkmark$ \\
\hline Irrigation Lines & $\checkmark$ & $\checkmark$ \\
\hline Irrigation Line Junctions & $\checkmark$ & $\checkmark$ \\
\hline Irrigation Valves & $\checkmark$ & $\checkmark$ \\
\hline Irrigation Filters & $\checkmark$ & $\checkmark$ \\
\hline Irrigation Supply Ponds & $\checkmark$ & $\checkmark$ \\
\hline Domestic Water Wells & $\checkmark$ & \\
\hline Fertilizer Tanks & $\checkmark$ & $\checkmark$ \\
\hline $\begin{array}{l}\text { Production Block Units } \\
\text { Crop Attribute Data }\end{array}$ & $\checkmark$ & $\checkmark$ \\
\hline $\begin{array}{c}\text { Production Blocks Units } \\
\text { Crop Yield Data }\end{array}$ & $\checkmark$ & $\checkmark$ \\
\hline Facilities & $\checkmark$ & \\
\hline $\begin{array}{l}\text { Housing Units } \\
\text { CAD Drawings }\end{array}$ & $\checkmark$ & \\
\hline $\begin{array}{l}\text { Housing Units } \\
\text { CAD Annotations }\end{array}$ & $\checkmark$ & \\
\hline Utility Lines & $\checkmark$ & \\
\hline Utility Poles & $\checkmark$ & \\
\hline
\end{tabular}


Table 3-2 Data requirements continued

\begin{tabular}{l|c|l}
\hline Data Sets & Web Map & Web Application \\
\hline Electrical Metes & $\checkmark$ & \\
\hline Electrical Switch Points & $\checkmark$ & \\
\hline Telephone Junction Boxes & $\checkmark$ & \\
\hline Soil Type & $\checkmark$ & \\
\hline
\end{tabular}

\subsubsection{Functional Requirements}

The functional requirements were determined through a careful needs assessment and then by applying that analysis to the potential use case scenarios that would arise when using the application. A user should be able to load different layer groups consisting of the tile drain, irrigation, and crop production layers. The crop production layer group consists of different representations of the same physical geometry, one containing attribute data specific to each crop production block unit feature, and three containing time specific yield information for the major variety groups. These coincident geometries made it necessary to provide for exclusive display of a single layer at a time. When viewing one of the time specific yield layers a user can view an animation of the temporal data by pressing play on the time slider widget. This allows the user to view the performance of different crop varieties over time. The user can also choose to view crop performance for an individual year by sliding the time slider to the appropriate position. The irrigation layer group contains a large number of layers each containing many features, thus the ability to turn selected layers on or off was deemed important. Likewise, due to the large number of features in some of the irrigation layers it was decided that a user should be able to turn the basemap layer on and off to facilitate identification of specific features. The user can tap or click a feature to bring up a popup window containing attribute information including, in some cases, photographs and supplemental attachments. The production and irrigation layer groups both contain editable layers that can be accessed by entering the edit mode. It should be noted that due to restrictions imposed by using data hosted through ArcGIS Online, multi-user editing is not possible. However, the needs assessment did not identify this as an important issue. A listing of the functional requirements is given in Table 3-2. 
Table 3-3 Functional data requirements

\begin{tabular}{l|l}
\hline Requirement & Requirement Description \\
\hline $\begin{array}{l}\text { Cross platform web } \\
\text { application }\end{array}$ & $\begin{array}{l}\text { A web application functional in Safari, Crome, and Firefox web } \\
\text { browsers that is compatible with touch aware tablet devices. }\end{array}$ \\
\hline $\begin{array}{l}\text { Group layer loading } \\
\text { Allows user to load different layer groups relating to specific } \\
\text { topics such as irrigation, drainage, and production. }\end{array}$ \\
\hline $\begin{array}{l}\text { Exclusive layer control } \\
\text { control }\end{array}$ & $\begin{array}{l}\text { Allows user to turn selected layers on or off. } \\
\text { on all other layers are turned off. }\end{array}$ \\
\hline Basemap control & Allows user to turn the basemap layer on or off. \\
\hline $\begin{array}{l}\text { Time enabled data } \\
\text { display }\end{array}$ & $\begin{array}{l}\text { The ability to display time enabled data for single user selected } \\
\text { time periods. }\end{array}$ \\
\hline $\begin{array}{l}\text { Time enabled data } \\
\text { animation }\end{array}$ & $\begin{array}{l}\text { Allows user to view an animation that cycles through time } \\
\text { enabled data. }\end{array}$ \\
\hline $\begin{array}{l}\text { Data editing } \\
\text { Popup display }\end{array}$ & $\begin{array}{l}\text { A single user can edit the attributes and geometries of editable } \\
\text { data layers. }\end{array}$ \\
\hline $\begin{array}{l}\text { Users can tap or click on data features and view a popup window } \\
\text { attachments }\end{array}$ \\
\hline
\end{tabular}

\subsubsection{Non-Functional Requirements}

Successful project execution is equally dependent on the proper identification of the nonfunctional requirements needed to accomplish the task. Non-functional requirements can deal with the technical components required to develop the system, the operational performance of the system, and any ancillary requirements such as system documentation. Table $3-3$ lists the non-functional requirements identified for this project.

While this project utilized the University of Redlands ArcSDE database and Arc Server architectures during the developmental stages, it should be noted that when publishing feature services to an ArcGIS Online organizational account neither of these technologies are required. As a result these technologies are not included in Table 3-3. To create time-enabled data, create attachments, and publish feature services, ArcGIS for Desktop V10.0 Standard edition or later is required. 
Table 3-4 Non-Functional data requirements

\begin{tabular}{l|l}
\hline Requirement & Requirement Description \\
\hline $\begin{array}{l}\text { ArcGIS Desktop Standard } \\
\text { v10 or later }\end{array}$ & $\begin{array}{l}\text { ArcGIS Desktop was used to create and manage the data } \\
\text { and file geodatabase and publish feature services. }\end{array}$ \\
\hline $\begin{array}{l}\text { ArcGIS Online } \\
\text { Organizational subscription }\end{array}$ & $\begin{array}{l}\text { An organizational subscription was required to host } \\
\text { editable feature services. }\end{array}$ \\
\hline Web server & $\begin{array}{l}\text { A web server was required for deployment of the } \\
\text { application code and serving the application to the web. }\end{array}$ \\
\hline ArcGIS API for JavaScript & $\begin{array}{l}\text { Required for embedding feature services, maps, and } \\
\text { processing tasks in the application. }\end{array}$ \\
\hline Dojo Toolkit and Mobile & Required for building a touch aware application. \\
\hline HTML5 & Required for building the application interface. \\
\hline $\begin{array}{l}\text { CSS3 } \\
\text { interface } \\
\text { compatible }\end{array}$ & Required for applying custom styling to the application. \\
\hline Aptana Studio 3 & $\begin{array}{l}\text { The development environment used to write the } \\
\text { application code. }\end{array}$ \\
\hline
\end{tabular}

\subsection{System Design}

With the advent of ArcGIS Online it is no longer necessary for an individual or corporation to invest in an maintain costly ArcSDE and Server technologies to host map services. Given the client's requirements and needs it was determined that a system based around ArcGIS Online was the appropriate route for hosting data that could be implemented in a web application.

The system developed consists of four components. ArcGIS Desktop version 10.1 was used for creating data, publishing map services, and creating and managing the file geodatabase. ArcGIS Online was used to host and serve the data and to host the online map document that was created for the data layers that were not incorporated into the application. The client's commercial web server was used to host the application code and the photographs of various infrastructure components that are displayed in certain feature popups. The final component is a client desktop or tablet device running Windows, iOS, or Android and either a Safari, Chrome, or Firefox web browser. It 
should be noted that due to the mobile device requirement the application is not compatible with Internet Explorer v10 or earlier web browsers.

\subsection{Project Plan}

A comprehensive project plan was developed in October, 2012 and is shown in Figure 31. There were no significant changes to the plan during the project life cycle and steady progress was made according to schedule. A detailed project plan was an essential component to the successful completion of this project.

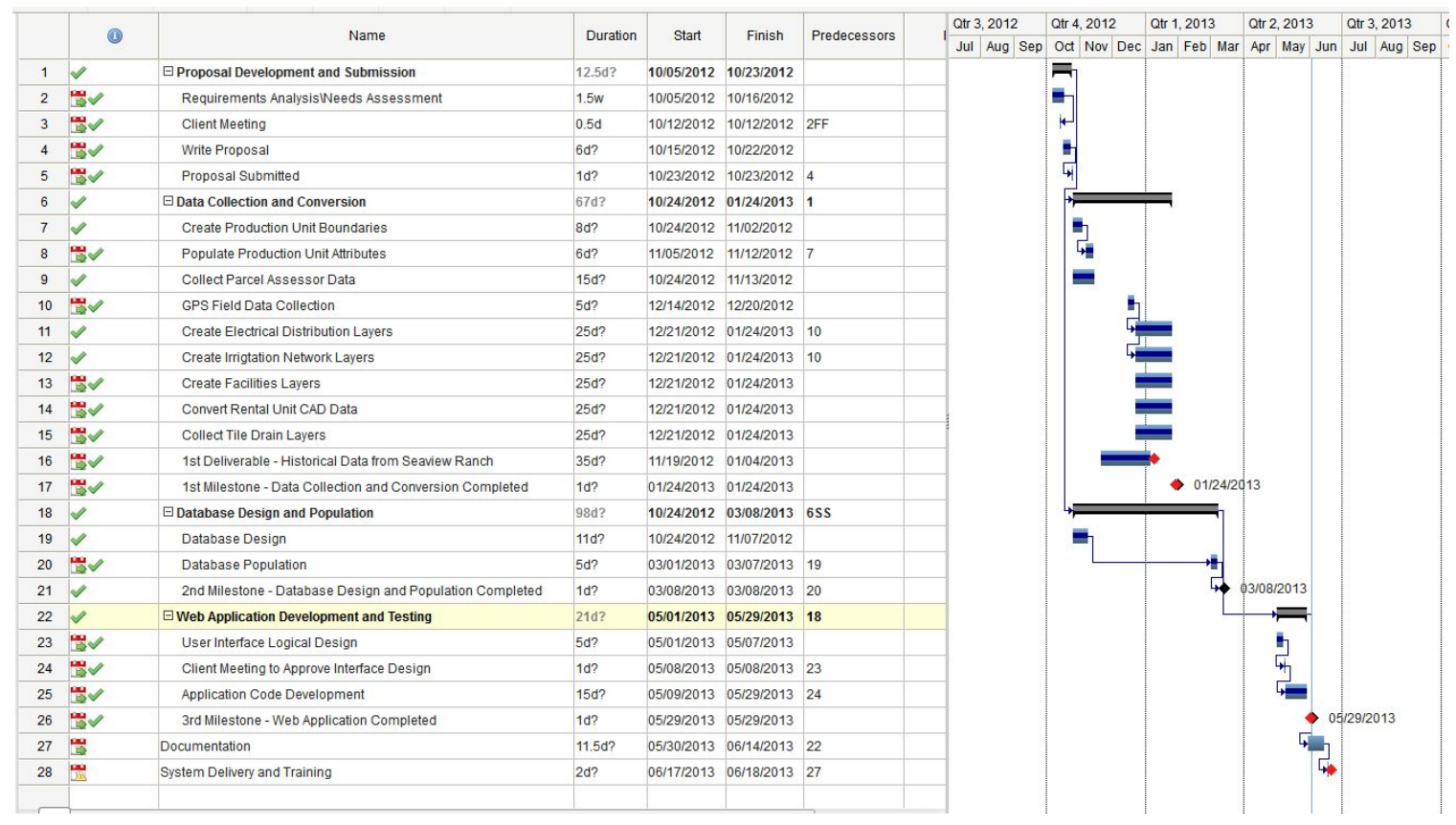

\section{Figure 3-1 Project plan}

The first stage of the project involved performing a requirements analysis and needs assessment. At the initial project pitch the client had delivered a comprehensive requirements document that outlined the data layers he would like to have included in the final project. Starting from this point it was a matter of deciding which functionalities the final web application should contain. Given that the client had no experience with GIS technologies and was not looking to make a major investment in such, it was decided early on that the best way forward would be to utilize an ArcGIS Online account. As the project moved forward it became unclear as to whether this option would be able to satisfy the necessary functionality requirements. At this point the client was presented with a matrix of the options available to achieve the project goals along with each option's respective advantages, disadvantages, and associated costs (Table 3-4). Shortly after this it was determined that an ArcGIS Online account would be able to satisfy the client's needs and this route was chosen. 
Table 3-5 IT configuration solutions matrix

\begin{tabular}{|c|c|c|c|}
\hline Solution Type & Pros & Cons & Costs \\
\hline ArcGIS Desktop & $\begin{array}{l}\text { Maximum } \\
\text { functionality }\end{array}$ & $\begin{array}{l}\text { Software } \\
\text { instillation with } \\
\text { associated learning } \\
\text { curve, no mobile } \\
\text { application, single } \\
\text { user }\end{array}$ & $\begin{array}{l}\text { Onetime } \\
\$ 1,500 \\
\text { For single user } \\
\$ 7,000 \\
\text { For multiuser } \\
\text { database editing }\end{array}$ \\
\hline ArcGIS Online & $\begin{array}{l}\text { Data hosting } \\
\text { supports web } \\
\text { application } \\
\text { development }\end{array}$ & $\begin{array}{l}\text { Lack of support for } \\
\text { editing of related } \\
\text { tables limits scope } \\
\text { of application } \\
\text { functionality }\end{array}$ & $\begin{array}{l}\text { Annual } \\
\$ 2,500 \\
\text { For five users }\end{array}$ \\
\hline $\begin{array}{l}\text { Arc Server } \\
\text { (In House) }\end{array}$ & $\begin{array}{l}\text { Maximum } \\
\text { functionality, for } \\
\text { both desktop and } \\
\text { mobile applications } \\
\text { seamlessly supports } \\
\text { any level of } \\
\text { expansion }\end{array}$ & $\begin{array}{l}\text { Requires an onsite } \\
\text { web server with the } \\
\text { added costs and } \\
\text { complexities of } \\
\text { installation and } \\
\text { maintenance }\end{array}$ & $\begin{array}{l}\text { Onetime } \\
\sim \$ 10,000 \\
\text { Software licensing } \\
\text { Plus server } \\
\text { hardware and } \\
\text { installation costs } \\
\text { Ongoing } \\
\text { Dollar value unknown } \\
\text { Server database and } \\
\text { administration }\end{array}$ \\
\hline $\begin{array}{l}\text { Arc Server } \\
\text { (Amazon Cloud) }\end{array}$ & $\begin{array}{l}\text { Same as in house } \\
\text { No onsite hardware } \\
\text { deployment } \\
\text { Server maintained by } \\
\text { Amazon }\end{array}$ & $\begin{array}{l}\text { Costs incurred both } \\
\text { for software licensing } \\
\text { and Amazon EC2 } \\
\text { Cloud usage }\end{array}$ & $\begin{array}{l}\text { Onetime } \\
\sim \$ 10,000 \\
\text { Software licensing } \\
\text { Ongoing } \\
\text { Dollar value unknown } \\
\text { Amazon Cloud storage } \\
\text { and data transfer fees }\end{array}$ \\
\hline
\end{tabular}

As it was known that the collection of field data and the subsequent creation of the majority of the data layers would be an extensive and time consuming process, adequate time was allocated for this portion of the project. The database model was based on the agricultural data model published by Esri in 1997 and was adjusted to fit the needs of the client. While the framework of the database model was completed in late 2012 it was not populated with data until all of the data layers were created. Individual file geodatabases were created for each of the individual feature data sets and were used during the data creation phase.

The web application development stage was completed ahead of schedule and benefitted greatly from the previous work done by Lertsakdadet (2012) in his master's thesis Mobile GIS Web Application for Agri-Empire and from the sample data code available from Esri's ArcGIS for JavaScript web site (Esri, 2013b). From both of these sources it was 
determined that JavaScript and Dojo mobile were the appropriate code frameworks to use in developing the application.

\subsection{Summary}

A detailed project plan was a critical component in the success of this endeavor. With the amount of time required in field data collection, creation of the necessary data sets, and the development of the final application, rigorous tracking of the tasks involved was essential. A thorough analysis of both the functional and non-functional requirements was also an integral component in the efficient completion of the web application. With a clear understanding of what was required of the application and which tools were required to accomplish the task it was possible to complete it ahead of schedule while satisfying all requirements. 


\section{Chapter 4 - Database Design}

Database design is a critical element of most GIS applications and this chapter will detail the database design used in this project. The conceptual model, outlining the structural entities of the database along with their interrelations, will be discussed in Section 4.1. The logical model will be covered in Section 4.2 and will detail the individual elements in the database and their associated attributes. Sections 4.3 and 4.4 will discuss, respectively, the data sources and the methods used to collect that data. Finally, Section 4.5 will cover the methods used to prepare the data for effective inclusion in the logical database model.

\subsection{Conceptual Data Model}

A conceptual model was developed around the Seaview Ranch property and is shown in Figure $4-1$. This model was used to gain an understanding of the functional and business relationships between the property and its various components. The model focuses on the Seaview Ranch property as an abstract business entity with aggregate components acting as sources of revenue, expense, or both. The crop production and facilities classes both act as sources of revenue and expense. The facilities class generates revenue due to the four rental dwellings located on the property and is modeled as many facilities to one property. Crop production is the primary revenue stream and is modeled as many crop varieties to one property. Both of these classes act as sources of expense with respect to maintenance and upkeep. In relation to the property the electrical, inputs, and irrigation classes act as expenses. These are modeled as one-to-one in the form of a single utility bill to a single payee. The inputs class, which relates to crop inputs such as pesticides and fertilizer, was not included as part of this project due to time constraints. It was included in the conceptual model for completeness.

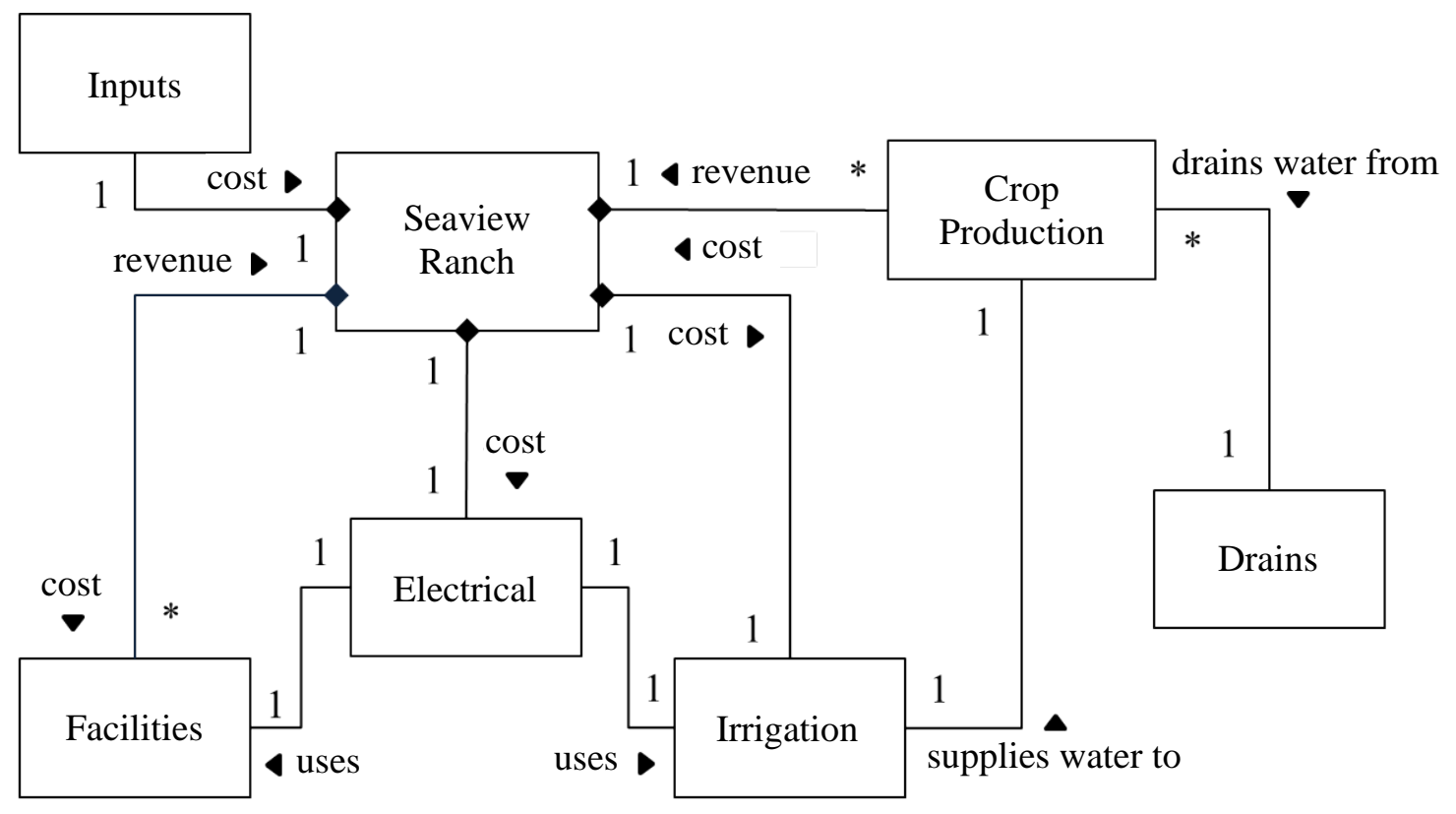

Figure 4-1 Conceptual model of the Seaview Ranch property 
It should be noted that the crop production class is modeled differently with relation to the property and the irrigation system. The property views the crop production class in terms of varieties of fruit, each of which will yield a different return and each of which can be a member of more than one crop production unit. A crop production unit is a single contiguous block of trees ranging from three to 12 acres and surrounded on all sides by dirt lanes (see Figure $4-2$ ). These units are known to the client as block groups. The irrigation system's relationship is one of individual pipeline to individual block group.

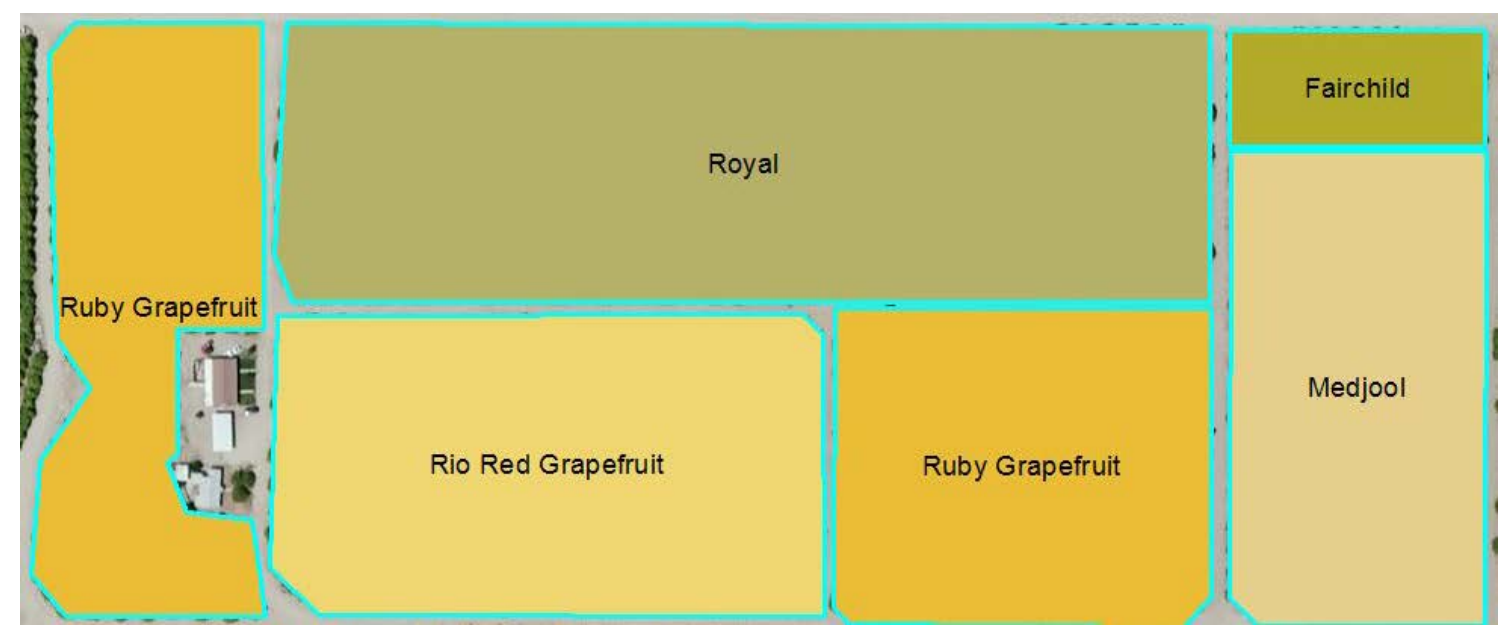

Figure 4-2 A portion of Seaview Ranch with individual block groups selected

In terms of the datasets required for this project the focus of the conceptual model is on the relationships between the facilities, electrical, drainage, irrigation, and crop production component classes. The electrical class is related to the facilities and the irrigation classes as it supplies power to both. Both of these relationships, electrical to facilities and electrical to irrigation, are one-to-one as the irrigation system and each facility are associated with individual electric meters. The irrigation class is modeled as having a one-to-one relationship to crop production as each block group is supplied by exactly one irrigation line. The drainage class is related to the crop production class in a one-to-many relationship where one drainage line services more than one block group.

\subsection{Logical Data Model}

In comparison to the conceptual model the logical model consists of the functional geodatabase design including all of the required datasets and the attributes contained therein. Feature datasets were created to group the individual feature classes into logical themes. The logical model was designed using ArcGIS Diagrammer while the final database was built in ArcCatalog 10.1 using the ArcGIS file geodatabase system. The various structural components will be discussed below and are illustrated in Figures 4-3 and 4-4. 


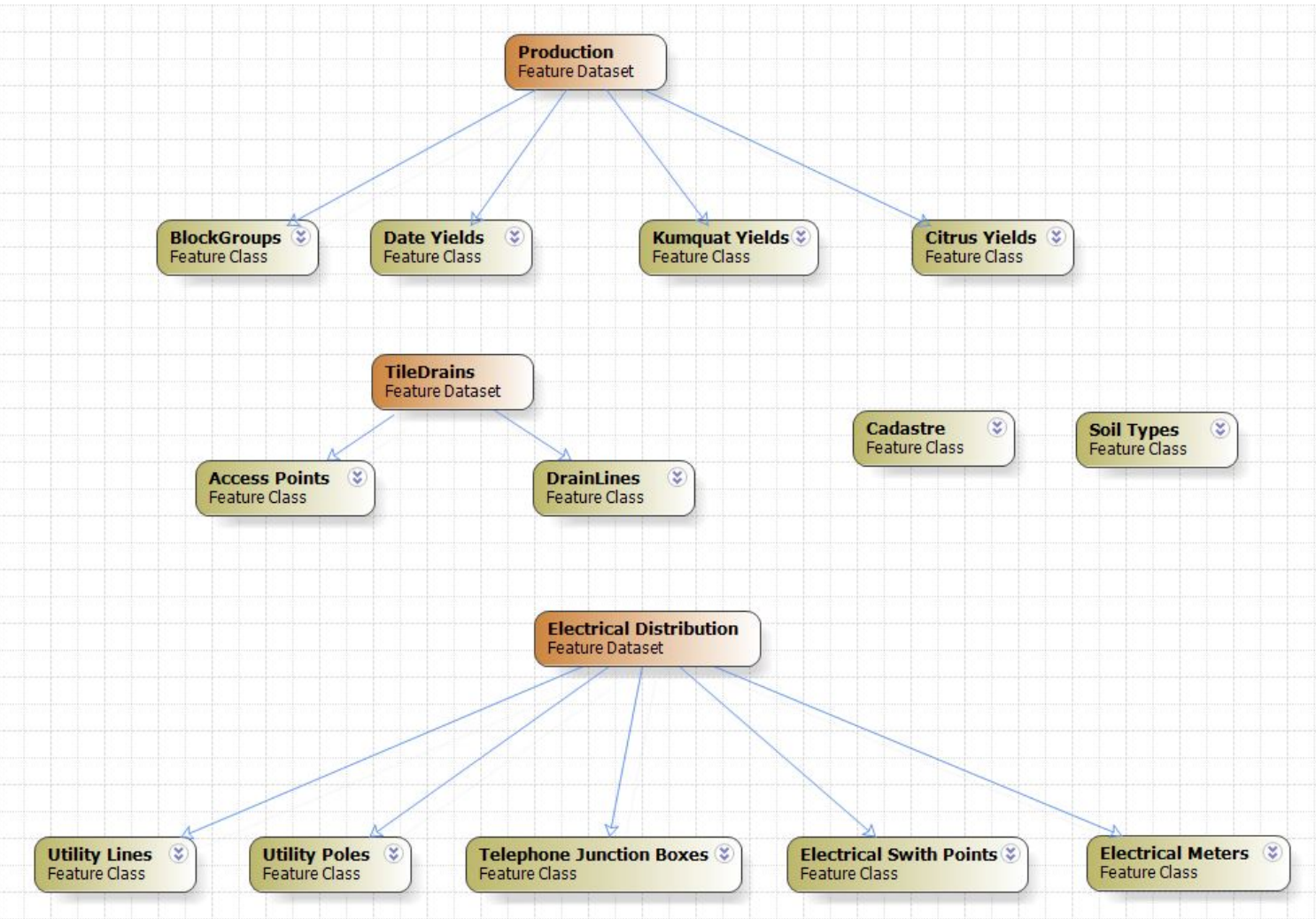

Figure 4-3 A portion of the logical data model showing the cadastre, soil type, tile drainage, electrical distribution, and production elements 


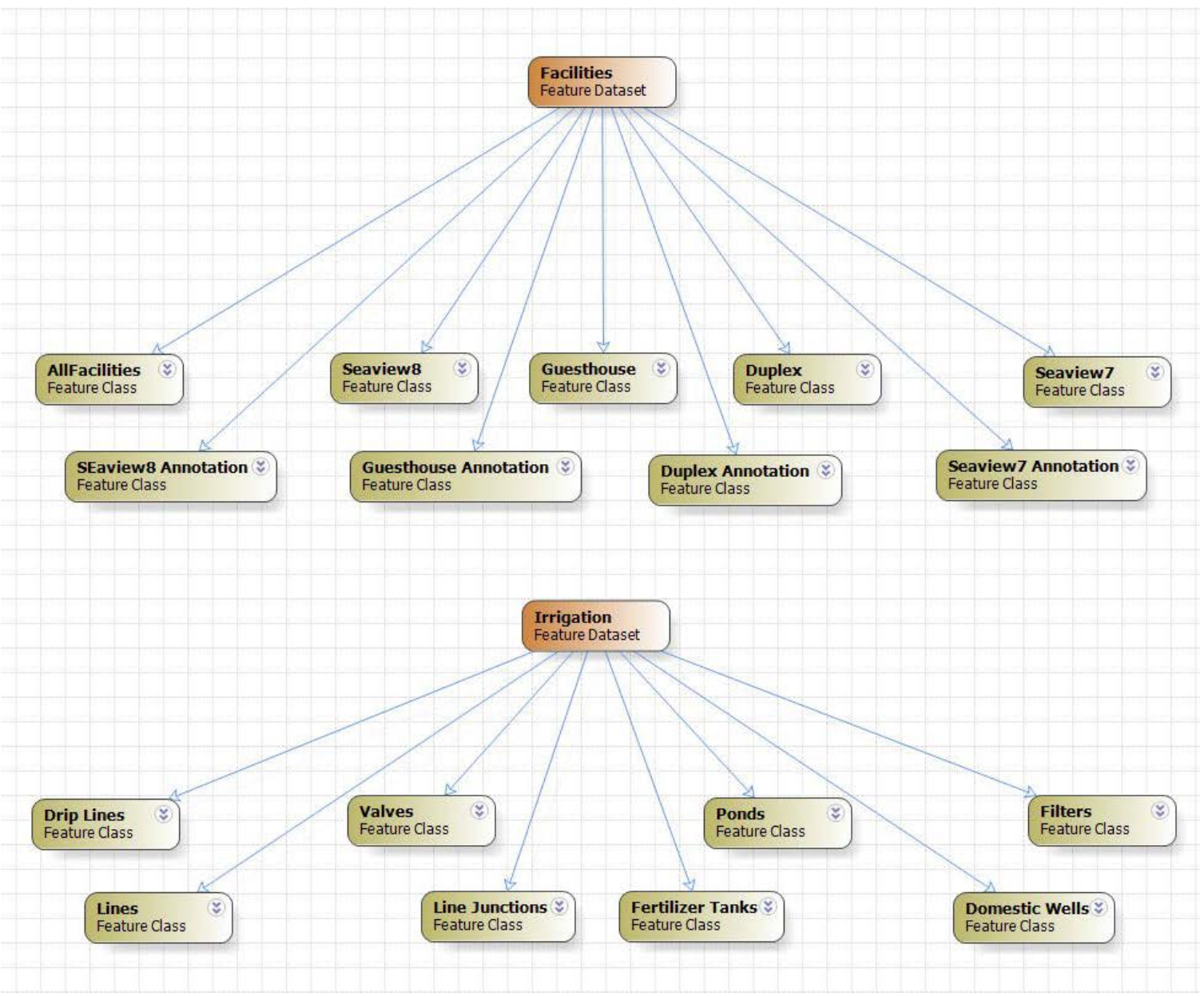

Figure 4-4 Logical data model showing the facilities and irrigation elements

The production dataset includes a feature class (BlockGroups) that consists of polygonal units that describe the boundaries and attributes associated with the individual block groups. The three other feature classes in this dataset describe the geometries and attributes of crop production units as grouped by the variety of fruit produced. Thus each feature in one of these datasets can be composed of more than one block group. These feature classes contain information on the estimated and realized annual yields for the various fruit varieties grown on the property. Initially it was conceived that the data relating to varietal production would be stored in a table related to the individual production units. However, due to limitations imposed by using data hosted solely through ArcGIS Online and the desire to implement an editable spatio-temporal representation of the production data, it was decided that separate feature classes describing the different varieties would be implemented. Three feature classes, Citrus Yields, Kumquat Yields, and Date Yields were created based on the differing scales the client uses to grade production levels for these varietal groups. The Citrus Yields feature class contains nine subtypes corresponding to the different varieties of juice citrus located on the property while the Kumquat and Date Yields classes each represent single varieties. 
For the client's needs the production datasets were the most important element of the project. As such it was critical to give great consideration to how they would interact with and edit these layers. As illustrated in Figure 4-2 the block groups do not form contiguous units with respect to variety. The various varieties are intermixed by block group across the property. Furthermore, yield values are not recorded at the block group level but at the varietal level. This posed a problem when considering how to create a simple and intuitive editing environment for a mobile application. The client needed to be able to both record yield data for each variety and have access to a visual representation of the yield performance for each variety over time. At the same time the client wanted access to specific information on the individual block groups such as crop variety, tree count, root stock, and planting date. The varietal yield classes were created to accomplish these goals.

The client had supplied production yield data that were only complete going back five years from $2007-2011$. As a result it was decided that the varietal yield classes would start with 2007 and go through 2018. Thus, each class contains a preset number of replications of the geometries associated with each variety grown on the property. Each class contains a date attribute for the production year so that the feature class is time enabled. The client can edit annual yield values by simply entering a yield value, and a date for each variety.

The Tile Drains dataset consists of two feature classes. One (Access Points) consists of two point entities that describe the sump pump used to pump the drainage water into the Salton Sea and the clean out access point used to periodically flush the drain lines. The Drain Lines class contains the geometries and attributes of the drain lines themselves.

The Electrical Distribution dataset contains feature classes describing the geometries and attributes of the utility poles and the underground and overhead utility lines. It also contains classes that describe the telephone junction boxes, electrical switch points, and electrical meters. The property has a number of rental units, as well as facilities that store hazardous chemicals. As a result, no on-site facilities were entered during data collection activities and all entities in the electrical distribution dataset correspond solely to equipment that was located external to any associated facility.

The final two elements illustrated in Figure 4-3 describe the property line and associated cadastral data, and the soil types located in and adjacent to the property.

Figure 4-4 shows the remaining two feature datasets and the entities they contain. The facilities dataset contains a layer describing the locations and geometries of all onsite structural facilities. This dataset also contains four layers that represent CAD renderings of selected dwellings and rental units located on the property. It also contains four additional layers that contain the CAD annotation layers associated with those structures.

The irrigation dataset contains all elements of the irrigation supply system and includes the irrigation supply ponds, filters, fertilizer tanks, above ground drip lines, buried supply lines, and selected line junctions. While not related to irrigation the locations of the numerous domestic water wells that have been drilled on the property were included in this dataset as they relate to the water supply infrastructure. Appendix A contains a complete listing of the attributes associated with each feature class used in this project. 


\subsection{Data Sources}

At the start of this project the client possessed no spatial data. The data they were able to provide consisted of two spreadsheets, CAD drawings of selected dwellings, and a few hand drawn sketches showing the locations of the domestic water wells, the layout of a group of buried power lines, and the layout of the irrigation system. The first spreadsheet contained all known information relating to the attributes of the individual block groups and included such information as the variety of tree, tree root stock, and the number of trees planted. The second spreadsheet contained information on the annual yield of each variety grown on the property going back to 1985 . As mentioned previously this dataset was incomplete both for selected varieties in a given year and for all varieties in other years. It did contain complete records from 2007 through the present so this portion of the data was included in the varietal yield data layers.

As the client did not possess any spatial data it was incumbent on the project staff to collect or create the required datasets. Two of these sets, soil type and property line, were available from public domain sources, in the desired projection (California State Plane VI), in either shapefile or file geodatabase format. The soil type data were downloaded from the U.S. Department of Agriculture (USDA) National Resource Conservation Service (NRCS) SoilDataMart website. The dataset was titled the Soil Survey Geographic (SSURGO) Database for Riverside and included comprehensive metadata. The property line datasets was provided as a free download from the Riverside County Transportation \& Land Management Agency (TLMA) online GISStore. The downloaded data were titled Parcel Attributed GIS Data and consisted of a file geodatabase containing polygon feature classes created from a relational join of the parcels feature class with the parcel assessors table. Although this dataset contained very incomplete metadata it is maintained and published by Riverside County TLMA and was considered definitive and used as provided.

Data relating to the tile drainage system were obtained from Matthew Palavido, the GIS/CAD supervisor at the Temecula Valley Water District, and consisted of scanned images of the survey diagrams and tables from the original installations. These scans were used in subsequent digitization of the drain lines.

All remaining data were created either from field collected GPS data or heads-up digitization. Digitization was performed using high resolution (1 meter GSD) orthoimagery as both a visual reference and a direct source. The imagery used was collected through the U.S. National Agricultural Inventory Program. It was downloaded from the USDA NRCS Geospatial Data Gateway and consisted of a stitched mosaic of all NAIP imagery collected in May, 2012 in Riverside County.

\subsection{Data Collection Methods}

The datasets created from field collection of GPS data are shown in Table 4-1 and are categorized by the feature dataset in the logical model to which they belong. GPS data were collected with a high resolution Trimble ${ }_{\circledast}$ GeoExplorer GPS receiver with an external Zephyr antenna mounted on a 2 meter monopod. All GPS data were collected with a 1 second sampling rate with 30 samples acquired for each position. The data were post processed using both code and carrier phase differential correction. The base station used for differential correction was the CORS (Continuously Operating Reference 
Station) station, SLMS_SCGN_CS1999, located in Salton City, CA. The SLMS station is approximately 12 miles from the Seaview Ranch property and operates at a 15 second sampling rate. The final location of each GPS position was given by the average of the 30 , post processed, samples taken at that position. Greater than $98 \%$ of the data had an estimated horizontal accuracy of less than 0.5 meters. Figure 4-5 illustrates the distribution across the property of the 174 sampled locations.

Table 4-1 Data created from field collected GPS data

\begin{tabular}{l|c|c}
\hline Tile Drainage & Electrical Distribution & Irrigation \\
\hline Access points & Utility poles & Valves \\
\hline & Telephone junction boxes & Line junctions \\
\hline & Electrical switch points & Fertilizer tanks \\
\hline & Electrical meters & Filters \\
\hline
\end{tabular}

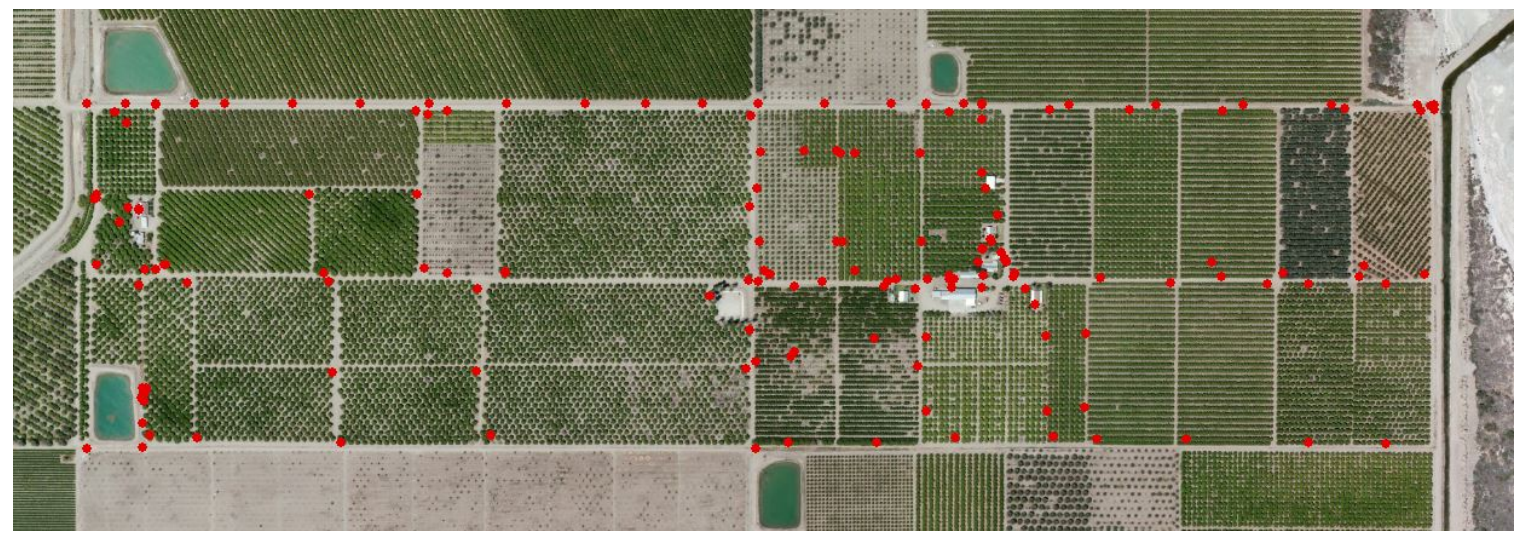

Figure 4-5 The distribution of sampled GPS locations across the property

The data that were created from manual heads-up digitization included the tile drain lines, irrigation lines, underground and overhead utility lines, the feature class showing all on-site structural facilities, and datasets relating to the block group geometries. The NAIP 2012 high resolution imagery was used as a base source for all data created using this process. The NAIP imagery has published horizontal accuracy of \pm 6 meters. When plotted with the GPS data (average accuracy better than 0.5 meter) it was apparent that in this region the horizontal accuracy of the NAIP imagery was sufficient.

All digitization was performed using the NAD 1983 California State Plane VI projection. The dimensions of the Seaview Ranch property are approximately 1 mile east to west by 0.25 miles north to south. This relatively small area combined with the 
inherent accuracy of the State Plane Coordinate system $(1: 10,000)$ provides for no significant distortion with regard to areas and lengths.

In the final production database all data were projected into WGS84 Web Mercator to ensure alignment with Esri's free online satellite imagery basemap layer that was used in the web application. While the ArcGIS API for JavaScript supports projection on-thefly for feature services, this process does place an additional demand on the client side web browser. In an effort to ensure optimal application performance it was decided not to rely on this additional service. As a result, all datasets, other than the CAD renderings, that contained area or length information had new attributes created to hold these values as derived from the State Plane projection. This was done to preserve the most accurate areas and lengths for these fields prior to conversion into Web Mercator.

The irrigation lines and line junctions were digitized using the original installation drawings provided by the client along with the GPS data associated with the irrigation valves. The major bends present in some of the irrigation lines were located in the field by following the drip line feeder tees that are visible at the soil surface and triangulating using the number of rows on two adjacent sides of a given block group. Using the NAIP imagery, bend and junction positions were estimated by triangulating against the same two adjacent sides of a corner in a given block group.

The tile drainage lines were digitized using the original installation drawings and tables provided by the CVWD along with the GPS data associated with the tile drain access points. The installation drawings and tables contained measurements of the feet of installed pipe that could be used along with the known access points to digitize the locations and lengths of the lines.

The CAD drawings and annotations were georeferenced using the NAIP imagery. They were also scaled to nominally match the size of the same structures on the imagery. As these datasets are referential and associated with annotation layers that contain projection independent information relating to square footages and lengths, these layers underwent no special preparation for conversion to Web Mercator.

The feature class containing all on-site structural facilities was digitized directly from the imagery as were those classes pertaining to the block group geometries. Digitization was performed at an image scale of 1:2000.

\subsection{Data Scrubbing and Loading}

A temporary file geodatabase was created for generating the feature classes that would fill a given feature dataset in the master project database. When loading a given dataset, an empty feature class was created in the temporary geodatabase and the required attributes, subtypes, and domains were implemented before the dataset was populated with specific features. Once all feature classes that would take part in any one feature dataset had been created they were loaded from the temporary geodatabase into the master database for the project. When populating the attributes supplied by the client into the block groups feature class it was noted that some of the numbers in the tree count field were in error. This necessitated doing a manual count of trees in each block group using the NAIP imagery. These revised tree count values were used to populate this field.

The datasets generated from the CAD drawings and the associated annotation layers contained a large number of attributes that relate only to how such files are 
rendered by a CAD program. The inclusion of these datasets in the project was requested by the client solely for referential purposes and considering this the vast majority of their attribute fields were removed. Only those relating to the default line color, line type, and annotation text were preserved.

In an effort to minimize the data load both in terms of ArcGIS Online storage and network traffic for the web application the soil type and property line datasets were clipped. The soil type data was clipped to approximately one square mile centered on the ranch property. The property line dataset contained over 800,000 polygon features and was clipped to just the four features covering the Seaview Ranch. These four features were then merged into one and converted to a polyline feature class. This was done to improve the user experience when interacting with the web application. This datasets also contained a large number of fields related to official bureaucratic designations that were not relevant to the property in question. In an effort to create a more user friendly dataset all of the native fields were deleted and replaced with fields containing the perimeter and area of the property. A PDF document was then created showing the original four feature geometries labeled with their assessor's parcel numbers along with all of the original fields relevant to the property. This document was included as an attachment in the property line feature class.

\subsection{Summary}

In this chapter the conceptual and logical data models were outlined detailing the entities involved and their interrelationships. The conceptual data model was developed using UML and the logical data model was designed in ArcGIS Diagrammer. The data sources were discussed followed by a detailed description of the instrumentation and the methods used to create the custom datasets that were required. The chapter concluded with a discussion of the processes used to prepare the data for effective inclusion in the designed geodatabase. 


\section{Chapter 5 - Implementation}

This chapter will detail the methods used to create both the feature services published to the ArcGIS Online account and the web application developed in this project. The preparation of the various map documents will be discussed in Section 5.1. Publishing the feature services to ArcGIS Online will be detailed in Section 5.2. Development of the web application will be covered in Section 5.3.

\subsection{Map Document Preparation}

The feature classes involved in this project were used in both the web application and in various web maps in the ArcGIS Online account. As a result, it was important to consider both how the client would interact with these layers in his online account and how they would be used in the web application. In an effort to provide a simple and logical organization of the large number of datasets involved, a total of seven map documents were created: one for each of the feature datasets in the logical model and one each for the cadastre and soil type feature classes. All features were symbolized using simple or picture marker symbols as more complex multilayer symbols may be downgraded in published feature services (Esri, 2013c).

The crop production feature dataset contained one feature class representing each of the individual block groups as well as three feature classes that group crop production units by variety. The majority of the crop varieties grown on the property are located in multiple block groups that are not contiguous and yield values are not measured at the block group level but at the varietal level. Thus, when considering how to provide a user friendly editing environment for updating yield values in the web application it was decided that it would be most intuitive for a user to interact with geometries representing individual varieties. If yield values were stored at the block group level, for each new production year, the user would be required to create a new feature and update the yield value for each block group that contained a specific variety. This would be a lengthy task using a desktop computing platform and was not considered feasible for a mobile device. Since the scale used to evaluate annual production volumes differs between dates, kumquats, and citrus it was necessary to create separate feature classes for each of these categories. Figures 5-1 and 5-2 show the map document for the production feature dataset illustrating the symbology used and the relationship between individual block groups and production varieties. In order to provide for the tracking of varietal yields over time the map document was time enabled following the work of Lertsakdadet (2012). 


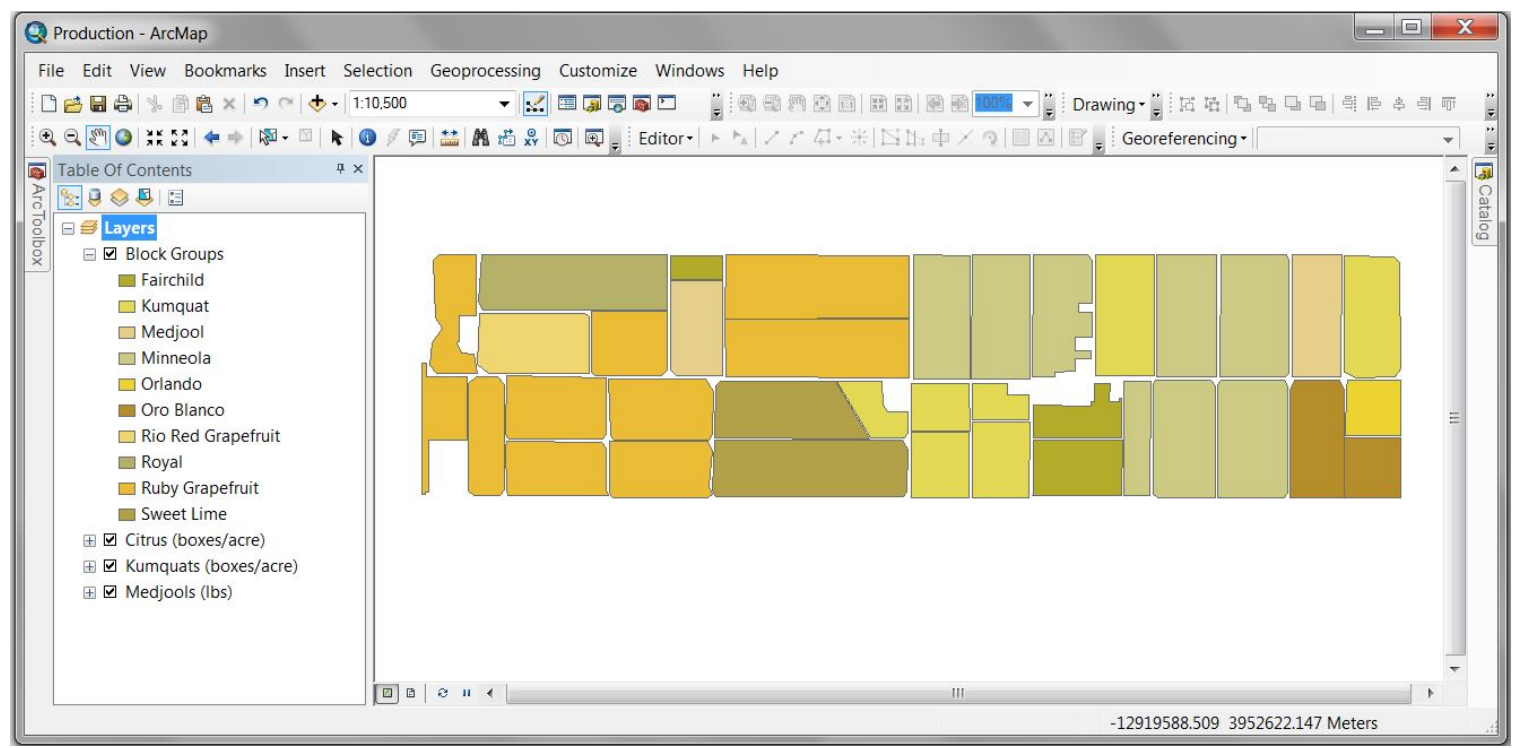

Figure 5-1 Production feature dataset map document showing the block group layer

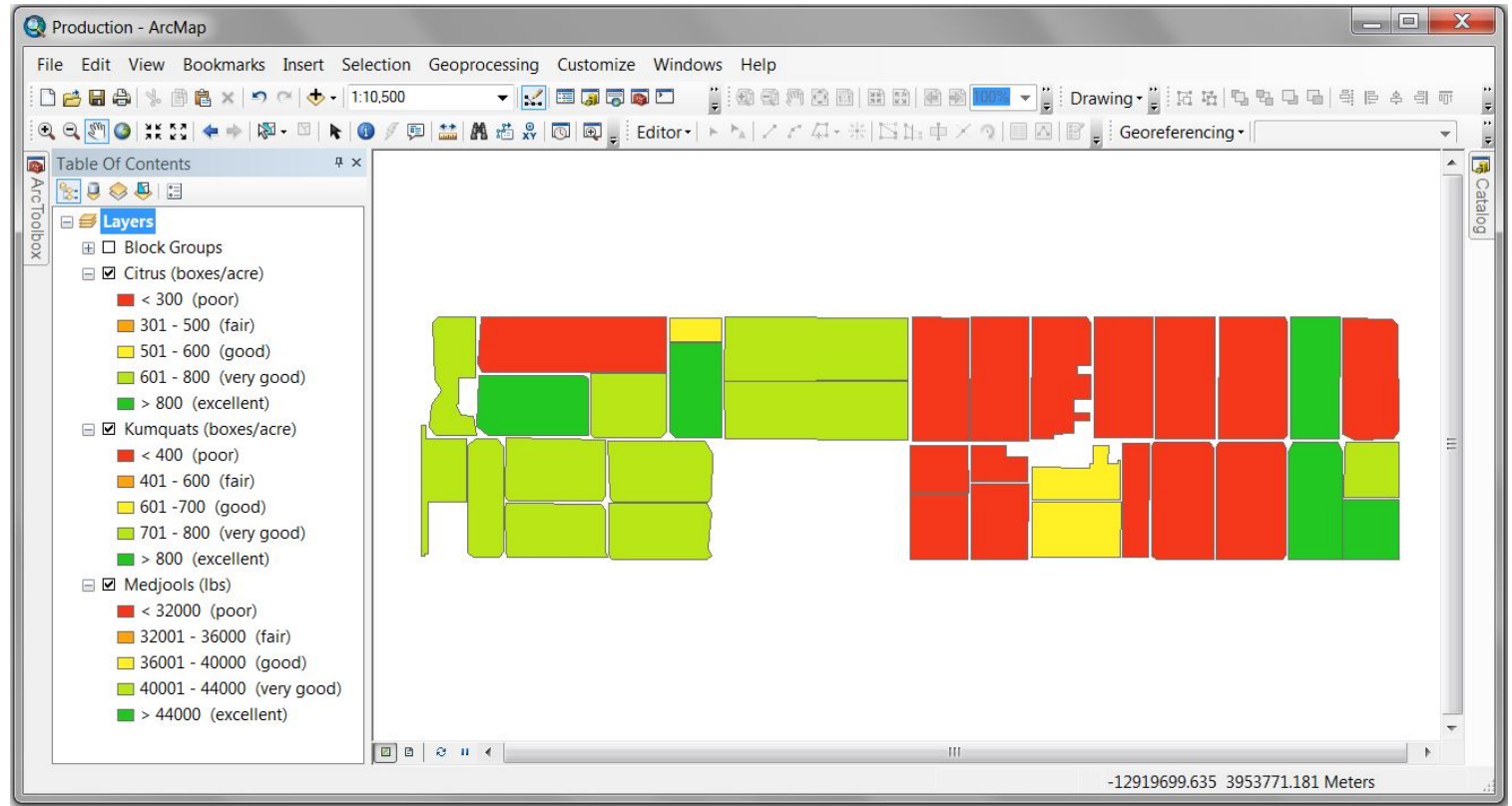

Figure 5-2 Production feature dataset showing the varietal yield layers

The remaining map documents were prepared by selecting appropriate symbologies for the various feature classes involved. The map documents prepared for each feature dataset as well as the cadastral and soil type feature classes are shown in Appendix B. 


\subsection{Publishing Feature Services}

A feature service is a variant of a map service that allows for querying and editing of features in a dataset that is served over the Internet. It also supplies the symbology for rendering the features and provides the editing template that was created in the map document (Esri, 2013d). With the exception of the soil type dataset all map documents created for this project were published as feature services as each contained at least one layer that the client might want to edit. Publishing feature services to ArcGIS Online requires an existing organizational account. Feature services cannot be published to a free personal account.

The process for publishing services to an online account is similar to that used to publish to an Arc Server account. As of ArcGIS version 10.1, however, map and feature services can only be published from within ArcMap, whereas previously this task could also be done from ArcCatalog. A user must be logged into their online account from within ArcMap before a service can be published. Figure 5-3 shows the login panel that is accessed through the file menu. Once logged in, services can be published until the session is terminated. Figure 5-4 shows the ArcGIS Online content panel in ArcMap. From here a user can see all content that has been published as well as any web maps or applications that have been created, in ArcGIS Online, from that content. Users can also access details about, or add data to, existing content.

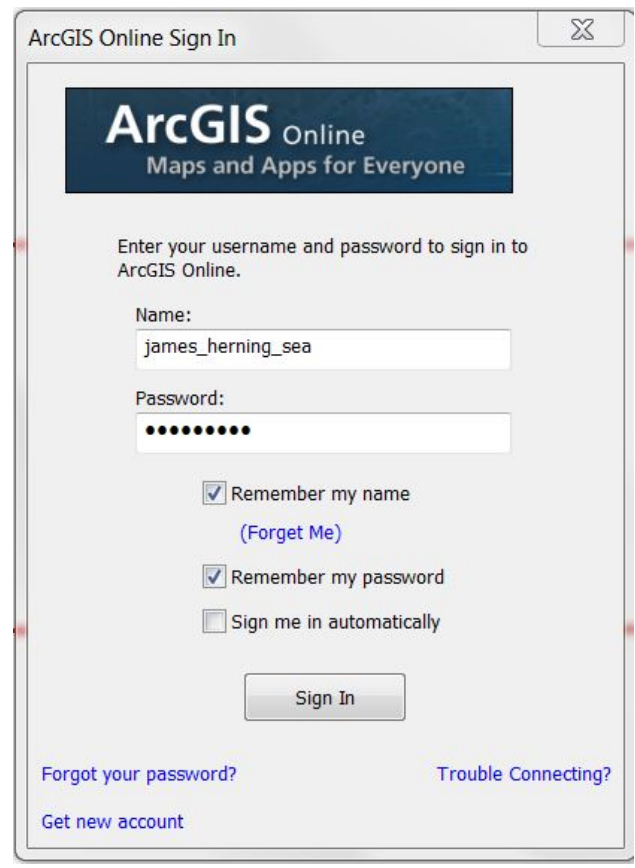

Figure 5-3 The ArcGIS Online log in panel accessed through ArcMap 


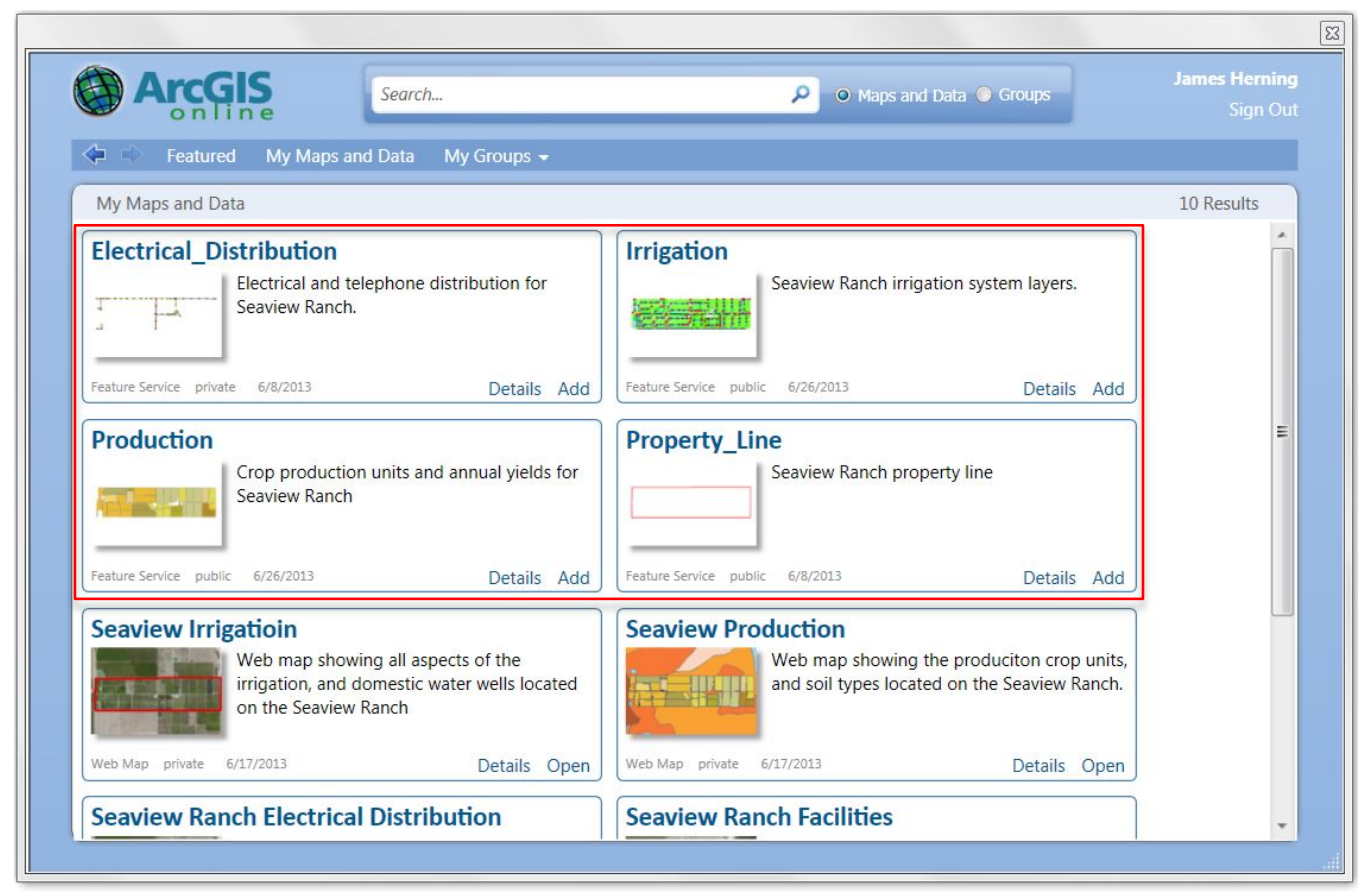

Figure 5-4 The ArcGIS Online content panel accessed through ArcMap showing
feature services in the red box with web maps below

The next step in publishing to an online account involves selecting My Hosted Services from the Choose a Connection drop down list in the Publish a Service wizard.

As compared to previous versions, ArcGIS version 10.1 provides more control over what types of editing operations are allowed for feature services. Figure 5-5 shows the service editor with the Operations allowed section highlighted. This figure illustrates the allowed operations configuration used for the production and yield datasets. As the geometries of these layers will not change only querying and updating are allowed. For those services where feature geometries might be changed or added, such as the irrigation, electrical, and tile drainage, the create and delete options would also be checked. The create and delete options are new to version 10.1. 


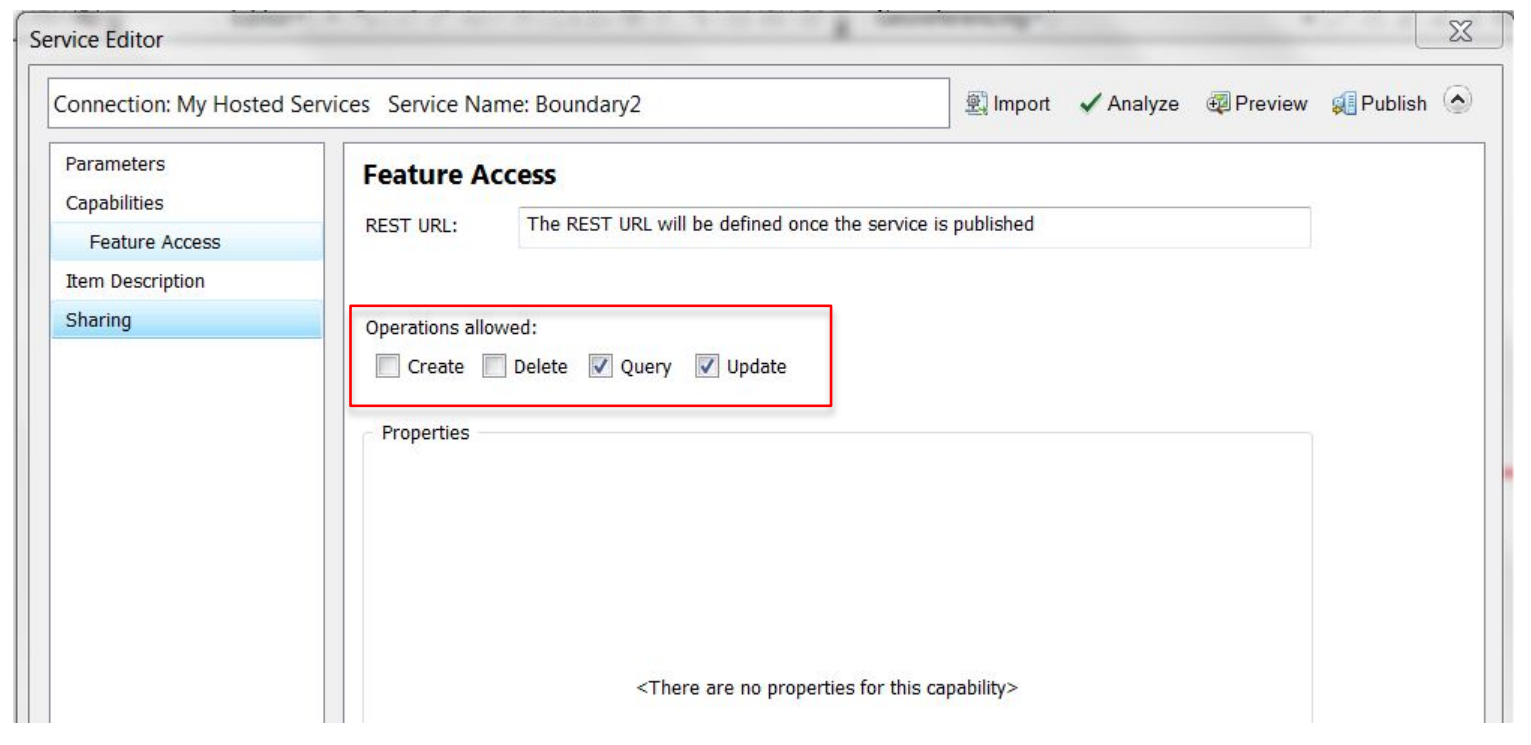

Figure 5-5 The Service Editor showing allowed editing operations for published feature services

\subsection{Web Application Development}

The application developed in this project consists of three main components: the user interface, the time slider widget, and the editing environment. The application was written using Dojo, JavaScript, HTML5, and CSS3. The functional components of the application were developed using the ArcGIS JavaScript API and the Dojo and Dojo Mobile toolkits. Dojo Mobile is designed to work with touch sensitive devices such as tablets and smart phones. The user interface was created using dijits (Dojo widgets), Dojo mobile, and HTML5 with custom styling implemented using CSS3. All code development was done in the Aptana Studio 3 integrated development environment and the application was debugged using the Firebug add-on for the Firefox web browser. Aptana Studio 3 and Firebug are both free open-source software packages.

\subsubsection{User Interface Design}

The user interface for this application is shown in Figure 5-6 and consists of the following elements: header, footer, right panel, and left panel. In HTML each of these elements are referred to as a $<\operatorname{div}>$. A div is used to define where thematic elements are placed in the browser. The term is derived from divider in that they subdivide the parent container into regions. Each div can be a child of another div, meaning it exists inside the space defined by its parent. Or, it can be the parent of multiple children (divs). The four div elements in the user interface presented here are all children of the Dojo BorderContainer widget which can be partitioned in up to five regions; left, right, top, bottom, and, a mandatory, center. "Each child element must have an attribute 'region' which indicates where it should be positioned (Dojo Foundation, 2013b). 


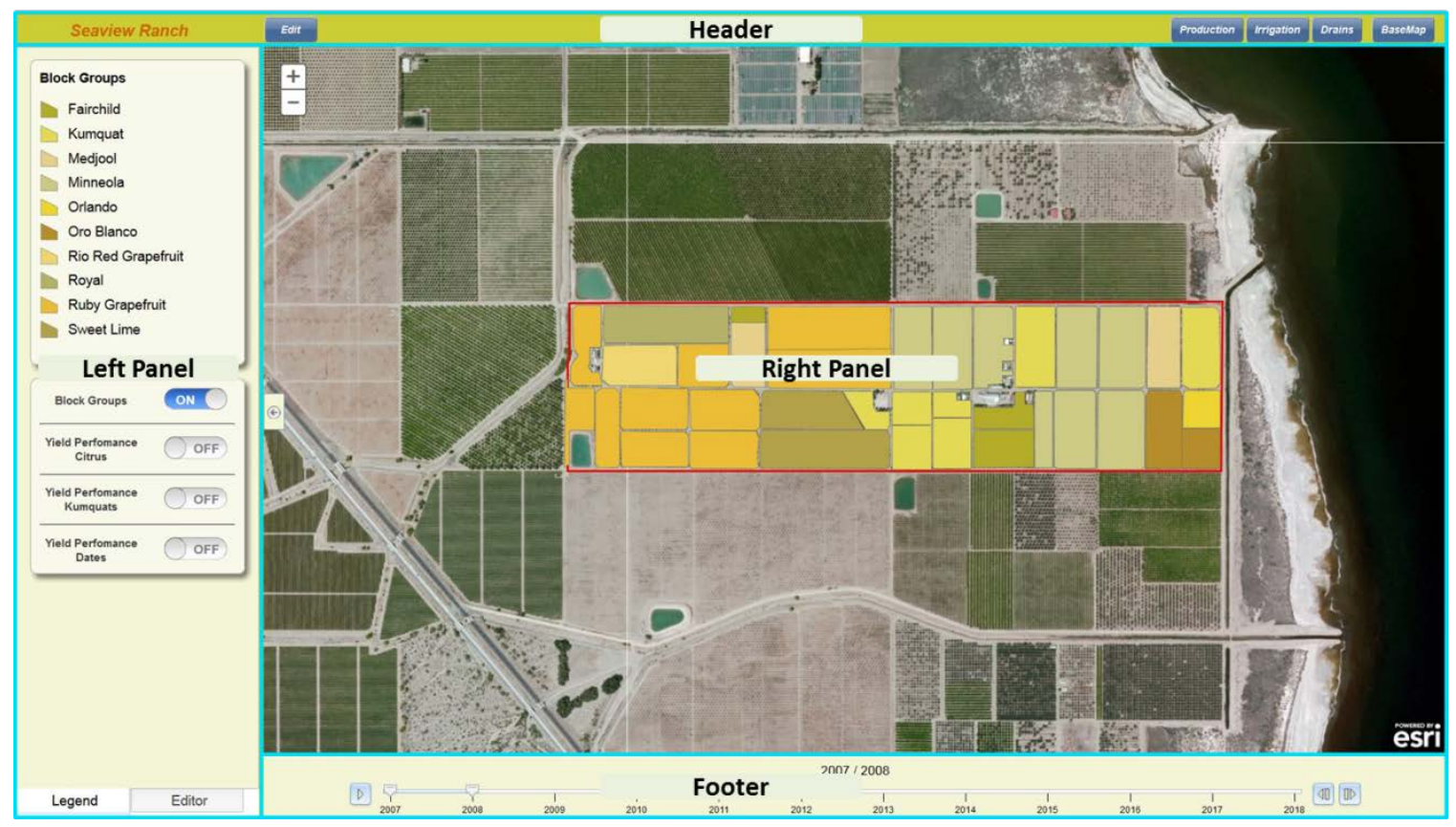

Figure 5-6 Layout of the web application user interface

Certain elements of user interface design are common to all web applications such as a header and footer, and a main content panel. The code required for the development of these elements only varies in the assignment of unique element ids and the styling employed. The user interface for this project drew directly from the work of Lertsakdadet (2012) both in the use of a tabbed left panel that can toggle on and off and in the use of Dojo mobile switches for enabling layer control.

The header element consists of the following components. On the far left is a title for the Seaview Ranch property followed by the Edit button that initializes the editing mode. On the far right are four buttons. From left to right are the three layer group buttons, Production, Irrigation, and Drains, followed by the Basemap button. Pushing one of the layer group buttons instigates a series of actions including removing all current map layers from the Dojo map widget in the right panel, loading the various map layers pertaining to the group button into the Dojo map widget for display, and initializing the legend and layer control switches in the left panel.

For the purposes of this application the basemap serves solely as a visual reference and as such it was decided that a single imagery basemap was all that was required. Pushing the Basemap button clears or loads the basemap image from the map display. This functionality was provided due to the large number of features that can be displayed in the irrigation layer group. When multiple layers are displayed simultaneously it can be easier to identify certain features when the basemap is not present.

The left panel was constructed using the Dojo TabContainer widget with two tabs labeled Legend and Editor. The Legend tab is the default view until a user enters edit mode. If the user presses the Edit tab while not in edit mode he or she is presented with the following message "You must be in an edit session to use this function". The Legend 
tab contains a legend for the currently loaded layer group along with the appropriate layer control switches. Figure 5-7 shows the default behavior of the Legend tab for each layer group showing from left to right Production, Irrigation, and Drains. The Production layer group contains the block groups layer and the three time enabled varietal yield layers for citrus, kumquats, and dates. Together the three yield layers share coincident geometry with the block group layer. As a result, for this layer group the layer control switches are exclusive in that only one layer may be shown at a time. Switching a new layer on will automatically switch the previous layer off. The legend also updates to match the currently displayed layer. The line junctions layer in the irrigation group has 186 features so to present a cleaner map display the default visibility of this layer is set to off. For this layer group the JavaScript legend widget was configured with the autoupdate parameter set to true. This removes the map symbology from the legend for layers that are turned off. The Drains group only contains two map layers so no layer control switches are provided.

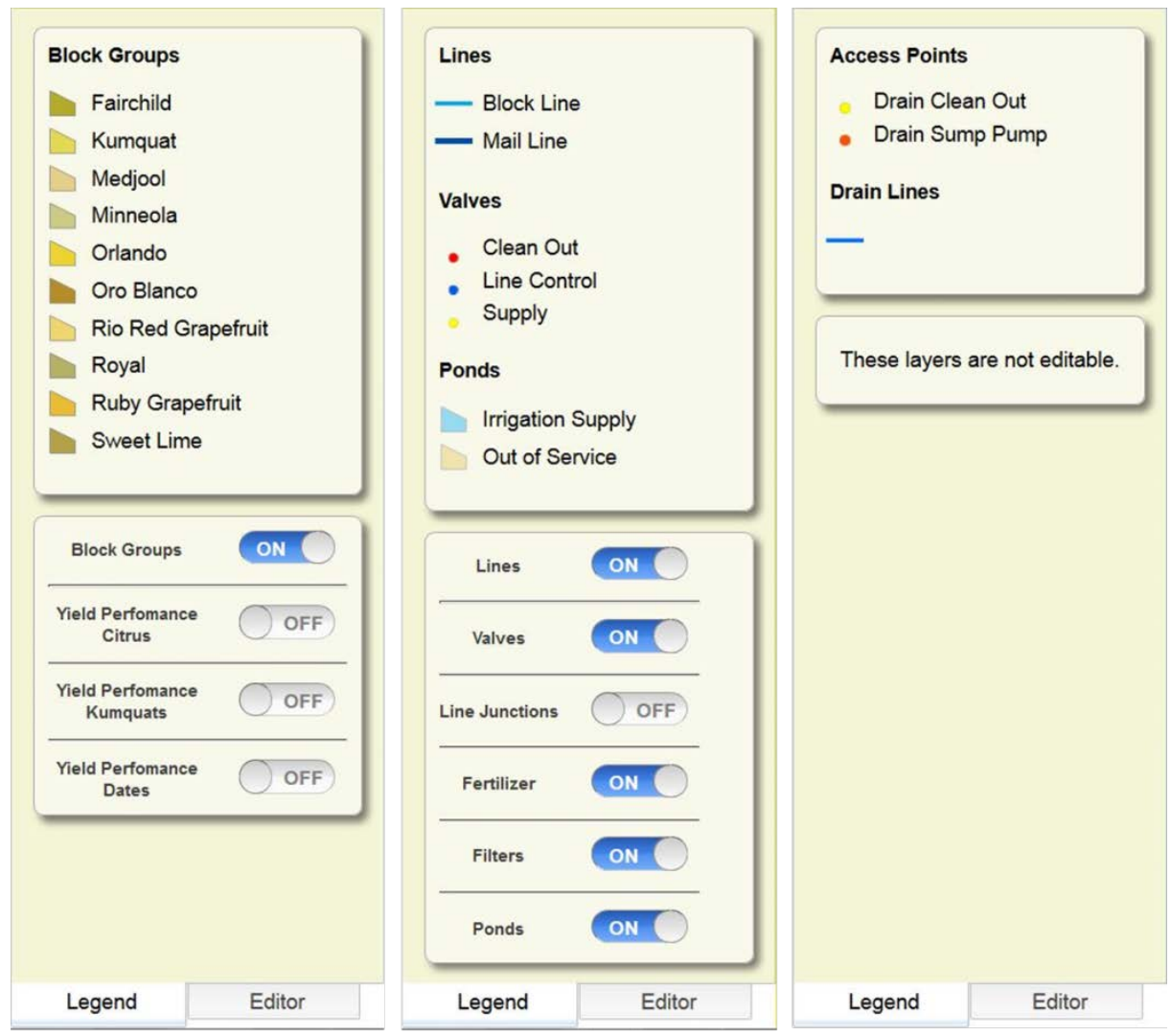

Figure 5-7 The default appearance of the Legend tab for each layer group.

The right panel was also constructed using the BorderContainer widget as it contains both the map widget that is part of the ArcGIS JavaScript API and a toggle switch. The toggle switch hides the left panel TabContainer providing a full screen view of the displayed map. The map widget controls the display of map layers and the popup windows that appear when a user taps or clicks a feature. The map widget was configured to display custom popup windows that show selected attributes and in some 
cases photographs depending on the currently loaded layer. The default styling of the popup windows was modified using CSS3.

The footer element contains the TimeSlider widget. This widget is a component of the ArcGIS JavaScript API and is used to display time enabled data. The time slider will be described further in the following section.

\subsubsection{Implementation of the TimeSlider Widget}

The time slider is used to control the display of the time enabled varietal yield layers and is shown in Figure 5-8. When a user presses the play button the current layer is animated to show the change in crop yield over time. The yield for a given production period can be displayed by moving the time slider tab to the year of interest. The various crop varieties grown on the property are harvested at different times throughout the year with the production season ranging from September through March of the next calendar year. As a result the client refers to a growing season by reference to a two year period for example 2012/2013. The label above the time slider is configured to reflect this.

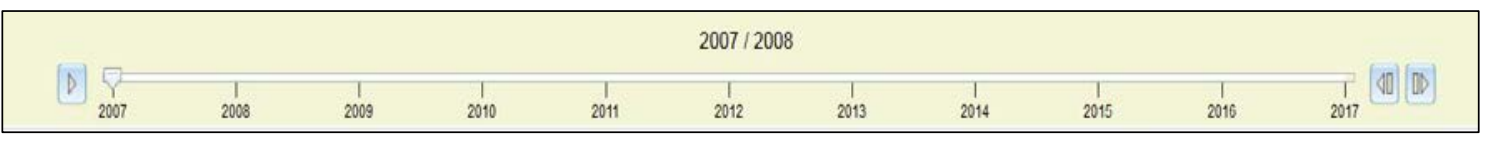

Figure 5-8 Time slider as configured for this application

\subsubsection{Data Editing Environments}

One of the main requirements for this application was that it supports the editing of certain data layers. However, not all layers needed to allow for the same types of edits. Two different editing environments are provided based on which group layer is currently loaded. The user instantiates the editing mode by pushing the Edit button located on the header portion of the user interface. This instigates a series of actions including removing all currently loaded map layers, switching from the Legend tab to the Editor tab, replacing all content in the Legend tab with the message "You are currently in an edit session.”, populating the Editor tab with the required content, and changing the label on the Edit button to Done.

The production layer group only allows for the update of feature attributes. The geometries of the block group layer do not change over time so deleting or creating features is not required. The varietal yield layers were created by merging the block group features that contain the same crop variety. While crop varieties are torn out and replaced periodically, often with a different variety, merging features is not supported by the ArcGIS JavaScript editing widget so these layers also do not support deletion and creation in the editing environment. As only attribute update operations are allowed the Editor tab is populated with the legend for the block group layer which shows what varieties are grown in each block group. Also, since the block group and varietal layers share coincident geometries, the Editor tab is populated with exclusive layer control switches as are used for this group in the Legend tab. Here, however, in order to control loading the appropriate layer data into the editor widget the default state of all switches is set to off. Figure 5-9 shows the default state of the Editor tab for the production group. 


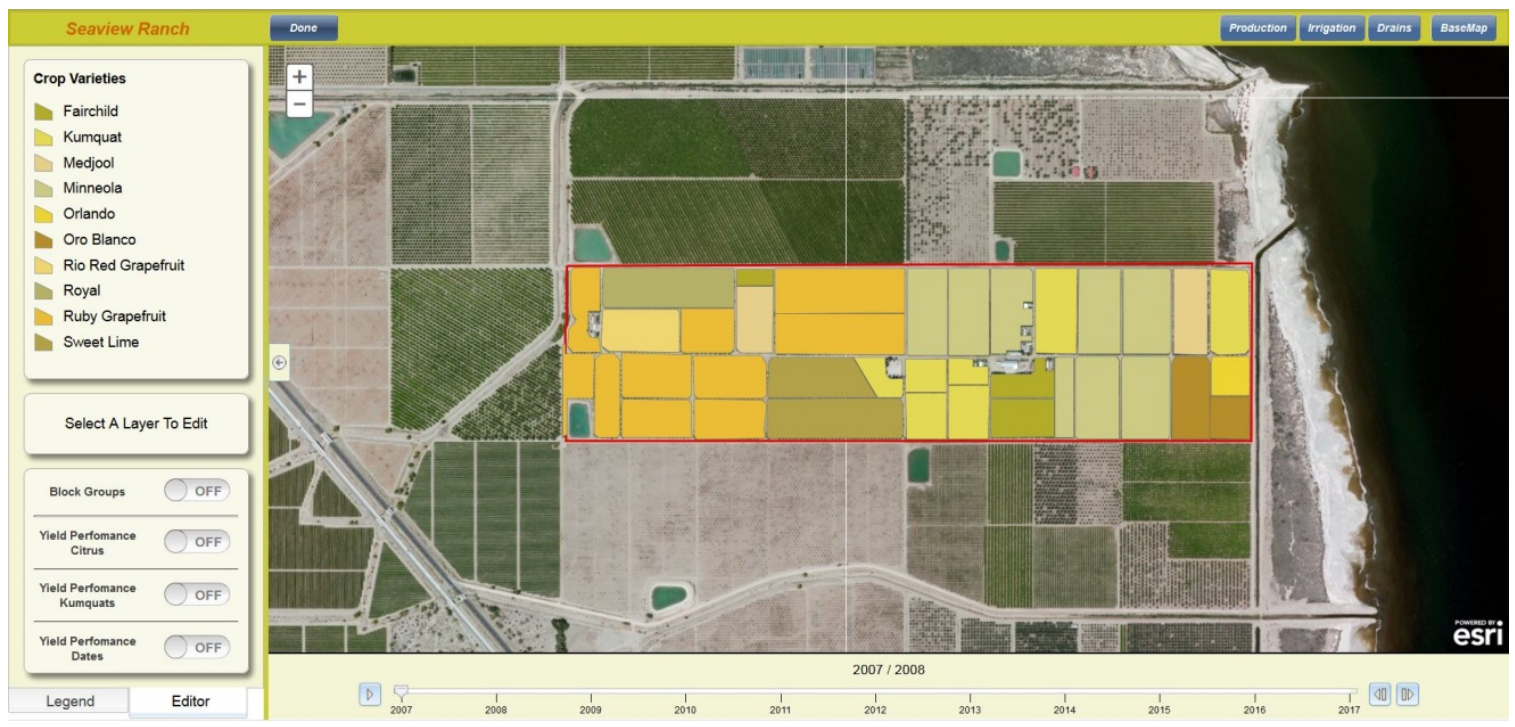

Figure 5-9 The default state of the Editor tab for the production layer group

As the figure shows the block group layer is initially visible. However, editing of the block group layer cannot commence until the Block Groups switch is turned on as shown in Figure 5-10. When the switch for one of the other layers is turned on any switch that is currently on is turned off and its visibility is set to false (removing the map from the display). Next the layer whose switch was turned on has its visibility set to true (displaying the map) and its data are loaded into the editor widget. This way only one layer is available for editing at any given time.

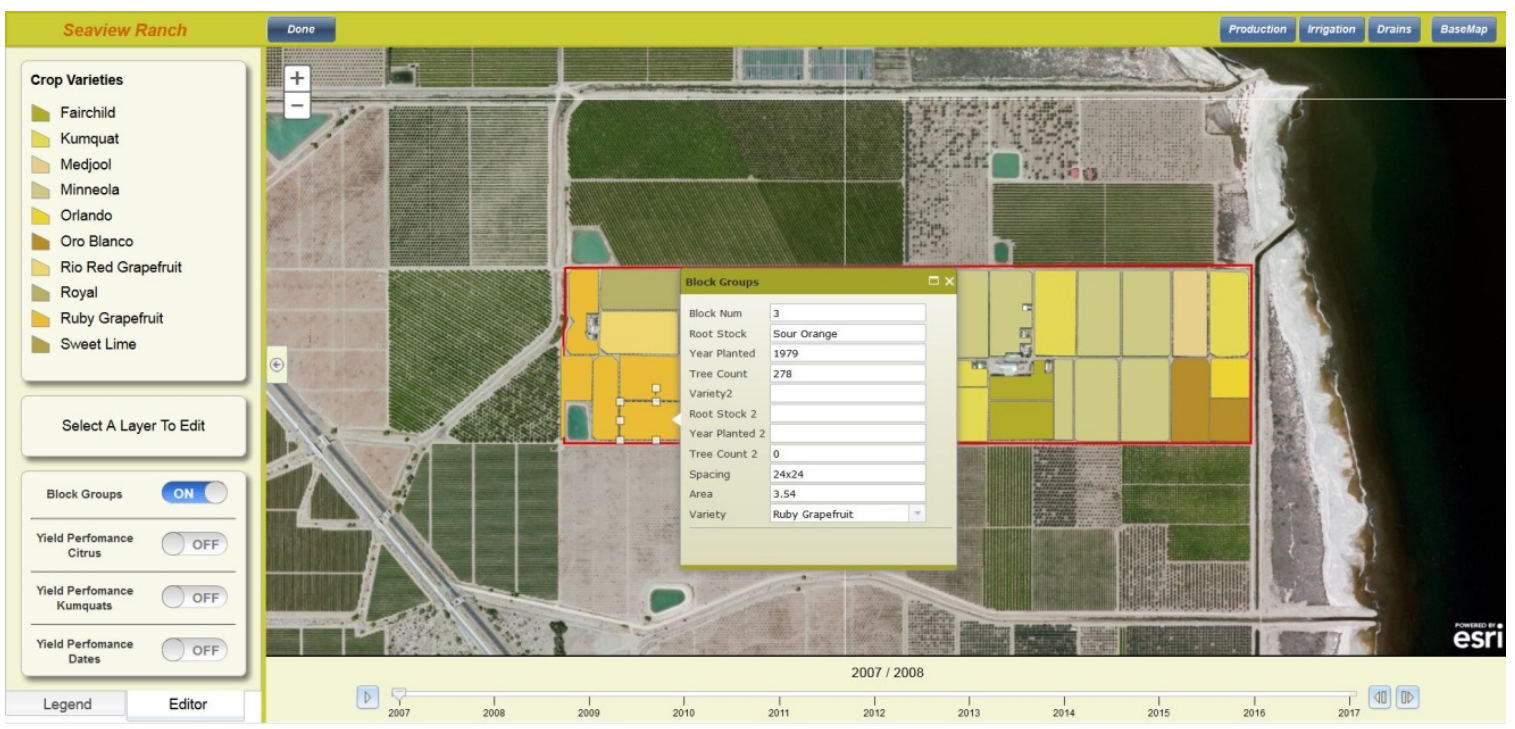

Figure 5-10 Editor tab with editing enabled for the block group layer 
For the irrigation layer group the deletion and creation of features are allowed along with the update of feature attributes. As a result the content of the Editor tab is different from that provided for the production group (Figure 5-11).

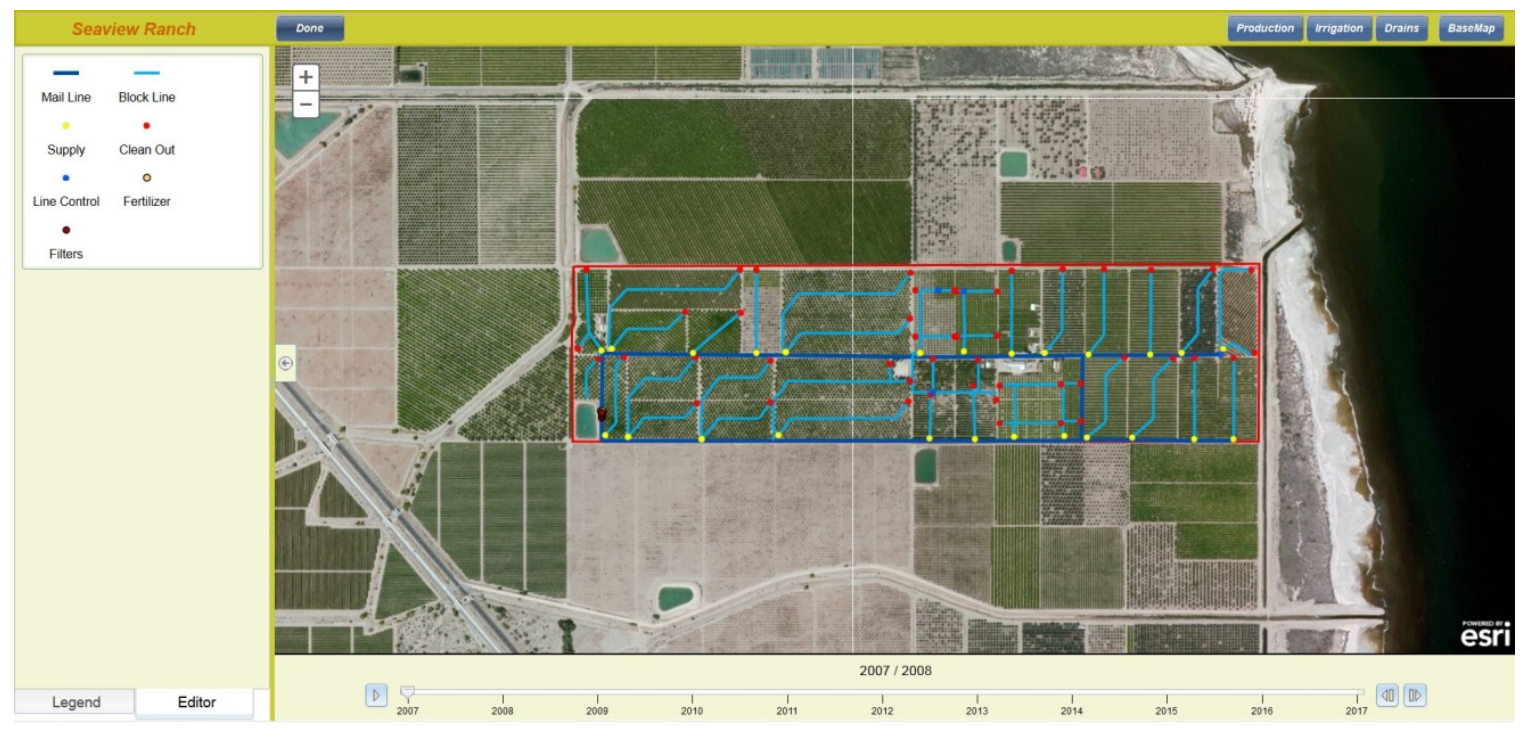

Figure 5-11 Edit environment for the irrigation layer group

Here there are no layer control switches and the ArcGIS JavaScript TemplatePicker widget is used to display the icons for the feature elements that can be created. To create a new feature users select the feature type they want to add to the map and then taps or clicks the location on the map where they want to place the feature. As with the production group, attributes of existing features can be edited by tapping or clicking on the feature of interest. With 168 point features in the line junctions layer it was decided that allowing for the edit of these features in the web application would be cumbersome and lead to excessive screen clutter, so this layer is not included in the irrigation editing environment. As no changes are anticipated to the geometries or attributes of the irrigation ponds, this layer was also not included.

When a user is done editing he or she presses the Done button which instigates the following events. The current content of the editor tab is destroyed and replaced with the default message mentioned previously. The legend tab is repopulated with the appropriate content for the currently loaded layer group and the label of the button is changed back to Edit.

\subsection{Summary}

Chapter 5 covered the steps taken to prepare the necessary map documents required for this project along with publishing those documents as feature services to an ArcGIS Online organizational account. This was followed by a discussion of the development of the web application using the ArcGIS JavaScript API, Dojo, HTML5, and CSS3 and finished with descriptions of the major functional components in the application: the user 
interface, the time slider, and the various editing environments. The complete source code for the web application is included in Appendix C. 


\section{Chapter 6 - Results and Analysis}

After collecting and creating datasets covering the cadastre, soils, and infrastructure associated with the Seaview Ranch property, a mobile compatible web application and a number of web maps were created using the data that were published to the client's ArcGIS Online organizational account. In this chapter the utility of the web maps and application will be discussed. Limitations in the application and in hosting the data in an ArcGIS Online account will also be covered.

\subsection{Web Maps}

In an effort to provide a streamlined application that focused on the core elements relating to crop production, a subset of the data pertaining to the property was included in the web application while the remaining data were uploaded to the client's ArcGIS Online account and configured into web maps. While these maps could be viewed using a mobile device, the intention was that they would be viewed from one with a larger screen such as a desktop or laptop. With the large number of layers present in some of the maps, viewing and interacting with them using a mobile device is not recommended. This section will discuss the utility of the web maps that were created.

\subsubsection{The Electrical Distribution System}

The web map created for the electrical distribution system provides a visual representation of the locations of utility poles, buried and overhead utility lines, both telephone and electric, telephone and electrical junction boxes, and electrical meters. From the map users can access information on the height and ID numbers of utility poles or the type of a selected utility line. For electrical meters they can access the type, voltage rating, and meter number as well as a photograph of the meter. For electrical junction boxes they can access photographs, and a description of the box type such as residential fuse box, facilities fuse box, or primary shut off. This map can be used to quickly identify the specifics of a given component of the electrical system in the event of a failure or maintenance issue.

\subsubsection{Structural Facilities}

Using the web map created for the structural facilities, a user can see the locations of all buildings located on the property and access their descriptions and the approximate square footages. For the buildings for which CAD drawings were supplied, the user can see a spatially registered drawing of the building's layout including bathroom and kitchen furnishings along with accompanying annotation detailing room descriptions and accurate square footage.

\subsubsection{Irrigation}

While the web application does contain the primary components of the irrigation infrastructure, there were some elements that were not included such as a representation

of the drip lines in each bock group and the locations of the domestic water wells. Using 
the web map the user can see all aspects of the irrigation and tile drainage systems at one time. As mentioned previously, due to the large number of points in the irrigation line junctions dataset this layer was not included in the editing environment of the mobile application. However, such edits can be made from the web map and the user can see any changes to irrigation line locations that were recorded while in the field.

\subsubsection{Soil Type}

The web map created to show the soil types includes the block groups layer which shows the layout of the crop production units located on the property. A user can see a general overview of which varieties are growing on which soil types and access details about those soil types such as slope, aspect range, available water storage capacity, and drainage. Such information can be useful for determining the best variety to plant in a given soil type when crops are replaced.

\subsection{Web Application}

The web application developed for this project allows users to visualize various infrastructure elements, crop production units, and temporal crop yields, and edit selected datasets from a mobile device while in the field. The utility of the developed web application will be demonstrated by illustrating the different ways in which users can interact with the application.

\subsubsection{Visualizing Crop Production Units and Temporal Yield Values}

One of the primary responsibilities of the farm manager is to survey the trees throughout the growing cycle and provide estimates of the expected yield for each variety. While in the field performing his survey he can now bring up a visual representation of the entire farm on his tablet device to quickly identify which varieties are growing in which block groups. He can also access information about a specific block group by simply tapping on the feature of interest as shown in Figure 6-1. 


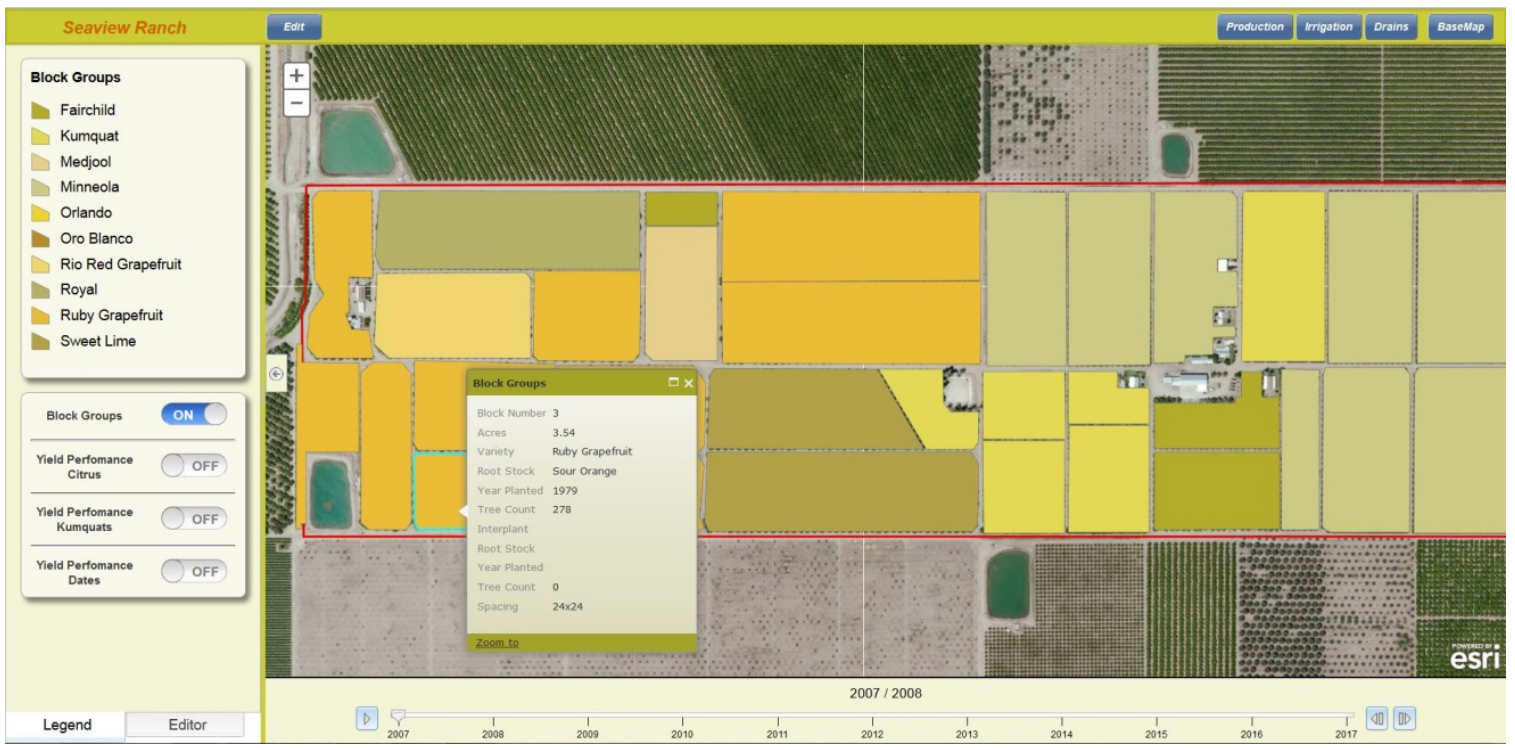

\section{Figure 6-1 Accessing information on a specific block group}

Suppose the farm manager is making his yield estimate for a certain crop variety and he thinks that the yield will be below average this year. Using the application he can look at the past performance for that variety by dragging the thumb tab through the previous years and examining the annual crop performance. The client uses an ordinal scale to rank crop yield, measured in boxes or pounds per acre depending on variety, which ranges from poor to excellent using five classes. In the application these ranks are symbolized progressing from red for "Poor” to green for "Excellent” (Figure 6-2). By tapping on a specific variety the farm manager can see the details of the estimated and realized yield for that variety for a given year.

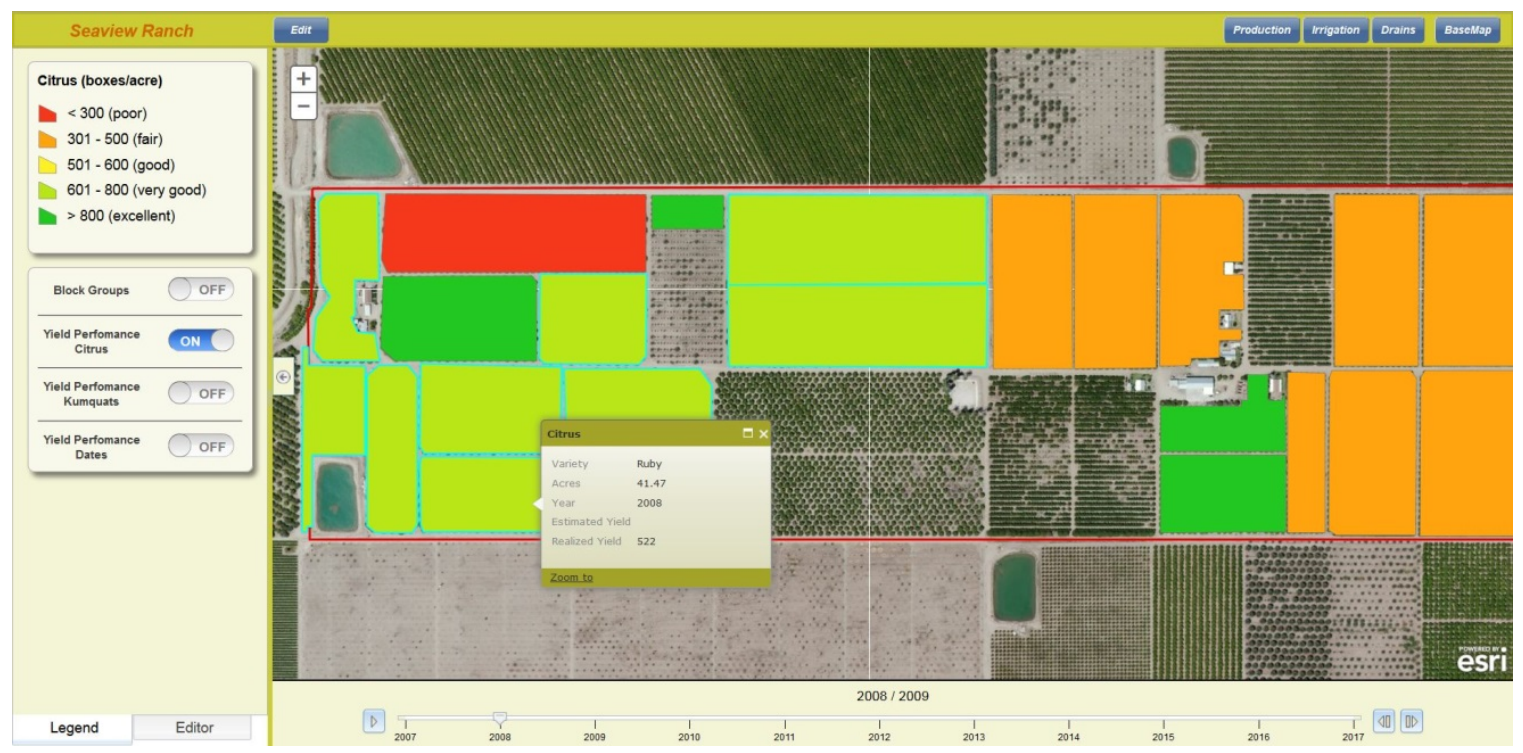

Figure 6-2 Accessing temporal information on Ruby Red grapefruit yields for 2008 


\subsubsection{Visualizing Irrigation System Components}

If while in the field the farm manager notices that a certain block group is not being supplied with water, he can access a map showing the layout of the irrigation supply lines and retrieve information about the valves that supply that particular block group (Figure 6-3). He can also bring up information about the service history for the filtration system or check on when the fertilizer tanks were last filled.

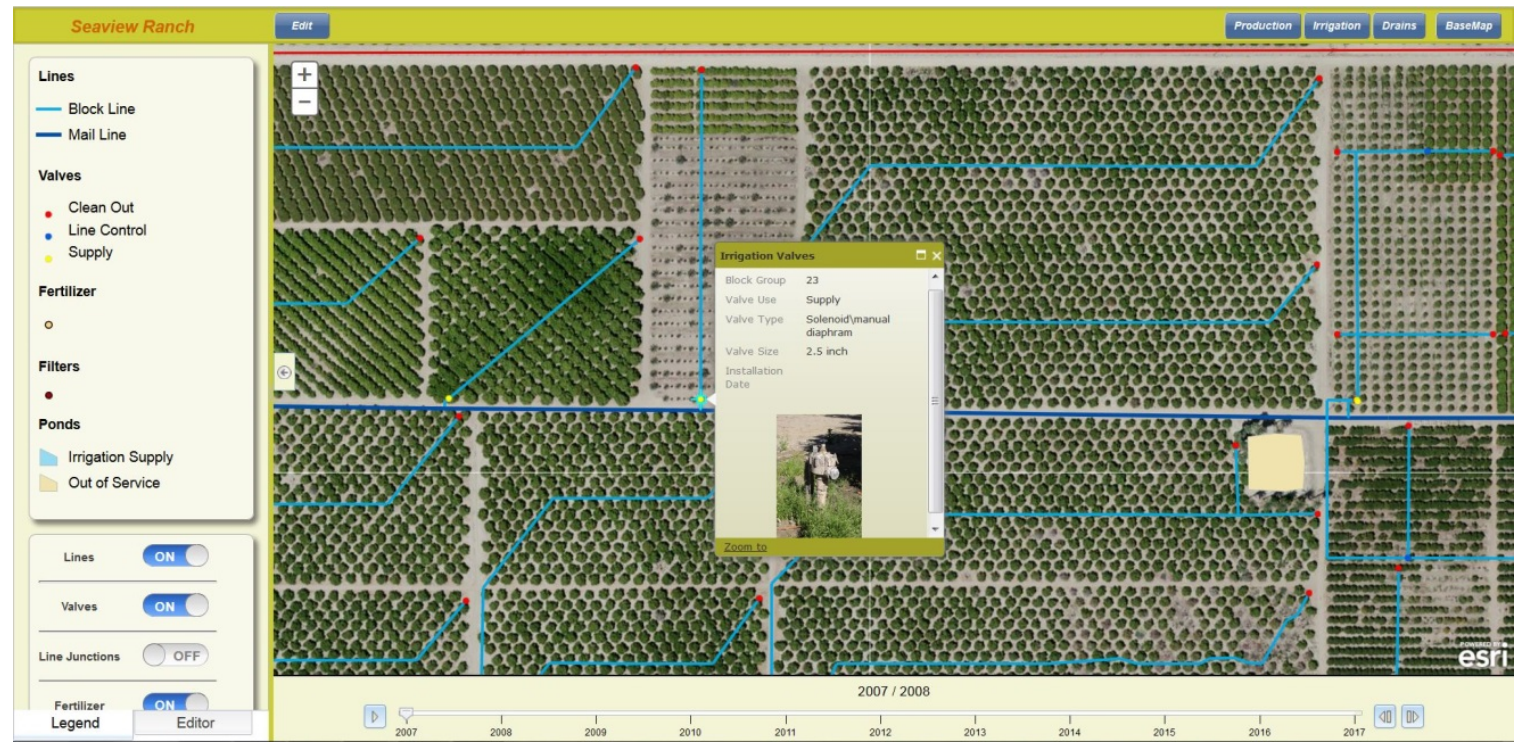

Figure 6-3 Accessing information about a specific irrigation valve

\subsubsection{Editing and Updating Information in the Field}

While in the field making his crop yield estimates the farm manager might notice that a number of trees in a certain block group are ailing and not producing adequate fruit and instructs the farm crew to remove those trees. Using the application he can edit the attributes for that block group to reflect the revised tree count by entering the edit mode, turning on the block groups layer and tapping on the appropriate feature (Figure 6-4). 


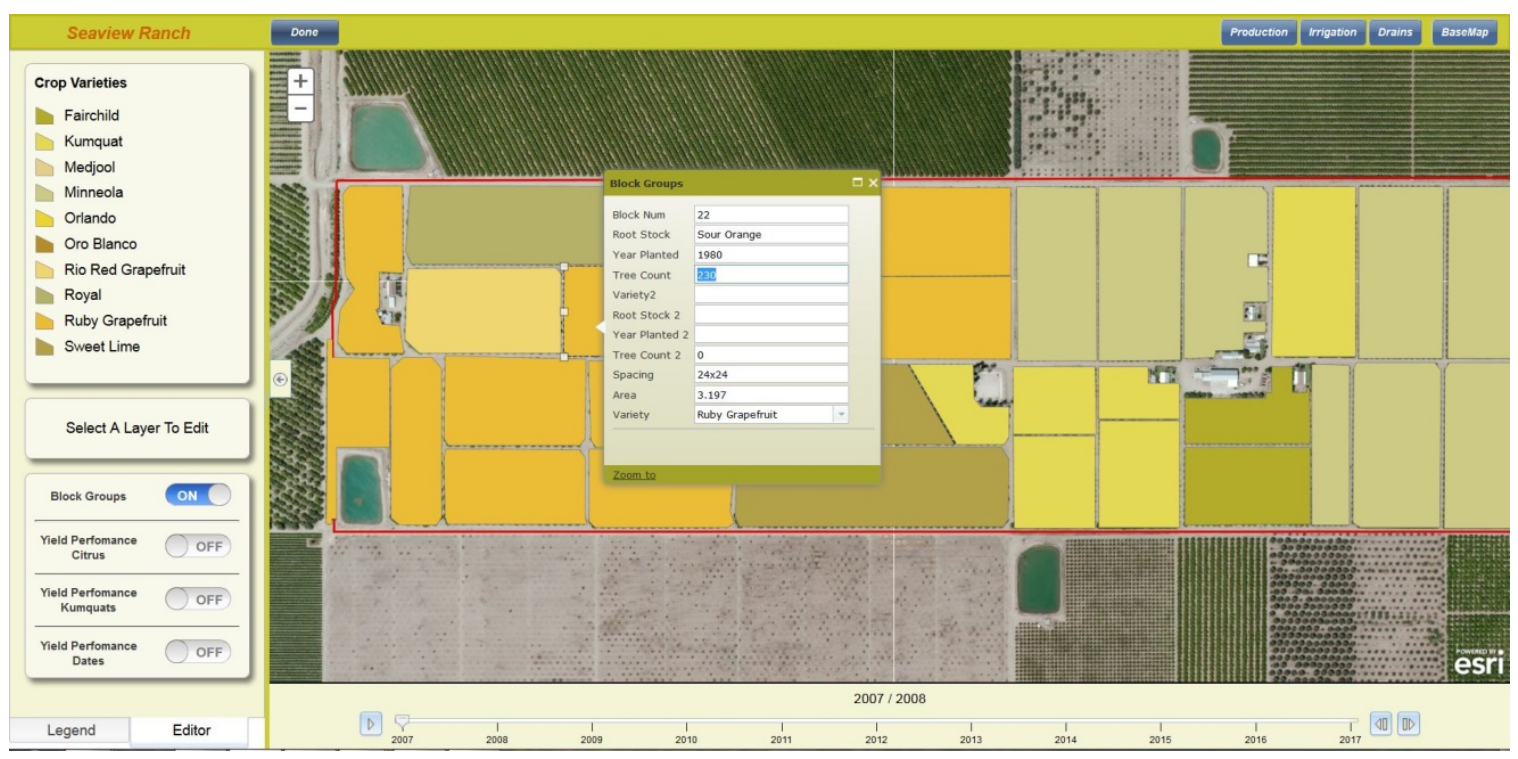

Figure 6-4 Editing the tree count attribute for block group 22

During the same edit session he can also record his yield estimates for that variety by turning on the appropriate crop yield layer, selecting the variety of interest, and entering his yield estimate in the feature associated with the current year as shown in Figure 6-5. In order to allow for tracking estimated versus realized annual production the yield layers have attributes for each value, however, the layer symbology is tied to the realized annual yield. As a result when the user enters a value for the estimated yield he must also enter the same value for the realized yield attribute. This ensures that the feature display is updated with the current estimated value. Once harvests are complete and realized yield values are known the user can go back into the application and finalize this value while at the same time maintaining the estimate. 


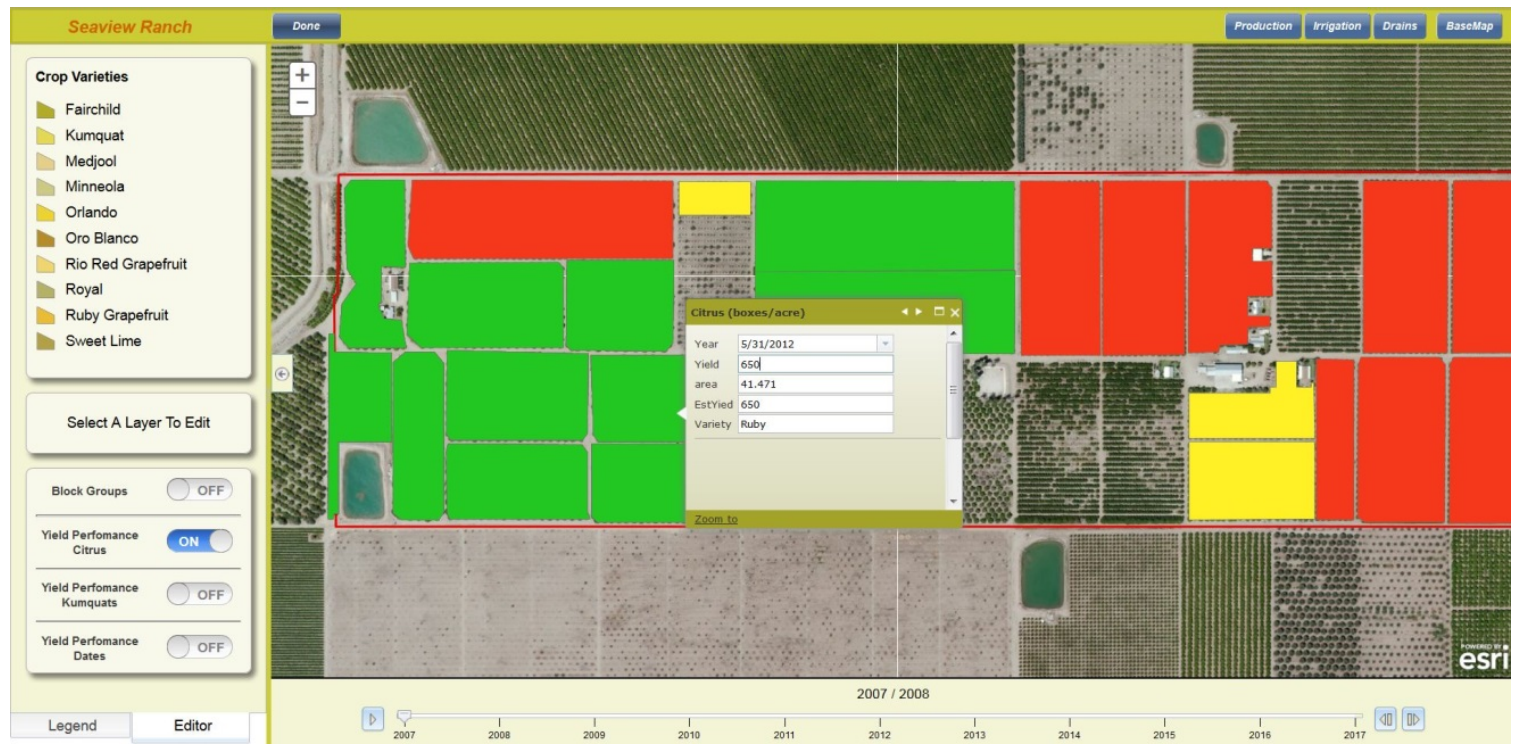

Figure 6-5 Entering yield estimates for the 2012/2013 season

Now suppose the farm manager has determined that the block group mentioned earlier that is not getting supplied with water has a broken valve. By entering the edit mode for the irrigation system he can update the attributes of the broken valve with those of the replacement (Figure 6-6). Likewise, suppose that all of the trees in a given block group have been torn out to be replaced with a new variety that will require a different watering profile and that this will necessitate a change to the layout and diameter of the irrigation supply lines and valves. Now that the client has the necessary spatial datasets and an application through which to edit them, such changes can be easily recorded so that he maintains accurate and current documentation on his vital infrastructure.

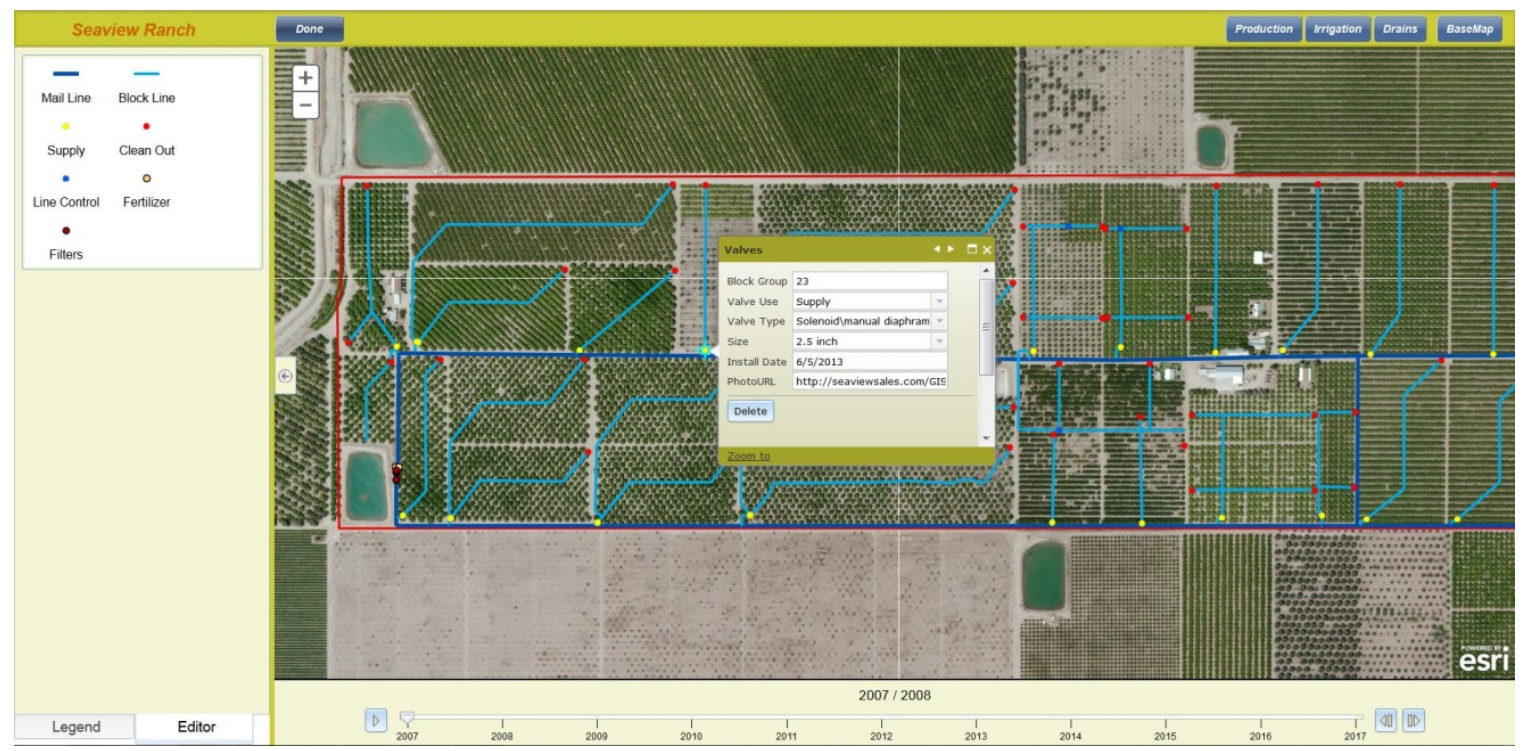

Figure 6-6 Editing information for a replaced irrigation valve 
In the past all of these tasks required recording data in the field and translating it to the appropriate documentation back at the company headquarters. In the case of the property's core infrastructure such documentation did not exist in a form that could be easily updated, and as a result the necessary changes were not always made. Now, with a suite of spatial data covering all elements of the property's infrastructure, along with the web maps and application, the client has a convenient means of updating changes and keeping his records current.

\subsection{Limitations of the Application and ArcGIS Online}

One of the main problems faced in this project was how to provide a solution for the client that did not require a major investment in new IT infrastructure. The client was not interested in deploying a full Arc Server implementation as he does not have the in-house technical staff to maintain it. To work around this issue and provide him with a useful product it was decided that all of his data would be stored and hosted using ArcGIS Online. This solution is a viable alternative for the short term but as he sees new uses of GIS for his enterprise and when he wants to expand the application to include the rest of his properties this will no longer be sufficient.

At present, since he does not have ArcMap, if a major change to one of the datasets is required he will need to contract with an outside resource to effect those changes. For example, if he decides to replace a given crop variety, which can include multiple different block groups with more than one new variety of tree, ArcGIS Online does not provide the necessary functionality to reconfigure the varietal yield layer to reflect this change. Also, since the data are stored in ArcGIS Online, in order to maintain a backup copy he will need to download the datasets periodically. And, since he does not have a local installation of ArcMap, he will not be able to update those changes in the master database that was provided as part of this project.

Another limitation of ArcGIS Online is that it has limited support for related tables. At present the only operations that can be performed with related tables are the query and update of existing records. Maintaining ongoing related temporal records for crop inputs, such as watering schedules, tree maintenance, and fertilizer and pesticide applications is not possible. The analysis of such data in relation to annual production values will be integral to future efforts to reduce costs and maximize profits.

An application related issue that has been noticed relating to hosting the data through ArcGIS Online is that the response time for the return of called data can vary considerably. When the application is first loaded, if it takes too long for the data to be returned then component widgets such as the TimeSlider, Legend, and the layer control switches will not load correctly and the application must be restarted. This behavior was not observed when the data were hosted through the University of Redlands Arc Server account during the initial development phase.

This application was developed using version 3.5 of the ArcGIS JavaScript API. As of this version the majority of the bugs and implementation issues noted by Lertsakdadet (2012) have been resolved. However, when using the default editor widget, the issue he noted with regards to editing features with coincident geometry still exists. As shown in Figure 6-7, when a user wants to edit temporal crop data for a new year the popup window opens with the first recorded year showing. To input the estimated or realized yield for a new year the user must tab through pages in the popup until he arrives at the 
current year. If the user is not careful he might end up editing the wrong year (Lertsakdadet, 2012).

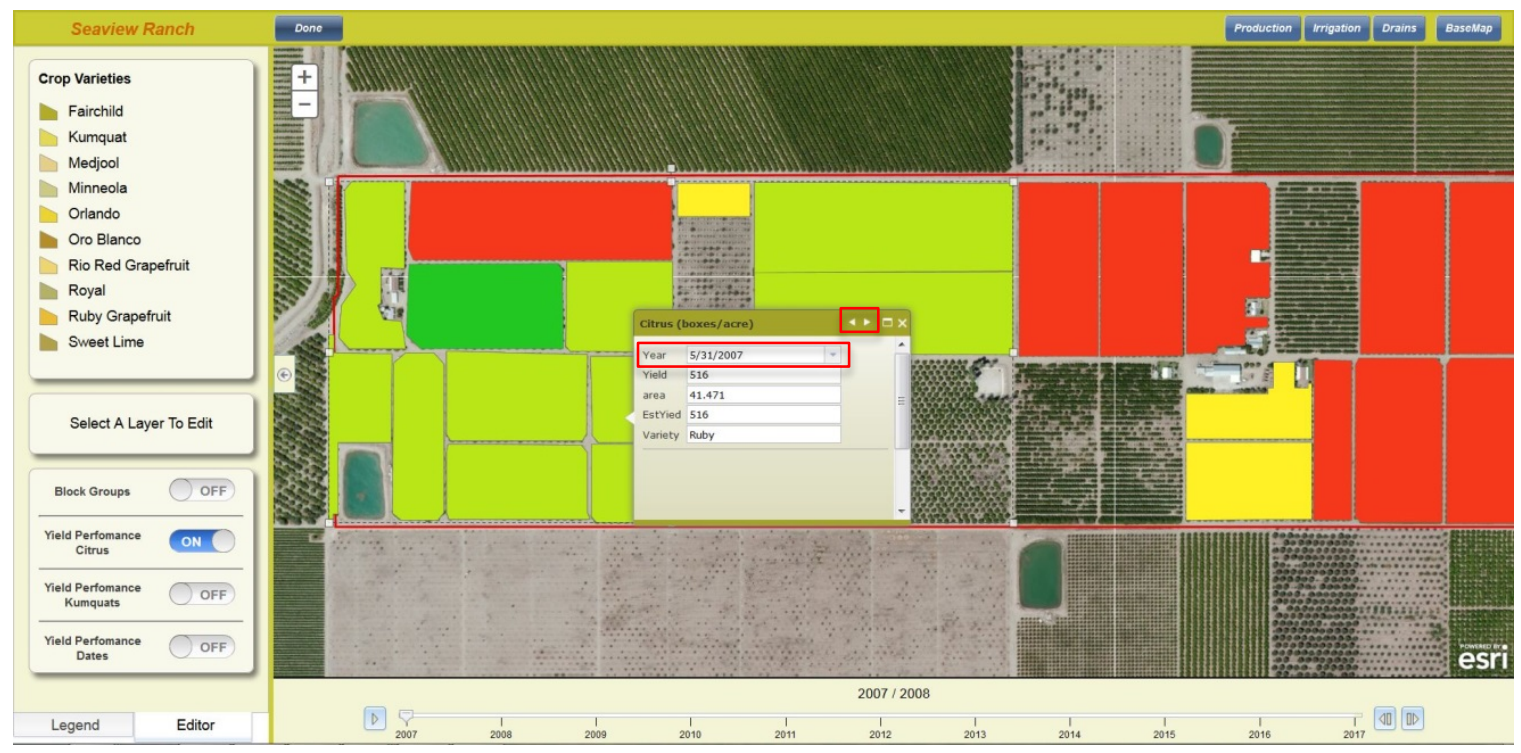

Figure 6-7 Editing yield values in multipage popups

\subsection{Summary}

The goals of this project were to create a set of spatial data and an interface through which the client can access and make use of that data. In an effort to create a lean, simple, and rich user experience not all of the datasets created were included in the web application. Instead, these were made available as web maps accessible through the client's ArcGIS online account. The utility of the maps and web application were described showing how a user can access temporal crop yield data and edit or update datasets while in the field. 


\section{Chapter 7 - Conclusions and Future Work}

There were three primary goals associated with this project. The first was to capture the infrastructure elements and spatio-temporal crop production values of the client's Seaview Ranch property into a digital format that would provide a unified point of access. The second was to develop a mobile compatible web application that would allow the client to manage selected infrastructure components, track crop production values, and collect and edit data on these elements while in the field. Finally the solution needed to be implemented in a manner that did not require a major investment in new IT infrastructure for the client. These goals were accomplished through the collection and creation of the required datasets using both public domain data sources and the field collection of high accuracy GPS data, the development of a web application using the Dojo Toolkit and ArcGIS JavaScript API, and implementing the solution using an ArcGIS Online organizational account for the storage and hosting of data. This chapter includes a summary of the deliverables provided to the client and a discussion of future work that could expand and improve the functionality of the web application.

\subsection{Summary of Deliverables}

At the beginning of the project the client provided a thorough requirements document outlining what datasets he needed and the functionality he expected from the data and the web application. The requested datasets were created and include the following:

- The property line along with complete cadastral information

- The soil types located on the property

- All elements of the irrigation system

- All elements of the underground tile drainage system

- On-site structural facilities including CAD drawings of selected dwellings

- All primary components of the phone and electrical utility distribution system

- The individual crop production units

- Spatio-temporal representations of the annual crop yields for the various fruit varieties grown on the property.

All of these datasets were uploaded to the client's ArcGIS Online account either as editable feature services or tiled map services. The datasets were also provided, on DVD, in the form of a file geodatabase.

A fully functional and mobile compatible web application was deployed to the client's commercial web hosting account. The application met all of the client's functional and non-functional requirements. Online security was provided using the IdentityManager widget which is part of the ArcGIS JavaScript API. A narrated screen capture video was provided that illustrates the various functionalities of the application through actual demonstrations of a user interacting with it and performing the tasks that it supports. Written documentation was also provided that describes the functionality of the application and the methods required for maintaining and modifying the datasets. 


\subsection{Future Work}

The client initiated this project as a proof-of-concept demonstration of how GIS could be used to help him manage his property and crops. It was implemented for one of the 23 properties that Oasis Ranch Management, Inc. owns or operates. A clear extension of the work done to date would involve creating the necessary datasets for one or more of the client's other properties and modifying the web application so that he could select a property of interest from a drop down list. The group layer buttons would then load the data related to the selected property when pressed.

The client has expressed interest in being able to visualize when workers can reenter a given block group following pesticide applications. Therefore, another extension of the current project would involve adding an editable data layer relating to pesticide applications that was symbolized based on pesticide application date and the minimum allowable time for safe reentry. This could include popups providing detailed information on the chemical applied such as health hazards, and allowable application rates and volumes. Pest infestations in the crop production units would also be a critical component related to pesticide applications. The farm manager could record which block groups are infested providing a quick visual method for tracking the spread of infestations across the property.

Another useful addition to the application would be including a dataset covering fertilizer inputs. By providing an analytical function that compared annual crop yields to fertilizer schedules and application rates, the client could further maximize his profitability by tailoring crop inputs based on performance from previous years. This could also help reduce costs resulting from excessive fertilizer application. The same could be done for tree maintenance and watering schedules.

It was made clear to the client that to effectively include all of his remaining properties in the application and to increase the analytical power of GIS for managing his crops it will be necessary to move beyond ArcGIS Online as the sole means for storing, managing, and hosting his data. As he begins to employ other advanced technologies in the field for managing his infrastructure and crop production, in order to harness the full power of GIS, he will need to transition to some form of GIS IT infrastructure that includes an installation of ArcMap and Server. At such a time as he decides to make such a change there will be a wide range of opportunities of extending both the application and its analytical power, and he will require expert help in making that transition.

\subsection{Summary}

ArcGIS Online and a mobile compatible web application have made it possible for agricultural producers with no existing GIS infrastructure to begin harnessing the power of spatial data to visualize and track temporal crop production data and manage their infrastructure without the cost and expertise required to administer and maintain a local Arc Server account. The created datasets along with the web application will help them to increase the efficiency with which they manage their property and provide for improved accuracy in their record keeping. 


\section{Works Cited}

Arctur, D., \& Zeiler, M. (2004). Designing Geodatabases: Case Studies in GIS Data Modeling. Redlands, CA: ESRI Press.

Davis, G., Casady, W., \& Massey, R. (1998). Precision Agriculture: an Introduction. In: Water Quality Focus Guide. Retrieved October 2012, from https://mospace.library.umsystem.edu/xmlui/bitstream/handle/10355/9432/Precisi onAgricultureIntroduction.pdf?sequence $=3$

Dojo Foundation. (2013a, July 18). dojo. Retrieved July 18, 2013, from dojotoolkit.org: http://dojotoolkit.org/

Dojo Foundation. (2013b). BorderContainer. Retrieved June 28, 2013, from dojotoolkit.org: http://dojotoolkit.org/referenceguide/1.6/dijit/layout/BorderContainer.html

Duryee, T. (2012, November 12). The Latest Long Apple Line: Developers Waiting for App Approval. Retrieved July 16, 2013, from All Things D:

http://allthingsd.com/20121108/the-latest-long-apple-line-developers-waiting-forapp-approval/

ESRI. (1997). ESRI GIS Solutions for Production Agriculture. Redlands, CA: ESRI.

Esri. (2013a). Arcpad. Retrieved July 18, 2013, from

http://www.esri.com/software/arcgis/arcpad

Esri. (2013b). ArcGIS API for JavaScript. Retrieved 2013, from ArcGIS API for JavaScript: https://developers.arcgis.com/en/javascript/jssamples/

Esri. (2013c, June 13). Authoring Feature Services. Retrieved June 28, 2013, from http://resources.arcgis.com/en/help/main/10.1/index.html\#/Authoring_feature_ser vices/0154000003nt000000/

Esri. (2013d, June 13). What is a Feature Service? Retrieved June 27, 2013, from http://resources.arcgis.com/en/help/main/10.1/index.html\#/What_is_a_feature_ser vice/0154000002w8000000/

Esri. (2013e, July). ArcGIS for Developers: Documentation. Retrieved July 18, 2013, from ArcGIS for Developers: https://developers.arcgis.com/en/documentation/

Fu, P., \& Sun, J. (2011). Web GIS Principles and Applications. Redlands: Esri Press.

Hetzroni, A., Peeters, A., \& Ben-Gal, A. (2012). Towards precision management of orchards: using automated monitoring to build a GIS-based spatial decision support system. International Conference on Agricultural Engineering. Valencia, Spain.

Koostra, B. K., Stombaugh, T. S., \& Dowdy, T. C. (2003). Development of a Precision Agricultural Tool Suite Using ArcPad. Esri International Users Conference. Redlands, CA: Esri.

Lambert, D., \& Lowenberg-Deboer, J. (2000). Precision Agriculture Profitability Review. Retrieved from Purdue University, Site-Specific Management Center.

Lertsakdadet, C. (2012). Mobile GIS Web Application for Agri-Empire (Master's Thesis). Redlands, CA: University of Redlands.

McBratney, A., Whelan, B., \& Ancev, T. (2005). Future Directions in Precision Agriculture. Precision Agriculture, 6, 7-23.

Norvell, J. (2003). Enhancing Farm Management and Record Keeping with GIS. ESRI International Users Conference. San Diego, CA: ESRI. 
Oasis Ranch Management. (2010). Oasis Ranch Management Services. Retrieved October 2, 2012, from Seaviewsales: http://www.seaviewsales.com/

PhoneGap. (2013, July 18). PhoneGap Documentation. Retrieved July 18, 2013, from PhoneGap.com: http://docs.phonegap.com/en/2.9.0/index.html

Pierce, F. J., \& Nowak, P. (1999). Aspects of Precision Agriculture. Advanced Agronomy, 69, 1-85.

Power, M. (2011, March). Mobile Web Apps. Retrieved July 15, 2013, from http://publications.cetis.ac.uk/wpcontent/uploads/2011/10/Mobile_Web_Apps.pdf

Rende, J. (2013, April 14). Native vs. HTML5 - looked at objectively, the debate is over [Web log post]. Retrieved July 16, 2013, from http://thinkmobile.appcelerator.com/blog/bid/284174/Native-vs-HTML5-lookedat-objectively-the-debate-is-over

Shibusawa, S. (2002). Precision Farming Approaches to Small-Farm Agriculture. Tai, Taiwan: Food and Fertilzer Technology Center for the Asian and Pacific Region.

Smith, L., \& Whigham, P. (1999). Spatial Aspects of Vineyard Management and Wine Grape Production. The 11th Annual Colloquium of the Spatial Information Research Centre. Dunedin, New Zealand: Spatial Information Research Center.

w3Schools.com. (2013, July 18). w3Schools.com. Retrieved July 18, 2013, from w3Schools.com: http://www.w3schools.com/

WebMapSolutions. (2011, November 04). Mobile GIS Apps for Agriculture. Retrieved July 15, 2013, from WebMapSolutions: http://www.webmapsolutions.com/mobile-apps-agriculture

Westervelt, J. D., \& Reetz, Jr., H. F. (2000). GIS in Site-Specific Agriculture. Danville, Ill.: Interstate Publishers, Inc. 


\section{Appendix A. Feature Class Attribute Tables}

\section{A.1 Production feature dataset feature class attribute tables.}

Table A 1 Attributes in the BlockGroups feature class

\begin{tabular}{c|l}
\hline Attribute & Description \\
\hline OBJECTID & Sequential unique whole numbers that are automatically generated \\
\hline SHAPE & Feature geometry (polygon) that is automatically generated \\
\hline SHAPE_Lenght & Feature perimeter (m) as calculated using WGS 1984 Web Mercator \\
\hline SHAPE_Area & Feature area (sq. m) as calculated using WGS 1984 Web Mercator \\
\hline BlkNum & Crop production block group number \\
\hline RtStock & Root stock of the block groups primary variety \\
\hline YrPlant & Year planted (primary variety) \\
\hline TrCount & Tree count of the primary variety \\
\hline Variety2 & Interplant variety \\
\hline RtStock2 & Root stock of the interplant variety \\
\hline YrPlant2 & Year planted (interplant variety) \\
\hline TrCount2 & Tree count of the interplant variety \\
\hline Spacing & Tree spacing \\
\hline Area & $\begin{array}{l}\text { Block group area (acres) as calculated using the NAD 1983 California } \\
\text { Sateplane VI coordinate system }\end{array}$ \\
\hline
\end{tabular}

Table A 2 Attributes in the Citrus and Kumquat yield feature classes

\begin{tabular}{c|l}
\hline Attribute & Description \\
\hline OBJECTID & Sequential unique whole numbers that are automatically generated \\
\hline SHAPE & Feature geometry (polygon) that is automatically generated \\
\hline Variety & Crop variety \\
\hline Year & Crop production year (September - March) for year of September \\
\hline
\end{tabular}


Table A 2 Attributes in the Citrus and Kumquat yield feature classes continued

\begin{tabular}{c|l}
\hline Attribute & Description \\
\hline Yield & Realized varietal yield (boxes/acre) \\
\hline EstYield & Estimated varietal yield (boxes/acre) \\
\hline Area & $\begin{array}{l}\text { Combined area (acres) of citrus variety as calculated using the NAD } \\
\text { 1983 California Sateplane VI coordinate system }\end{array}$ \\
\hline SHAPE_Length & Feature perimeter (m) as calculated using WGS 1984 Web Mercator \\
\hline SHAPE_Area & Feature area (sq. m) as calculated using WGS 1984 Web Mercator \\
\hline
\end{tabular}

Table A 3 Attributes in the Medjool yield feature classes

\begin{tabular}{c|l}
\hline Attribute & Description \\
\hline OBJECTID & Sequential unique whole numbers that are automatically generated \\
\hline SHAPE & Feature geometry (polygon) that is automatically generated \\
\hline Variety & Crop variety \\
\hline Year & Crop production year (September - March) for year of September \\
\hline Yield & Realized varietal yield (boxes/acre) \\
\hline Quality & Date crop quality \\
\hline EstYield & Estimated varietal yield (boxes/acre) \\
\hline Area & Combined area (acres) of medjool date variety as calculated using the \\
& NAD 1983 California Sateplane VI coordinate system \\
\hline SHAPE_Length & Feature perimeter (m) as calculated using WGS 1984 Web Mercator \\
\hline SHAPE_Area & Feature area (sq. m) as calculated using WGS 1984 Web Mercator \\
\hline
\end{tabular}




\section{A 2 TileDrains feature dataset feature class attribute tables.}

Table A 4 Attributes in the DrainAccessPoints feature class

\begin{tabular}{c|l}
\hline Attribute & Description \\
\hline OBJECTID & Sequential unique whole numbers that are automatically generated \\
\hline SHAPE & Feature geometry (point) that is automatically generated \\
\hline Description & Description of the access point \\
\hline ServiceDate & Date of last service \\
\hline ServiceDescription & Description of last service \\
\hline
\end{tabular}

Table A 5 Attributes in the DrainJunctions feature class

\begin{tabular}{c|l}
\hline Attribute & Description \\
\hline OBJECTID & Sequential unique whole numbers that are automatically generated \\
\hline SHAPE & Feature geometry (point) that is automatically generated \\
\hline Type & Junction type - feature class subtype $(1=$ tee, $2=$ reducer, $3=$ bend $)$ \\
\hline Size & Junction diameter (inches) \\
\hline
\end{tabular}

Table A 6 Attributes in the DrainLines feature class

\begin{tabular}{c|l}
\hline Attribute & Description \\
\hline OBJECTID & Sequential unique whole numbers that are automatically generated \\
\hline SHAPE & Feature geometry (polyline) that is automatically generated \\
\hline Diam & Drain line diameter (inches) \\
\hline Type & Drain line construction material \\
\hline LineNum & Drain line number as recorded on CVWD installation records \\
\hline InDate & Instillation date \\
\hline Length & $\begin{array}{l}\text { Feature length (ft) as calculated using the NAD 1983 California } \\
\text { Sateplane VI coordinate system }\end{array}$ \\
\hline SHAPE_Length & Feature length (m) as calculated using WGS 1984 Web Mercator \\
\hline
\end{tabular}




\section{A 3 Irrigation feature dataset feature class attribute tables.}

Table A 7 Attributes in the DripLines feature class

\begin{tabular}{c|l}
\hline Attribute & Description \\
\hline OBJECTID & Sequential unique whole numbers that are automatically generated \\
\hline SHAPE & Feature geometry (point) that is automatically generated \\
\hline Size & Drip line diameter (inches) \\
\hline Material & Drip line construction material \\
\hline BlockGroup & Crop production block group \\
\hline Length & $\begin{array}{l}\text { Feature length (ft) as calculated using the NAD 1983 California } \\
\text { Sateplane VI coordinate system }\end{array}$ \\
\hline SHAPE_Length & Feature length (m) as calculated using WGS 1984 Web Mercator \\
\hline
\end{tabular}

Table A 8 Attributes in the Lines feature class

\begin{tabular}{c|l}
\hline Attribute & Description \\
\hline OBJECTID & Sequential unique whole numbers that are automatically generated \\
\hline SHAPE & Feature geometry (polyline) that is automatically generated \\
\hline Size & Buried irrigation supply line diameter (inches) \\
\hline Type & $\begin{array}{c}\text { Line type }- \text { feature class subtypes: 1 = block group line, } 2 \text { = main } \\
\text { supply lines }\end{array}$ \\
\hline Material & Line construction material \\
\hline InstallDate & Installation date. \\
\hline Length & $\begin{array}{l}\text { Feature length (ft) as calculated using the NAD 1983 California } \\
\text { Sateplane VI coordinate system }\end{array}$ \\
\hline SHAPE_Length & Feature length (m) as calculated using WGS 1984 Web Mercator \\
\hline
\end{tabular}


Table A 9 Attributes in the LineJunctions feature class

\begin{tabular}{c|l}
\hline Attribute & Description \\
\hline OBJECTID & Sequential unique whole numbers that are automatically generated \\
\hline SHAPE & Feature geometry (point) that is automatically generated \\
\hline Size & Buried irrigation supply line junction size (inches) \\
\hline Type & $\begin{array}{l}\text { Line junction type }- \text { feature class subtypes: } 1=\text { bend, } 2=\text { cross, } 3= \\
\text { elbow, } 4=\text { reducer, } 5=\text { tee, } 6=\text { wye }\end{array}$ \\
\hline Material & Line junction construction material \\
\hline InstallDate & Installation date.
\end{tabular}

Table A 10 Attributes in the Valves feature class

\begin{tabular}{c|l}
\hline Attribute & Description \\
\hline OBJECTID & Sequential unique whole numbers that are automatically generated \\
\hline SHAPE & Feature geometry (point) that is automatically generated \\
\hline BlockGroup & \\
\hline ValveUse & $\begin{array}{l}\text { Valve use - feature class subtypes: 1 = supply 2 = clean out, 3 = line } \\
\text { control }\end{array}$ \\
\hline ValveType & Valve type description (butterfly, compression, diaphragm) \\
\hline Size & Valve size (inches) \\
\hline PhstallDate & Installation date \\
\hline
\end{tabular}

Table A 11 Attributes in the Filters feature class

\begin{tabular}{c|l}
\hline Attribute & Description \\
\hline OBJECTID & Sequential unique whole numbers that are automatically generated \\
\hline SHAPE & Feature geometry (point) that is automatically generated \\
\hline Description & Description of the feature \\
\hline
\end{tabular}


Table A 11 Attributes in the Filters feature class continued

\begin{tabular}{c|l}
\hline ServiceDate & Date of last service \\
\hline ServiceDescription & Description of last service \\
\hline PhotoURL & $\begin{array}{l}\text { URL of the photo associated with the feature (used for enabling } \\
\text { photographs in ArcGIS Online popups) }\end{array}$ \\
\hline
\end{tabular}

Table A 12 Attributes in the Fertilizer feature class

\begin{tabular}{c|l}
\hline Attribute & Description \\
\hline OBJECTID & Sequential unique whole numbers that are automatically generated \\
\hline SHAPE & Feature geometry (point) that is automatically generated \\
\hline TankNum & ID number stenciled on the side of an irrigation tank \\
\hline FillDate & Date of last fill \\
\hline FillVolume & Volume of last file \\
\hline Capacity & Maximum tank volume \\
\hline FillType & Type of fertilizer on last fill \\
\hline PhotoURL & $\begin{array}{l}\text { URL of the photo associated with the feature (used for enabling } \\
\text { photographs in ArcGIS Online popups) }\end{array}$ \\
\hline
\end{tabular}

Table A 13 Attributes in the Ponds feature class

\begin{tabular}{c|l}
\hline Attribute & Description \\
\hline OBJECTID & Sequential unique whole numbers that are automatically generated \\
\hline SHAPE & Feature geometry (point) that is automatically generated \\
\hline Type & $\begin{array}{l}\text { Pond type - feature class subtypes: } 1=\text { irrigation supply, } 2 \text { out of } \\
\text { service }\end{array}$ \\
\hline Volume & Maximum pond volume \\
\hline SHAPE_Length & Feature perimeter (m) as calculated using WGS 1984 Web Mercator \\
\hline SHAPE_Area & Feature area (sq. m) as calculated using WGS 1984 Web Mercator \\
\hline
\end{tabular}


Table A 14 Attributes in the Wells feature class

\begin{tabular}{c|l}
\hline Attribute & Description \\
\hline OBJECTID & Sequential unique whole numbers that are automatically generated \\
\hline SHAPE & Feature geometry (point) that is automatically generated \\
\hline WellNum & Well number from original illustrations \\
\hline
\end{tabular}

\begin{tabular}{c|l}
\hline Description & Description of the feature \\
\hline ServiceDate & Date of last service \\
\hline ServiceDescription & Description of last service \\
\hline PhotoURL & $\begin{array}{l}\text { URL of the photo associated with the feature (used for enabling } \\
\text { photographs in ArcGIS Online popups) }\end{array}$ \\
\hline
\end{tabular}

\section{A 4 ElectricalDistribution feature dataset feature class attribute tables.}

Table A 15 Attributes in the Poles feature class

\begin{tabular}{c|l}
\hline Attribute & Description \\
\hline OBJECTID & Sequential unique whole numbers that are automatically generated \\
\hline SHAPE & Feature geometry (point) that is automatically generated \\
\hline PoleID & Utility pole ID number as stamped on pole tag \\
\hline PoleUse & $\begin{array}{l}\text { Line type carried by pole }- \text { feature class subtypes: } 1=\text { primary } \\
\text { distribution (main line) }, 2=\text { secondary distribution (line from } \\
\text { transformer to service), } 3=\text { telephone }\end{array}$ \\
\hline Material & Construction material \\
\hline Height & Pole height \\
\hline AdjunctEquipment & Adjunct equipment attached to pole \\
\hline AdjEquip2 & Adjunct equipment attached to pole (alternate type) \\
\hline
\end{tabular}


Table A 16 Attributes in the Lines feature class

\begin{tabular}{c|l}
\hline Attribute & Description \\
\hline OBJECTID & Sequential unique whole numbers that are automatically generated \\
\hline SHAPE & Feature geometry (point) that is automatically generated \\
\hline LineType & $\begin{array}{l}\text { Line type carried by pole - feature class subtypes: 1 = primary } \\
\text { overhead (main line) , 2 = secondary overhead (line from transformer to } \\
\text { service), 3 = telephone overhead, 4 = secondary underground, 5 = } \\
\text { telephone underground }\end{array}$ \\
\hline Voltage & Voltage carried by line \\
\hline Length & $\begin{array}{l}\text { Feature length (ft) as calculated using the NAD 1983 California } \\
\text { Sateplane VI coordinate system }\end{array}$ \\
\hline SHAPE_Length & Feature length (m) as calculated using WGS 1984 Web Mercator \\
\hline
\end{tabular}

Table A 17 Attributes in the Meters feature class

\begin{tabular}{c|l}
\hline Attribute & Description \\
\hline OBJECTID & Sequential unique whole numbers that are automatically generated \\
\hline SHAPE & Feature geometry (point) that is automatically generated \\
\hline MeterNumber & Electric meter number \\
\hline Voltage & Meter voltage rating \\
\hline
\end{tabular}

Table A 18 Attributes in the Subpanels feature class

\begin{tabular}{c|l}
\hline Attribute & Description \\
\hline OBJECTID & Sequential unique whole numbers that are automatically generated \\
\hline SHAPE & Feature geometry (point) that is automatically generated \\
\hline Type & Panel type; primary safety, residential distribution, facilities distribution \\
\hline Description & Locational description \\
\hline PhotoURL & $\begin{array}{l}\text { URL of the photo associated with the feature (used for enabling } \\
\text { photographs in ArcGIS Online popups) }\end{array}$ \\
\hline ID & ID number assigned for relation to Subpanel_contents table \\
\hline
\end{tabular}




\section{A 5 Structures feature dataset feature class attribute tables.}

Table A 19 Attributes in the Allbuildings feature class

\begin{tabular}{c|l}
\hline Attribute & Description \\
\hline OBJECTID & Sequential unique whole numbers that are automatically generated \\
\hline SHAPE & Feature geometry (polygon) that is automatically generated \\
\hline Type & Panel type; primary safety, residential distribution, facilities distribution \\
\hline Name & The name of the structure as given by Oasis Ranch Management \\
\hline SHAPE_Length & Feature perimeter (m) as calculated using WGS 1984 Web Mercator \\
\hline SHAPE_Area & Feature area (sq. m) as calculated using WGS 1984 Web Mercator \\
\hline
\end{tabular}

Table A 20 Attributes in the Guesthouse, SeaviewDuplex, Seaview7, Seaview8, and SeaviewMobileHome feature classes

\begin{tabular}{c|l}
\hline Attribute & Description \\
\hline OBJECTID & Sequential unique whole numbers that are automatically generated \\
\hline SHAPE & Feature geometry (polyline) that is automatically generated \\
\hline Entity & Object type from original CAD attributes \\
\hline Color & Color of lines from original CAD attributes \\
\hline Linetype & Type of line from original CAD attributes \\
\hline RefName & Name of feature item from original CAD attributes \\
\hline SHAPE_Length & Feature perimeter (m) as calculated using WGS 1984 Web Mercator \\
\hline
\end{tabular}

\section{A 6 PropertyLine feature class attribute table.}

Table A 21 Attributes in the PropertyLine feature classes

\begin{tabular}{c|l}
\hline Attribute & Description \\
\hline OBJECTID & Sequential unique whole numbers that are automatically generated \\
\hline SHAPE & Feature geometry (polyline) that is automatically generated \\
\hline
\end{tabular}


Table A 21 Attributes in the PropertyLine feature classes continued

\begin{tabular}{c|l}
\hline Perimeter & $\begin{array}{l}\text { Property perimeter (feet) as calculated using the NAD 1983 California } \\
\text { Sateplane VI coordinate system }\end{array}$ \\
\hline Area & $\begin{array}{l}\text { Property area (acres) as calculated using the NAD 1983 California } \\
\text { Sateplane VI coordinate system }\end{array}$ \\
\hline SHAPE_Length & Feature perimeter (m) as calculated using WGS 1984 Web Mercator \\
\hline
\end{tabular}




\section{Appendix B. Map Documents Prepared For Publication to ArcGIS Online}

Production layer group map document showing the Block Groups layer.

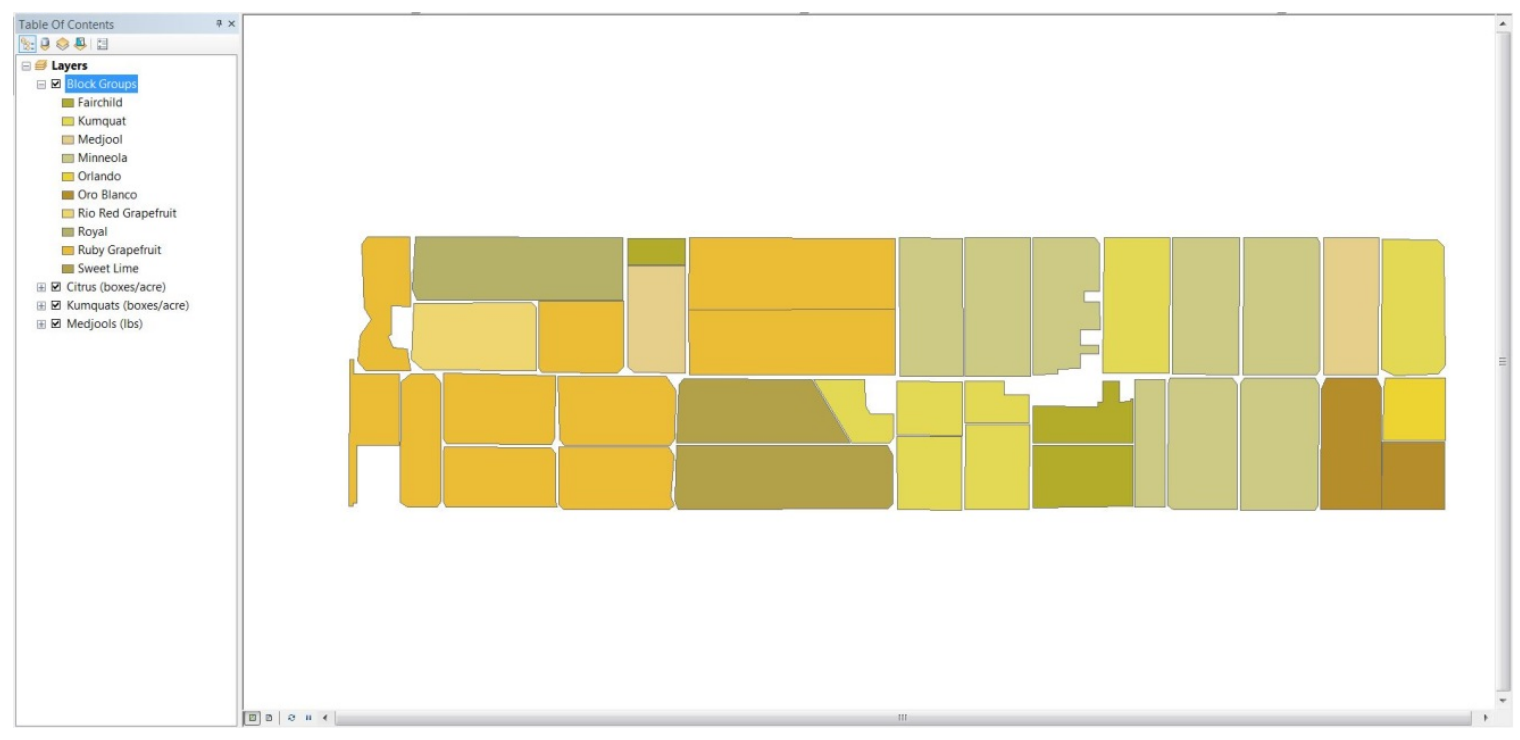

Production layer group map document showing the Citrus, Kumquat, and Dates Yield layers.

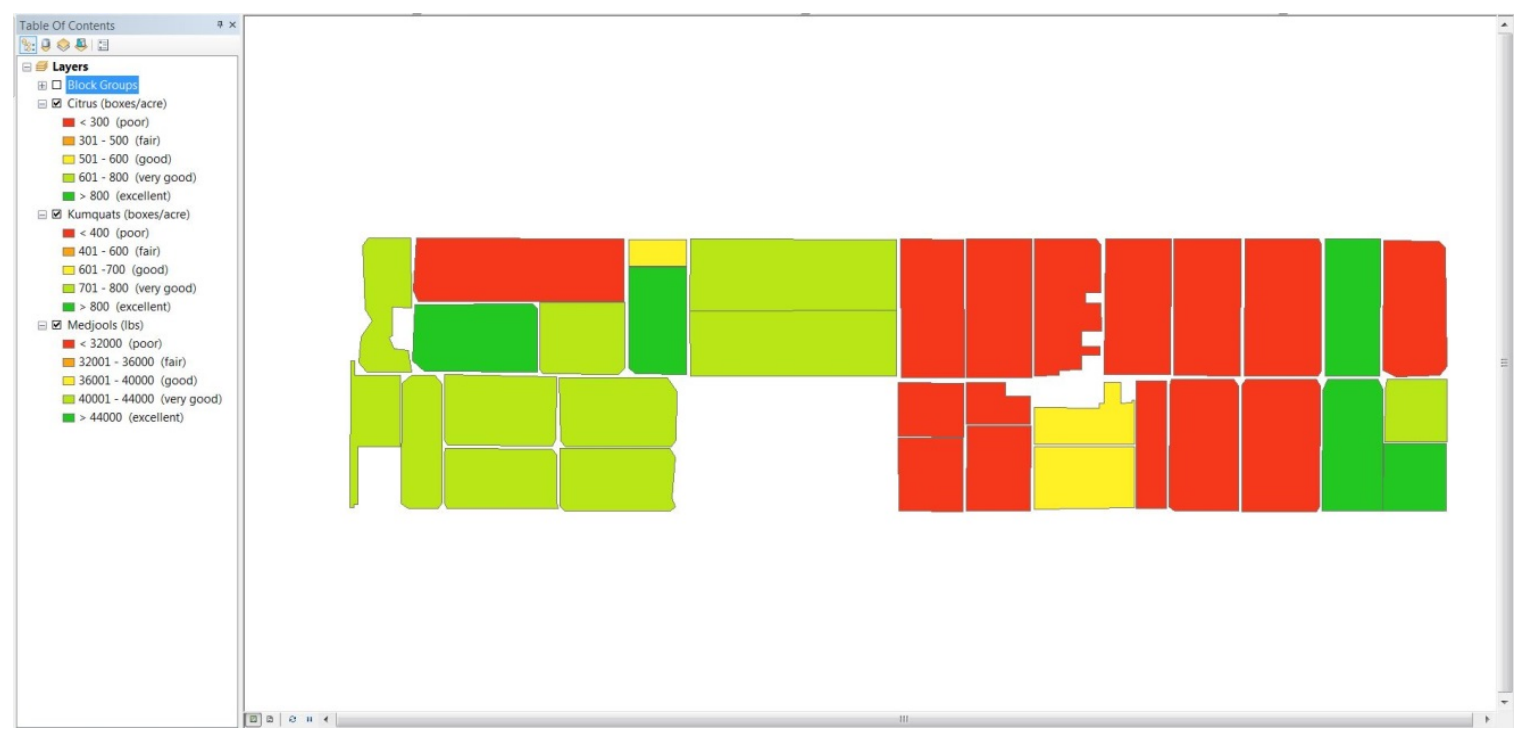


Irrigation layer group map document.

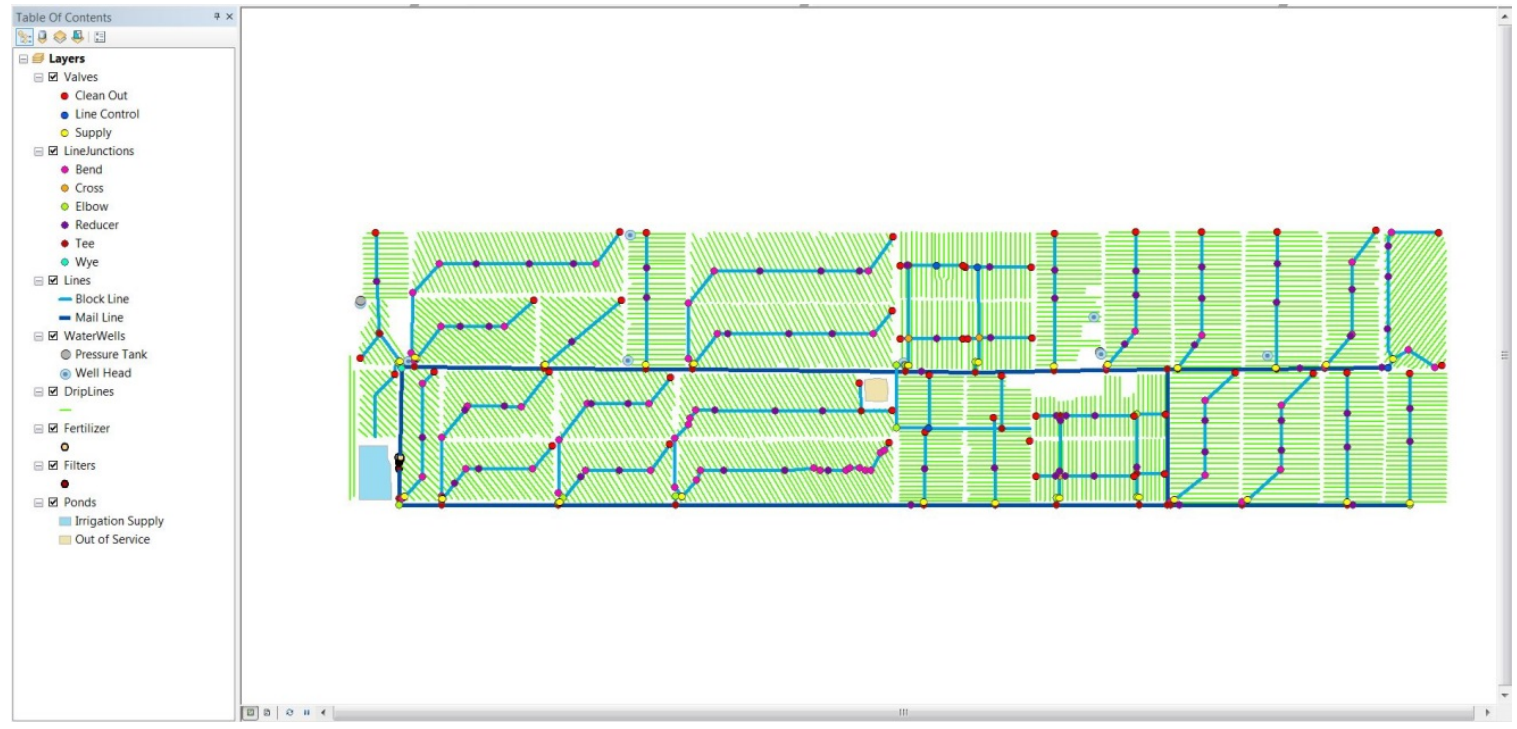

Tile Drains layer group map document.

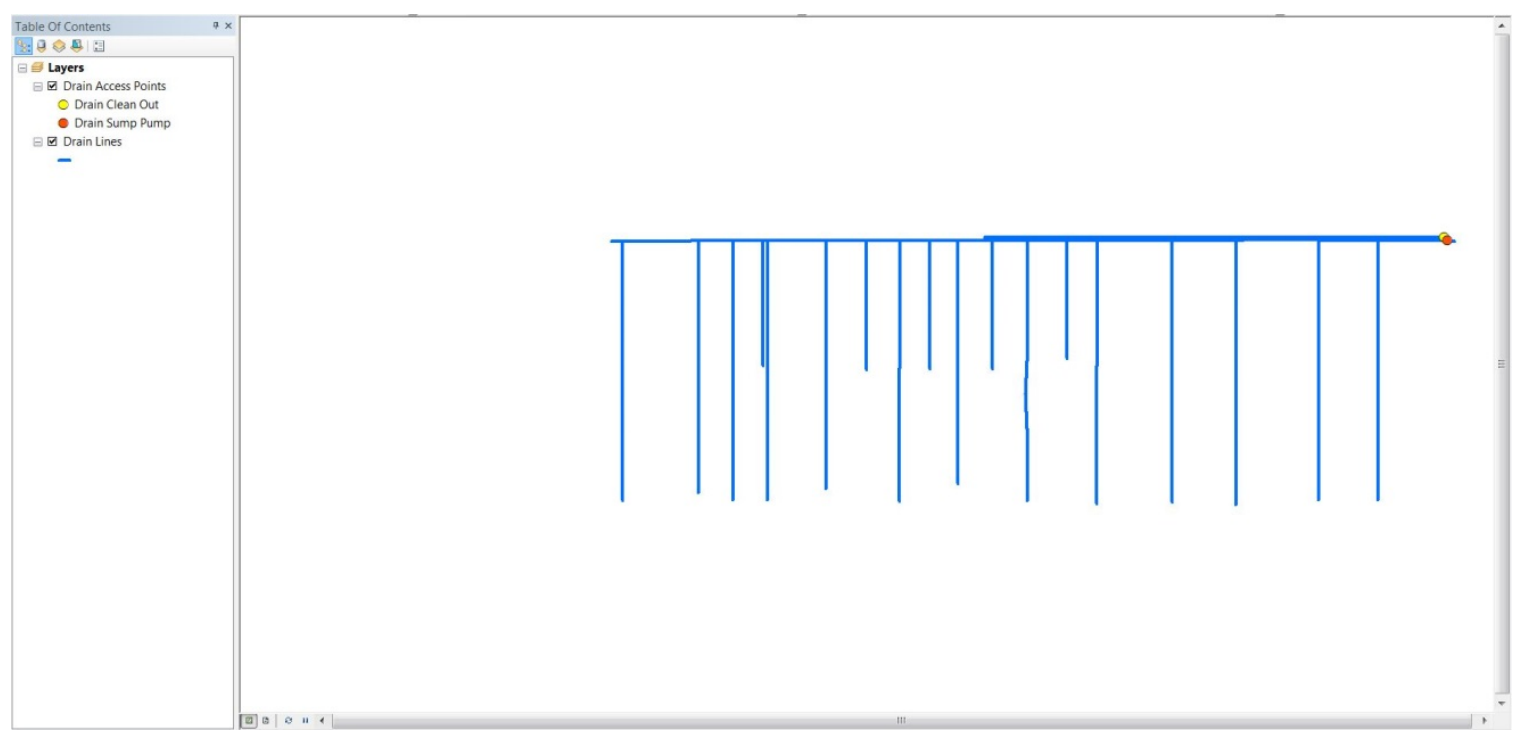


Electrical Distribution layer group map document.

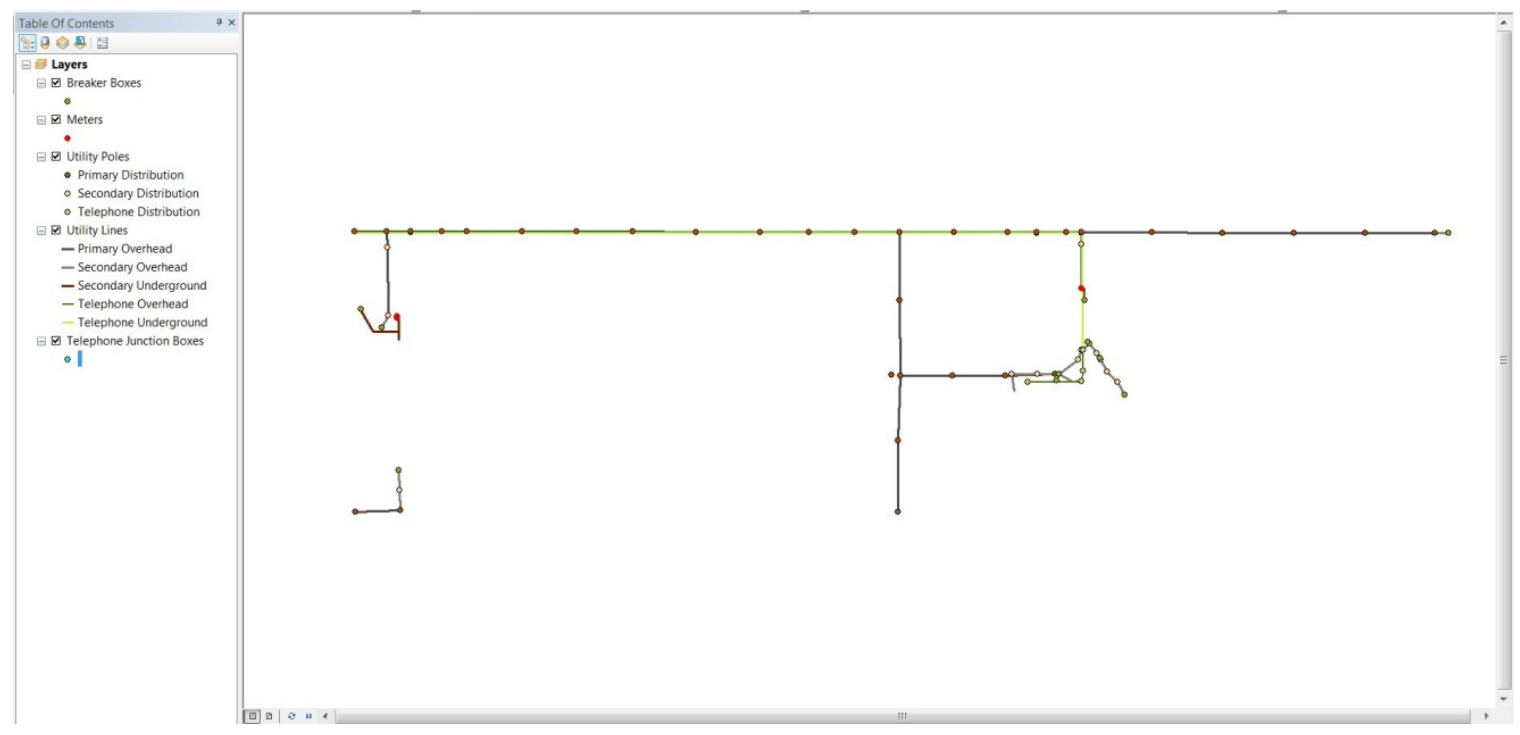

Facilities Layer group map document.

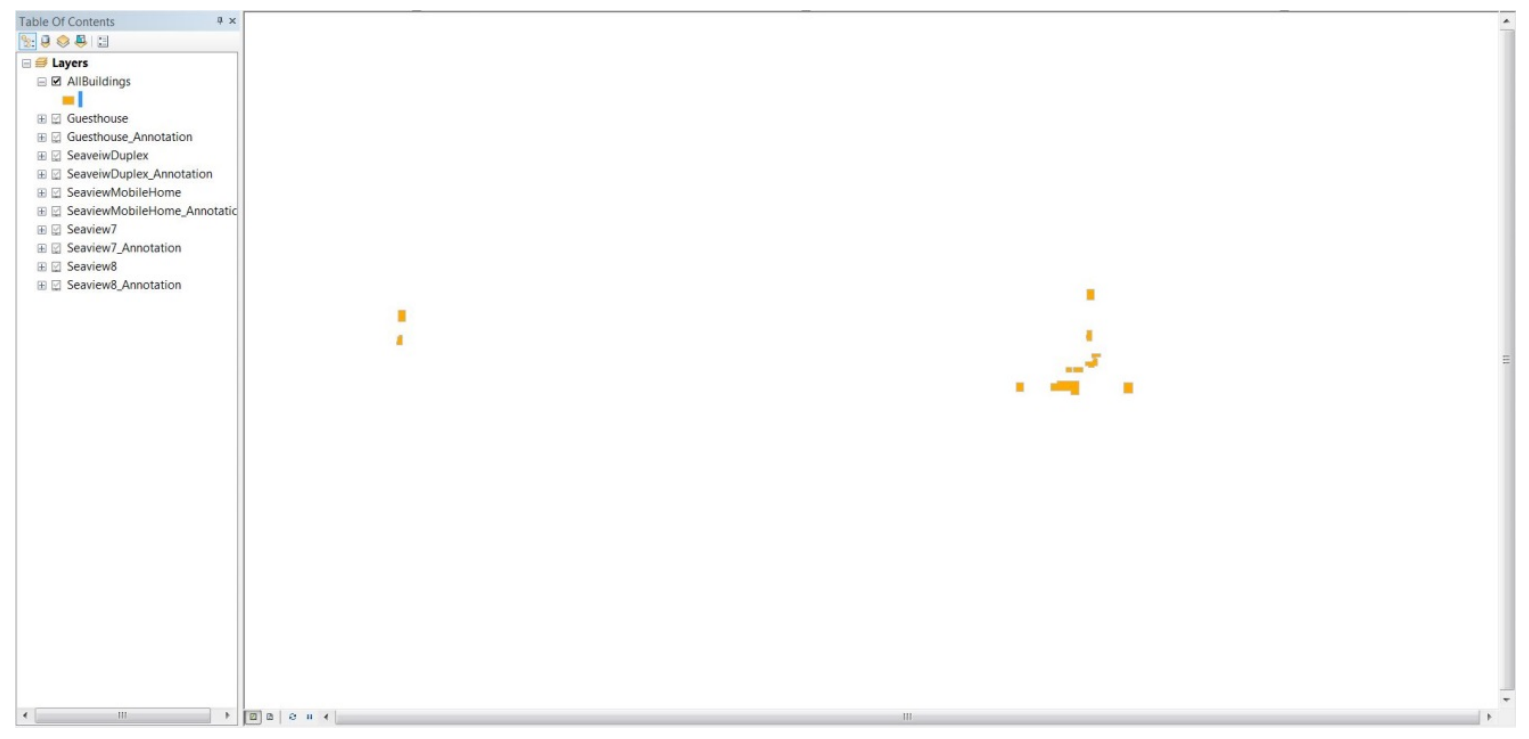


Property Line map document.

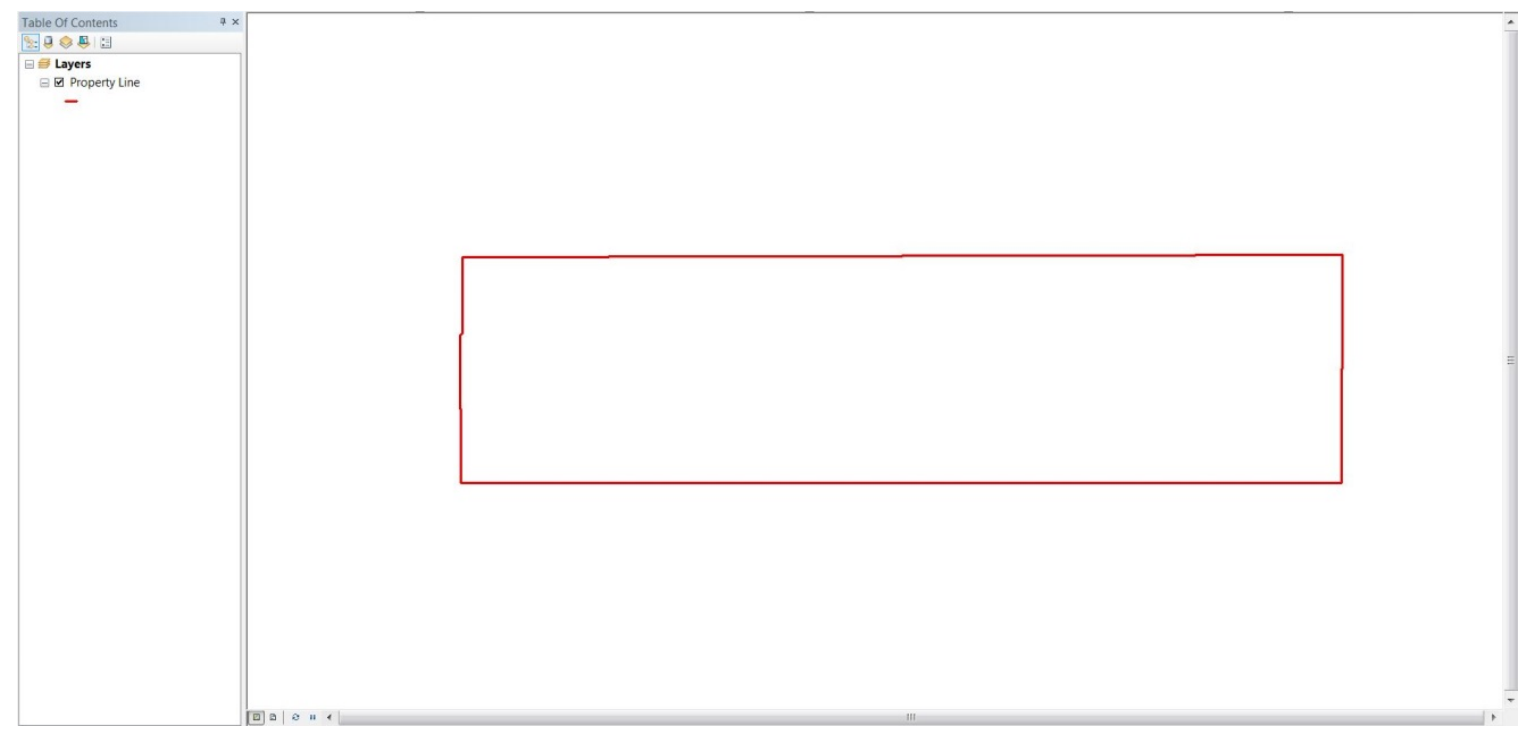

Soil Type map document.

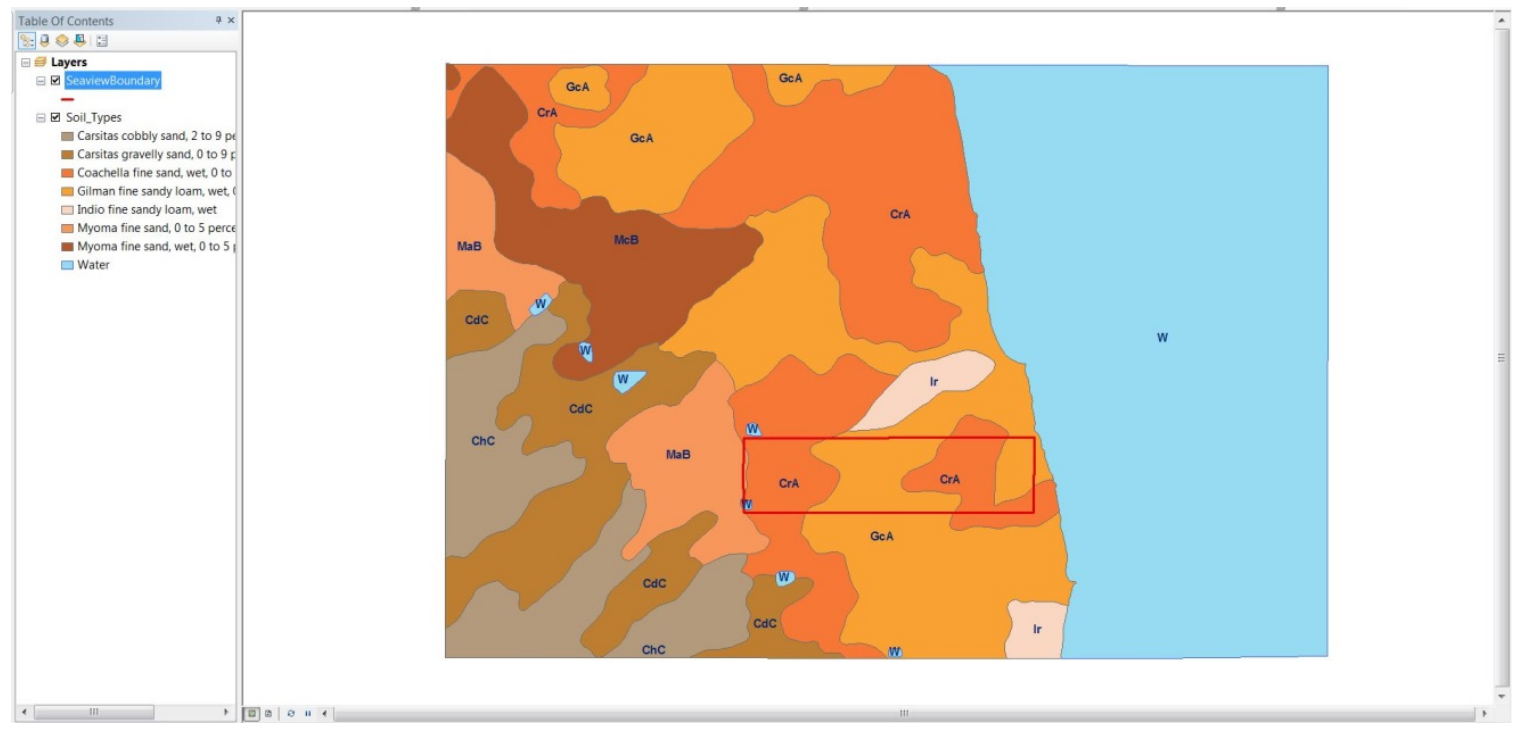




\section{Appendix C. Web Application Source Code}

The following code contains the operational JavaScript, dojo, and HTML5 code that comprises the user interface layout and functional operations of the application. The code can be found in the SeaviewRanch.html file.

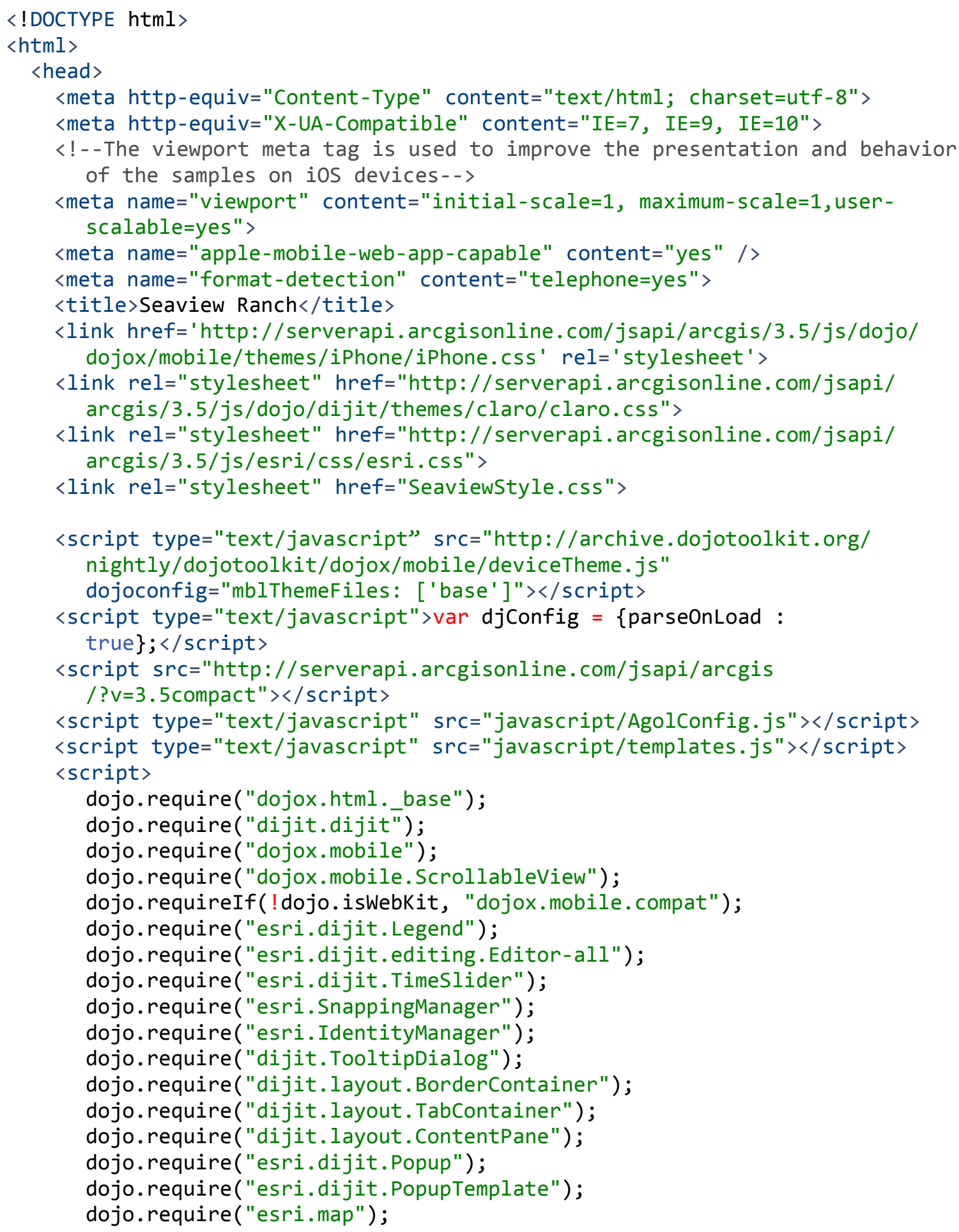




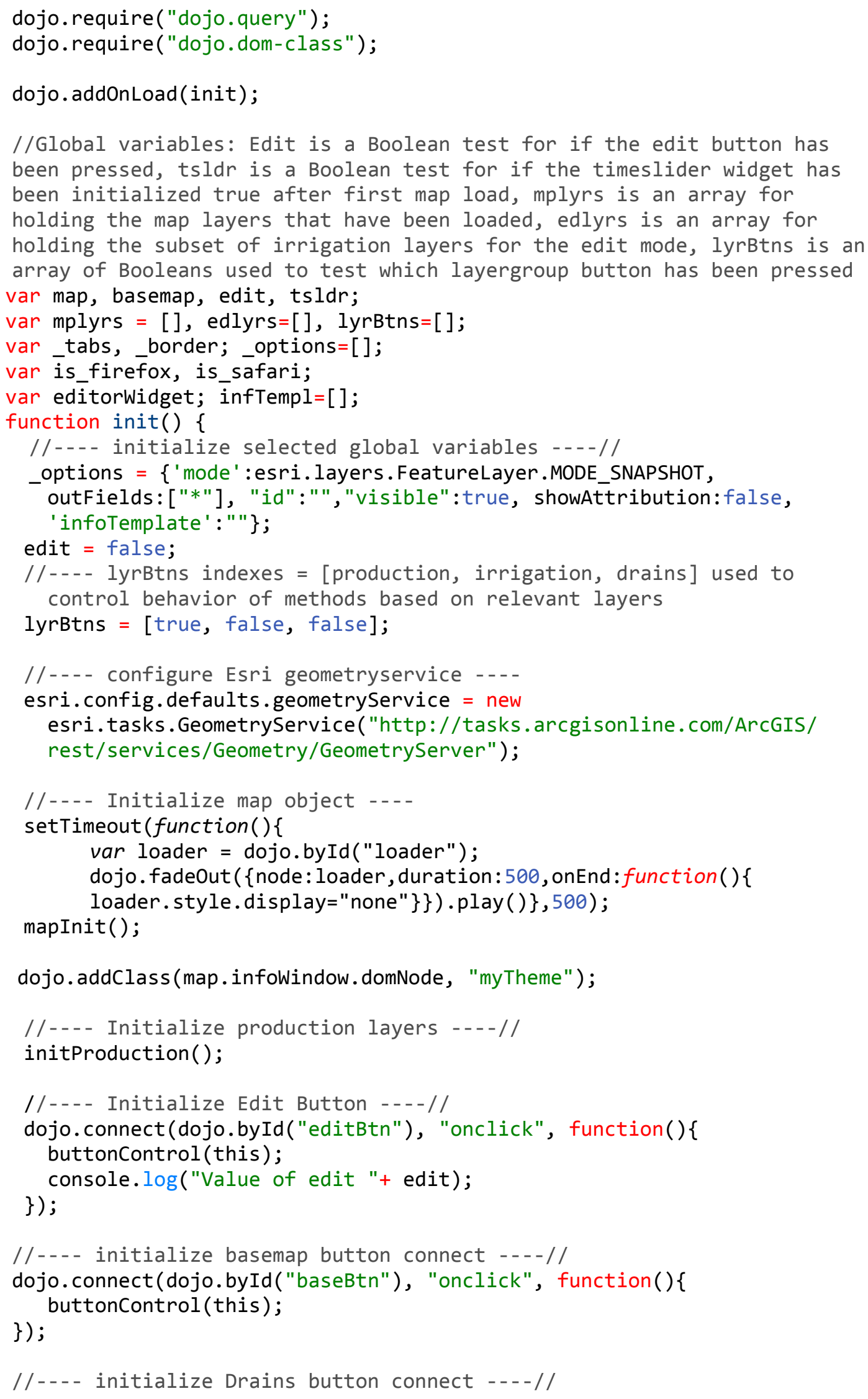




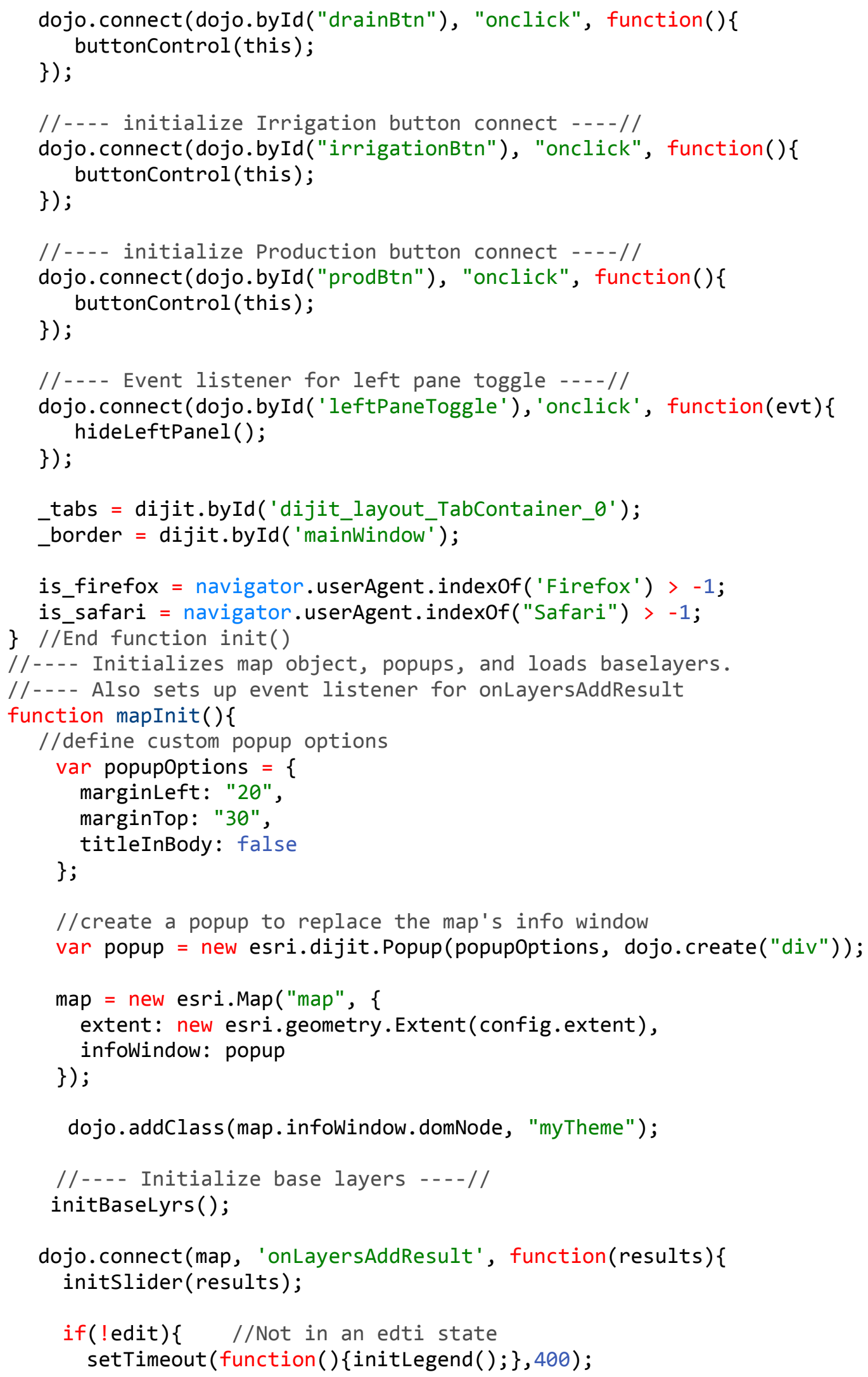




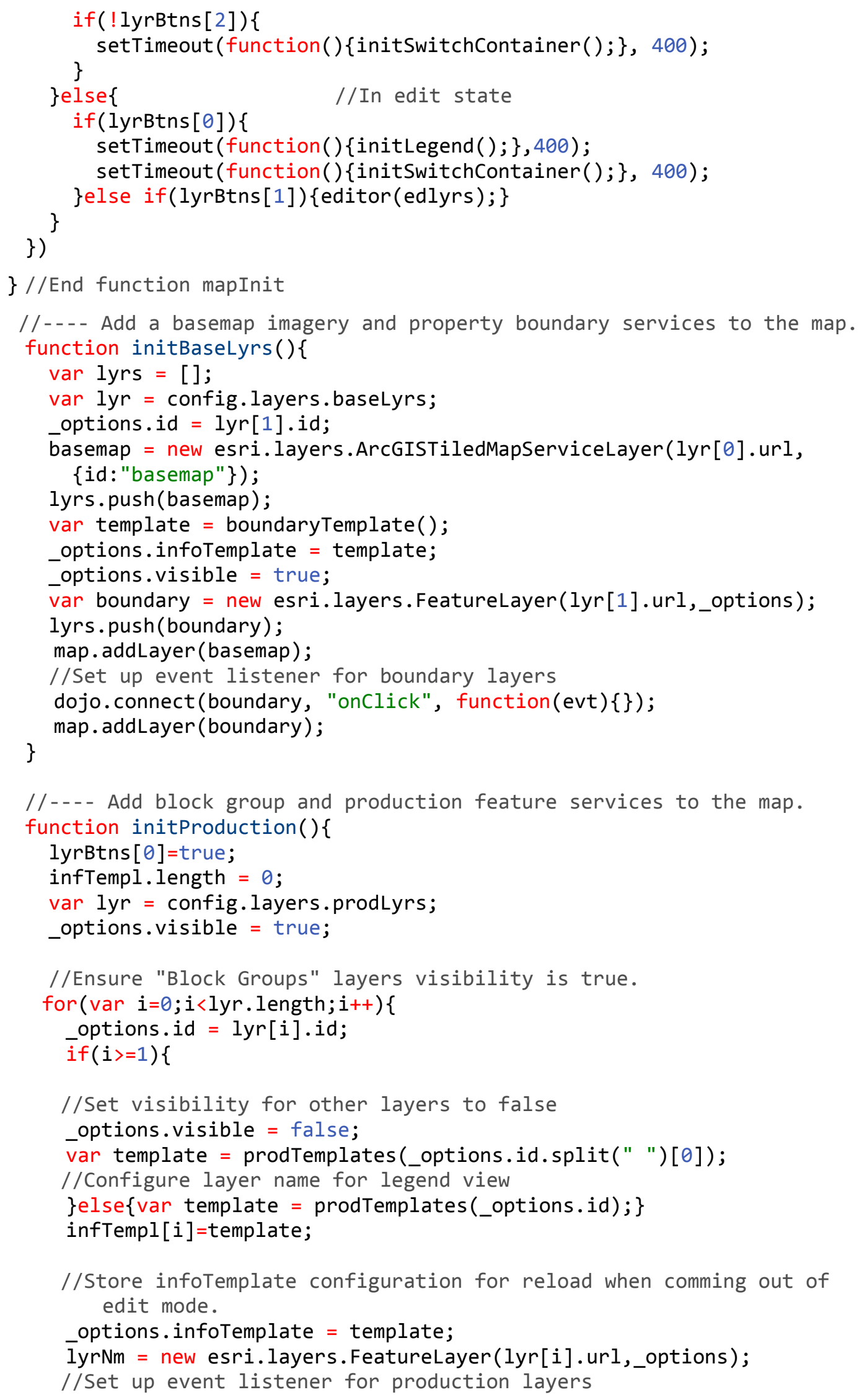




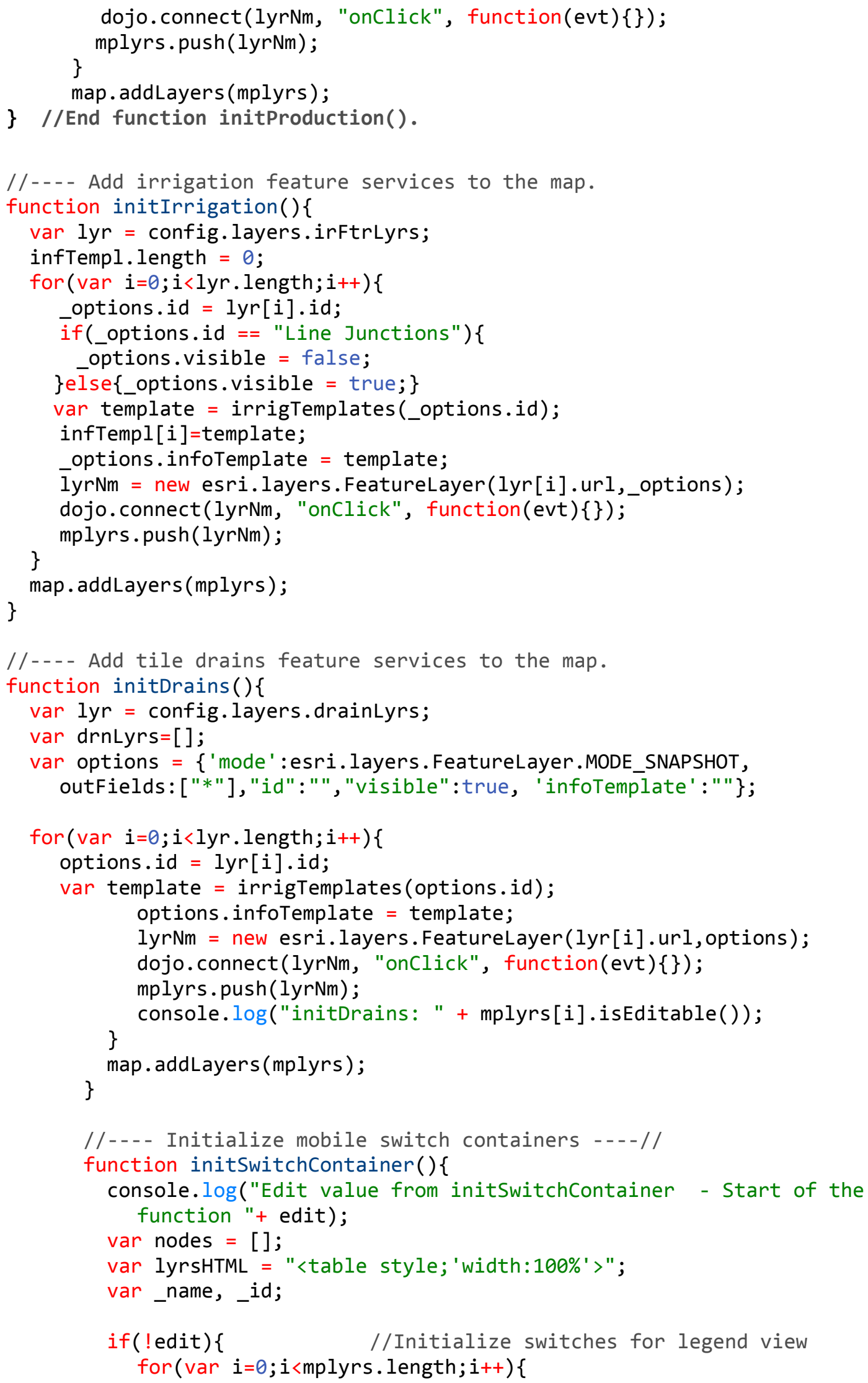




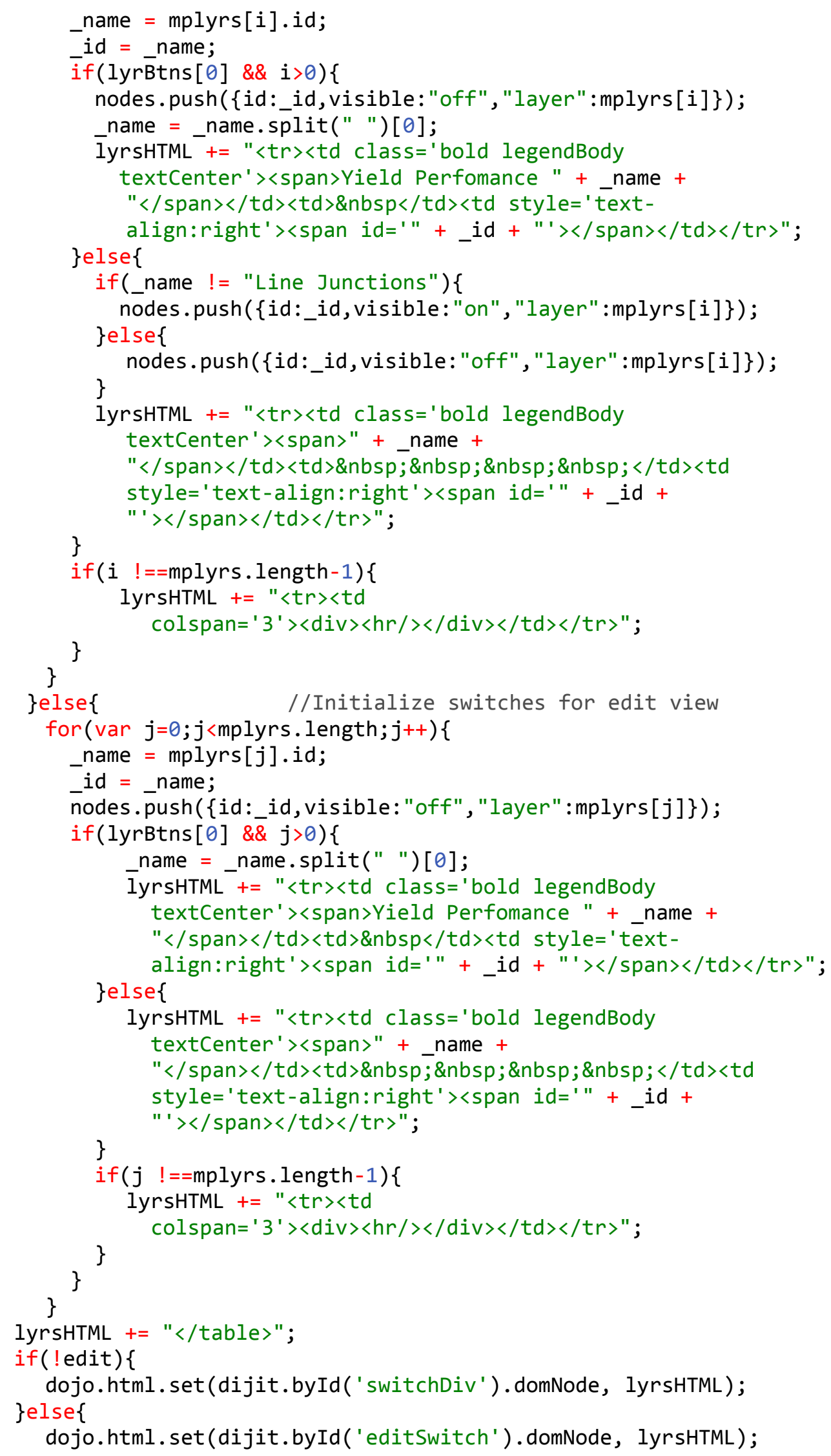




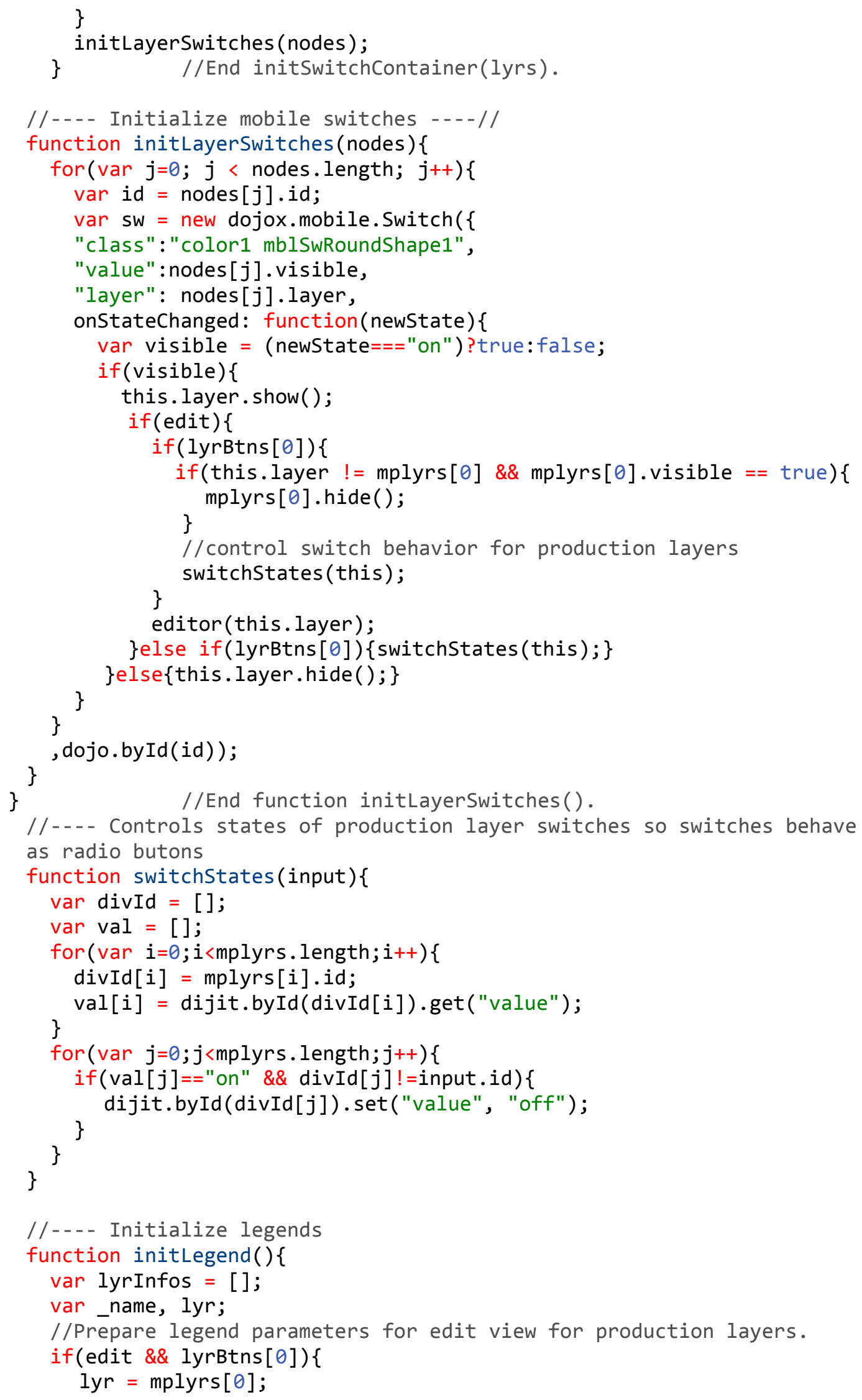




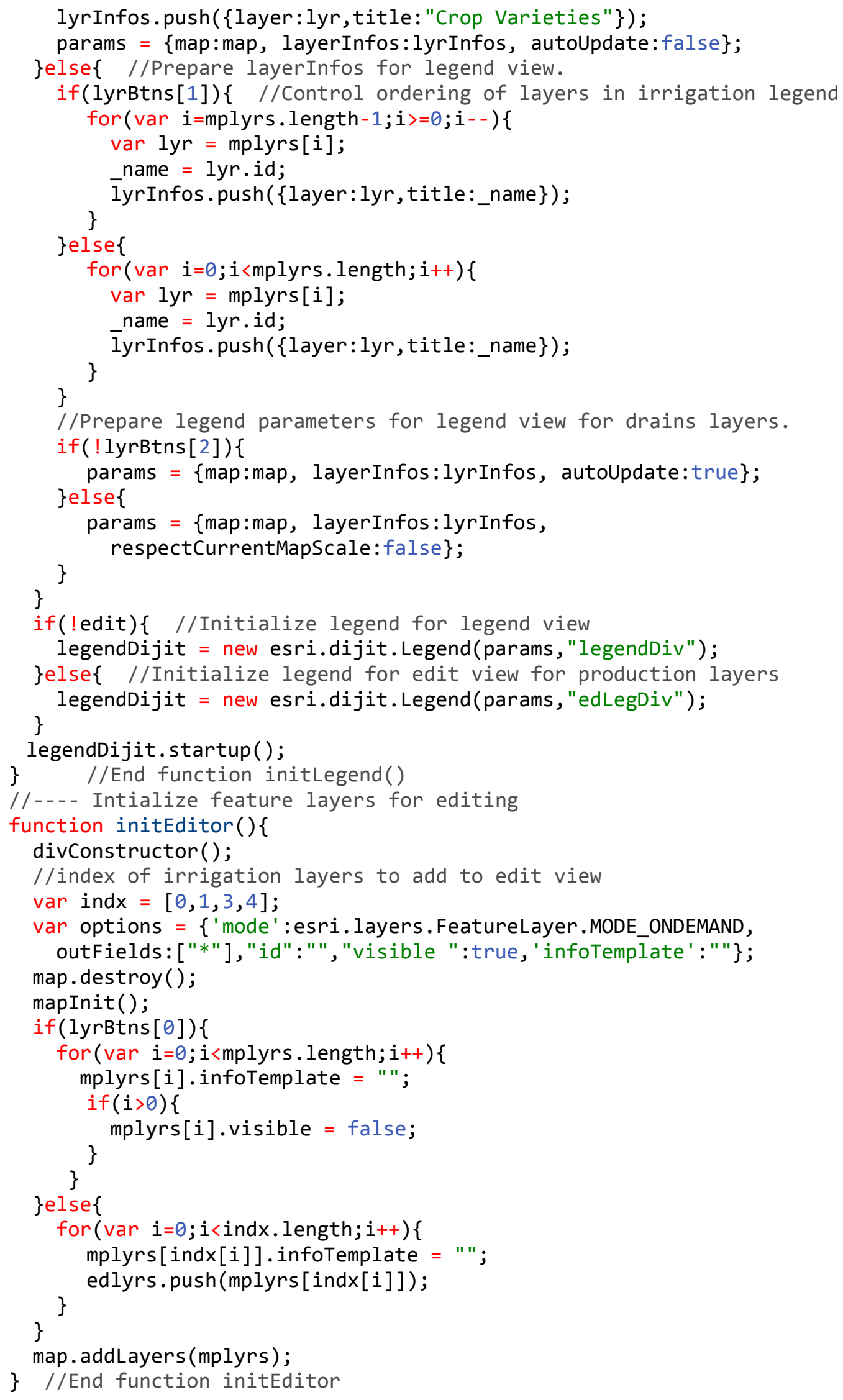




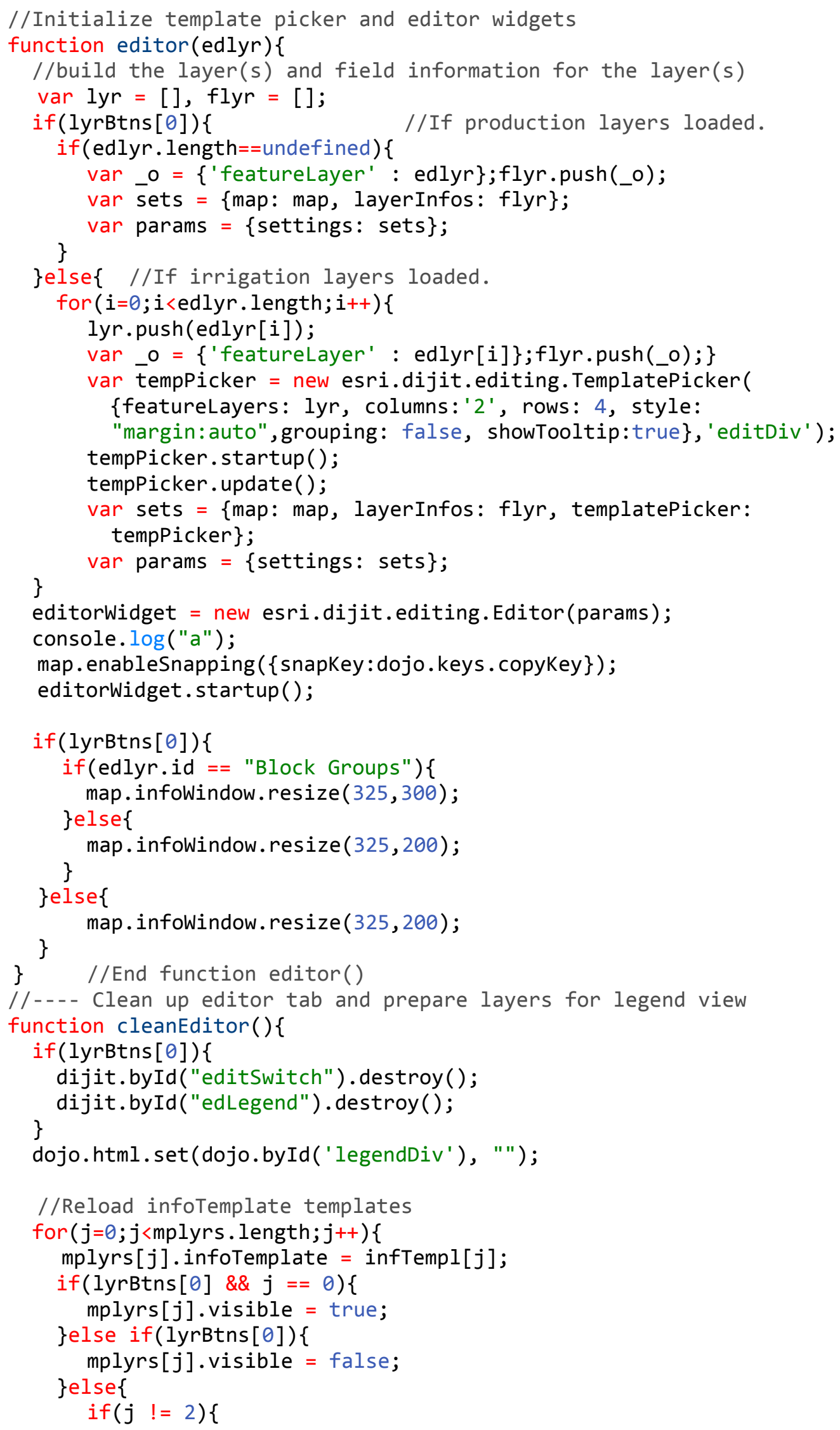




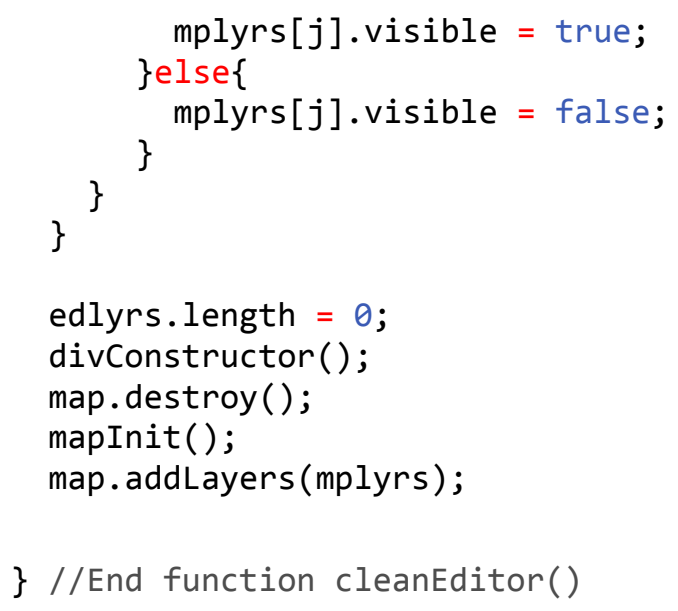

\} //End function divConstructor() 


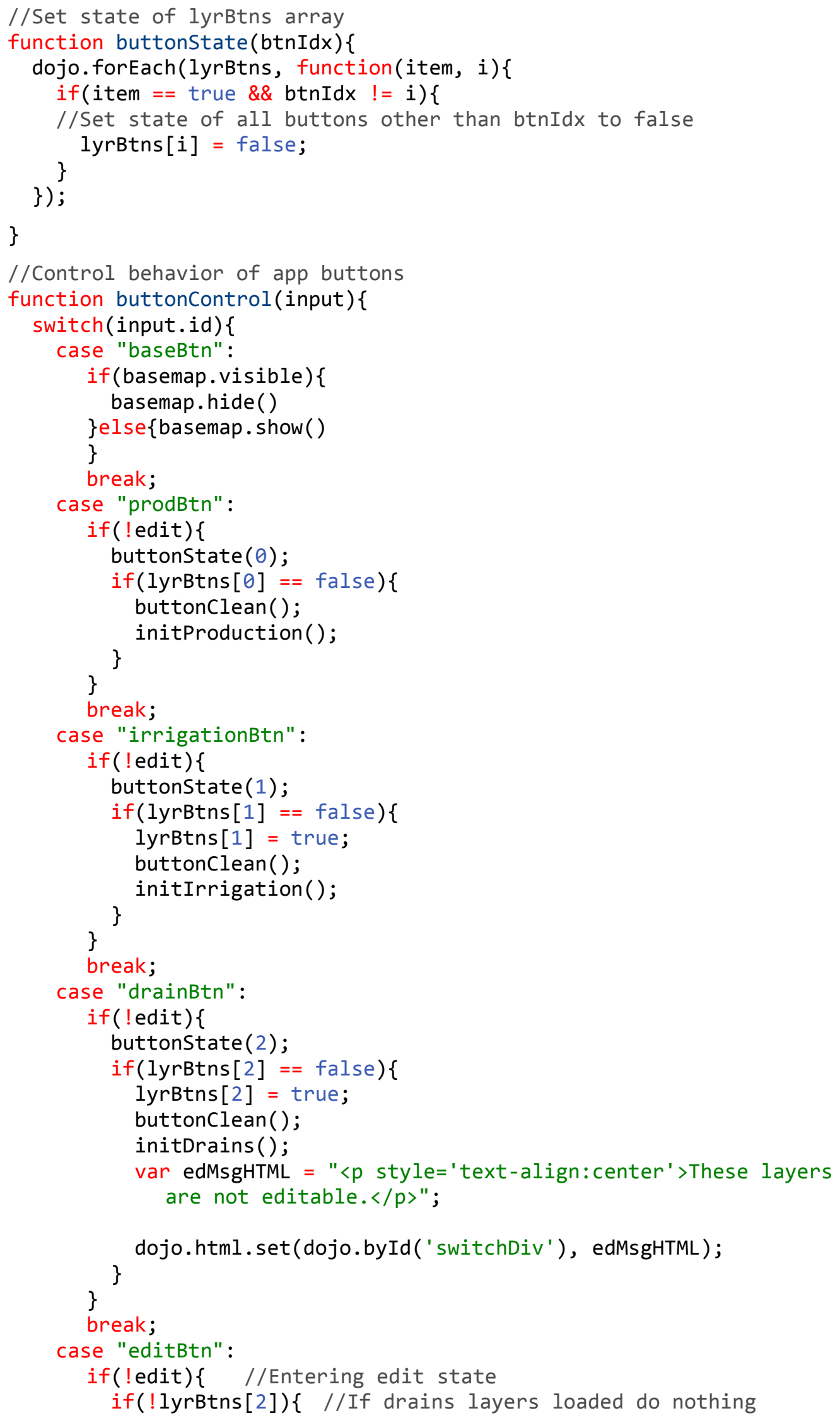




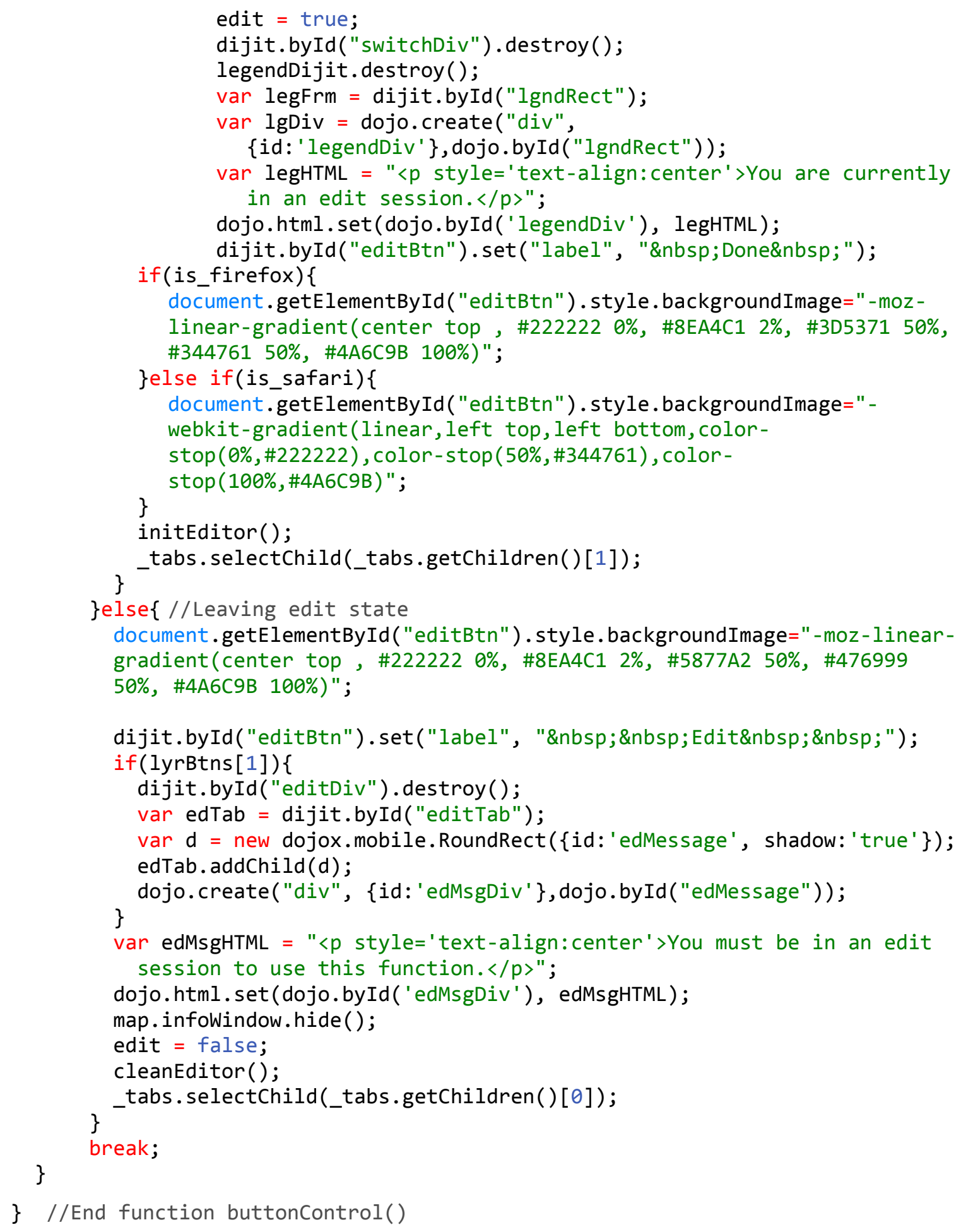




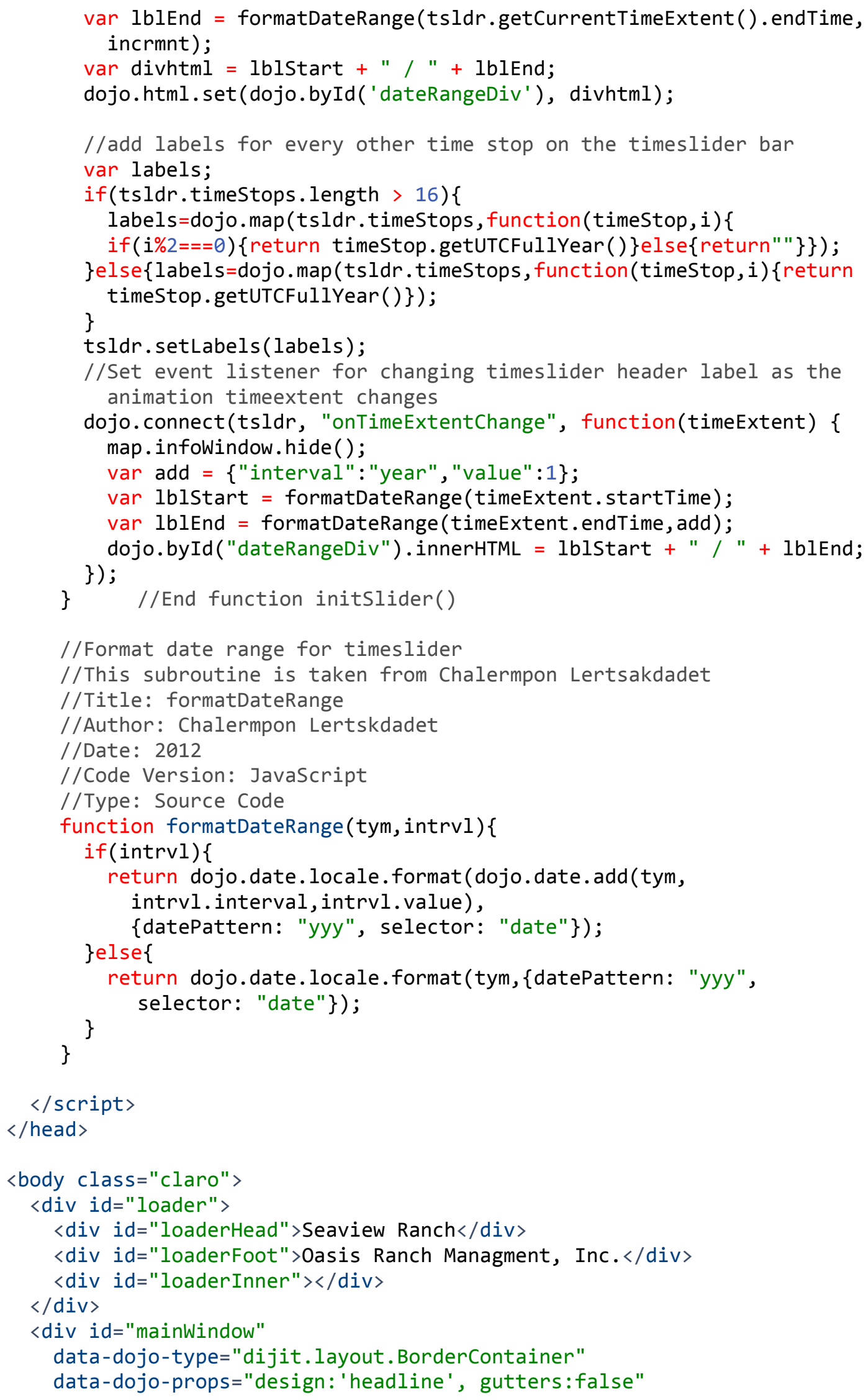




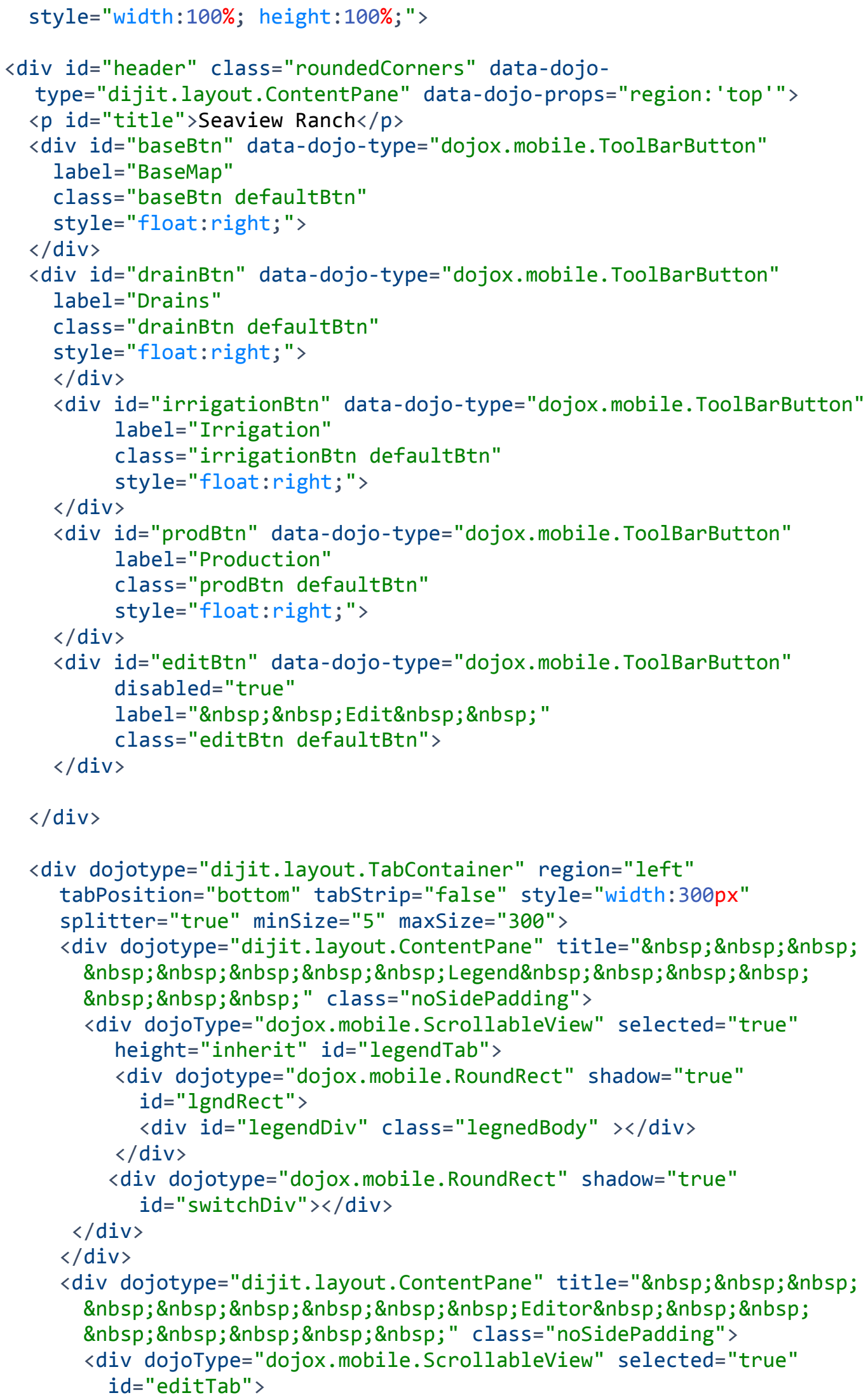




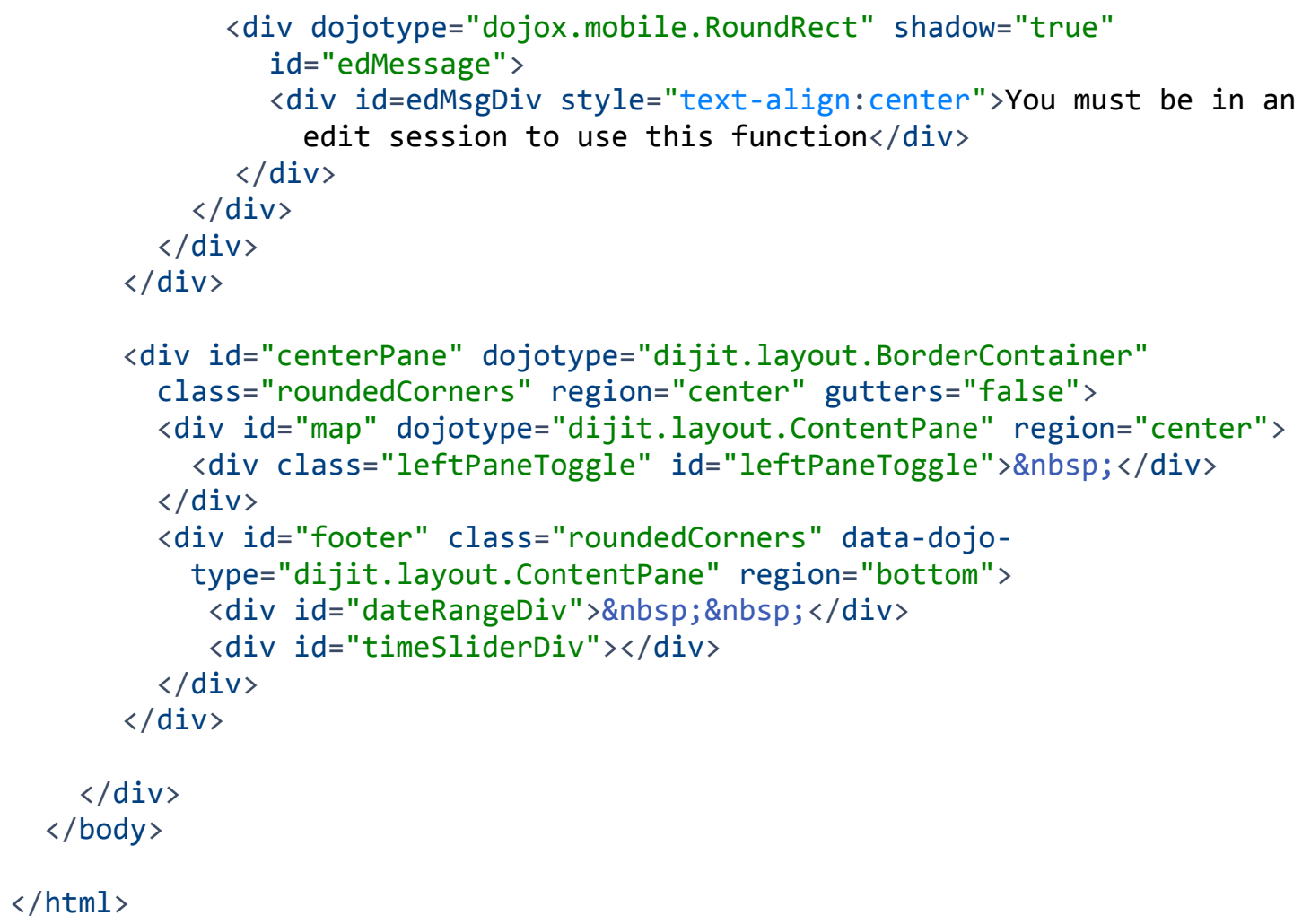

The following code contains the functions that return infotemplate values for loading into the custom popup windows. The code can be found in the templates.js file.

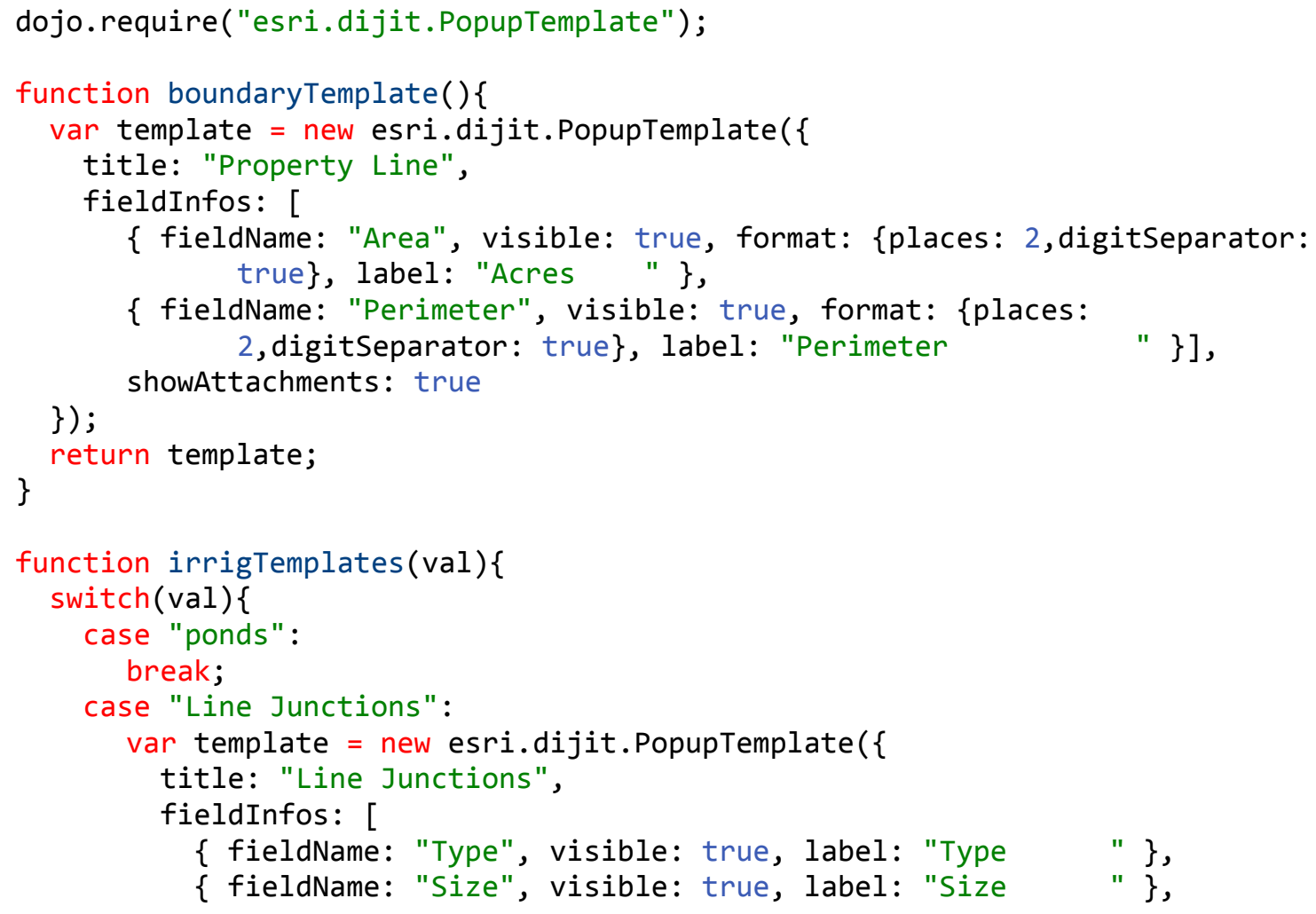




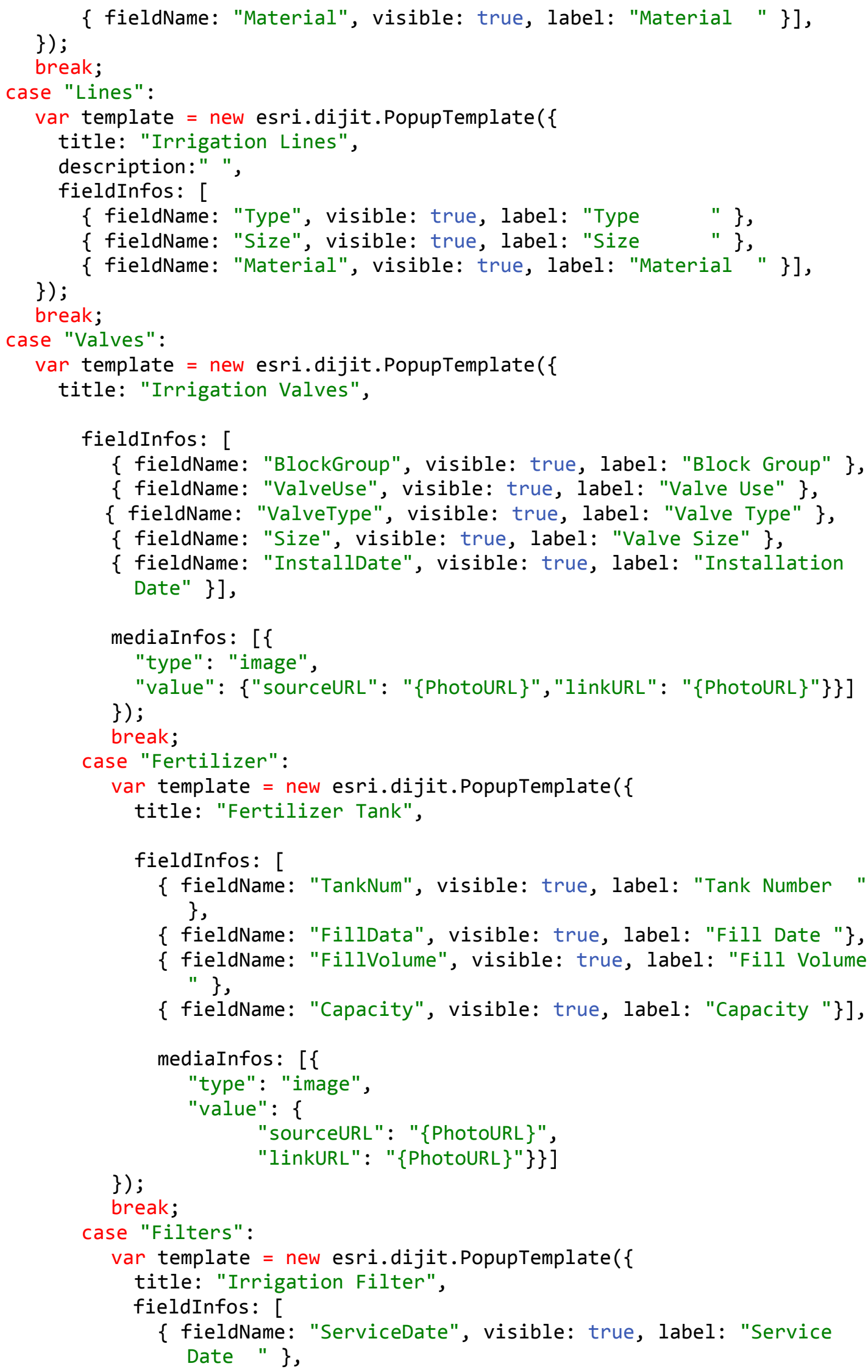




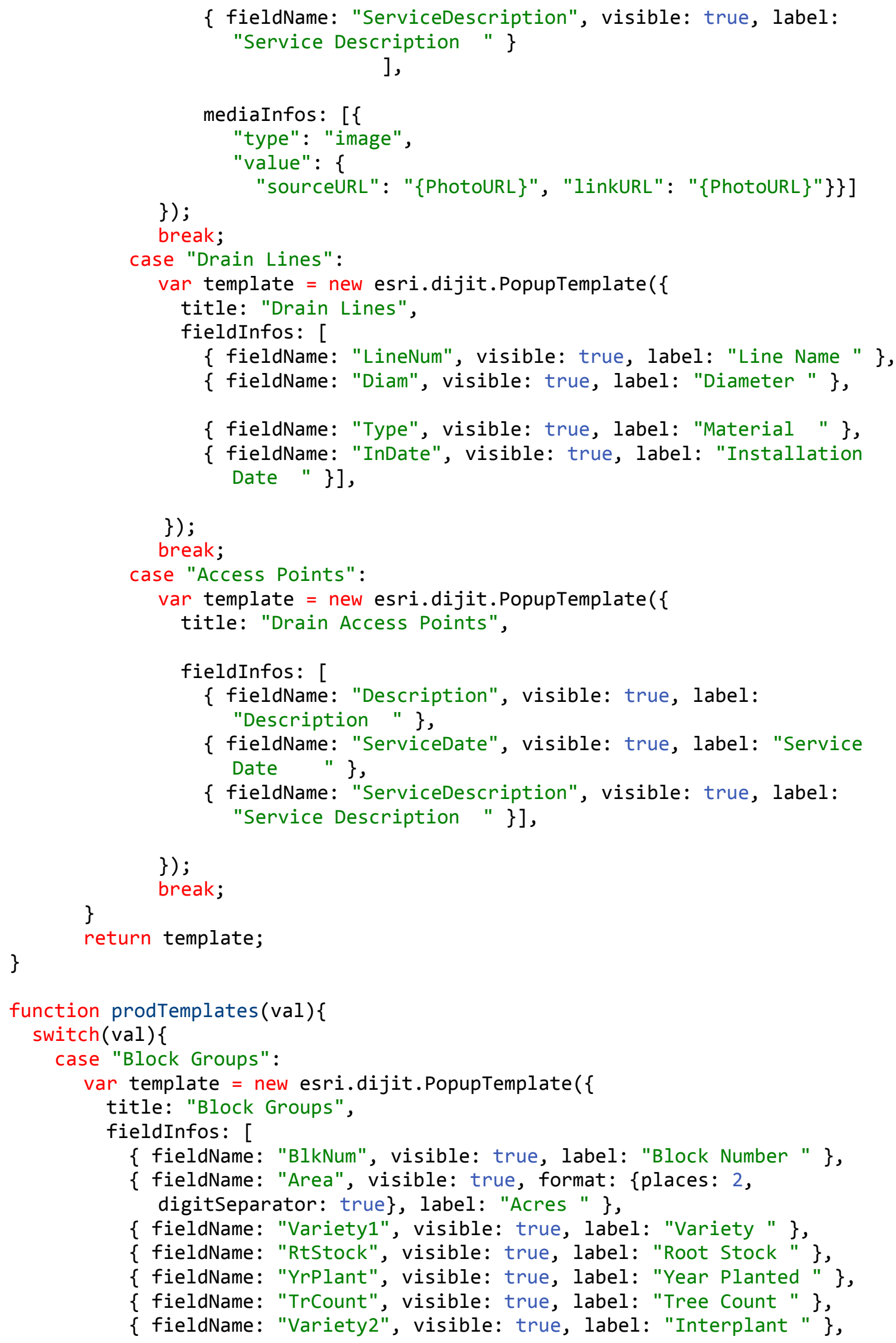




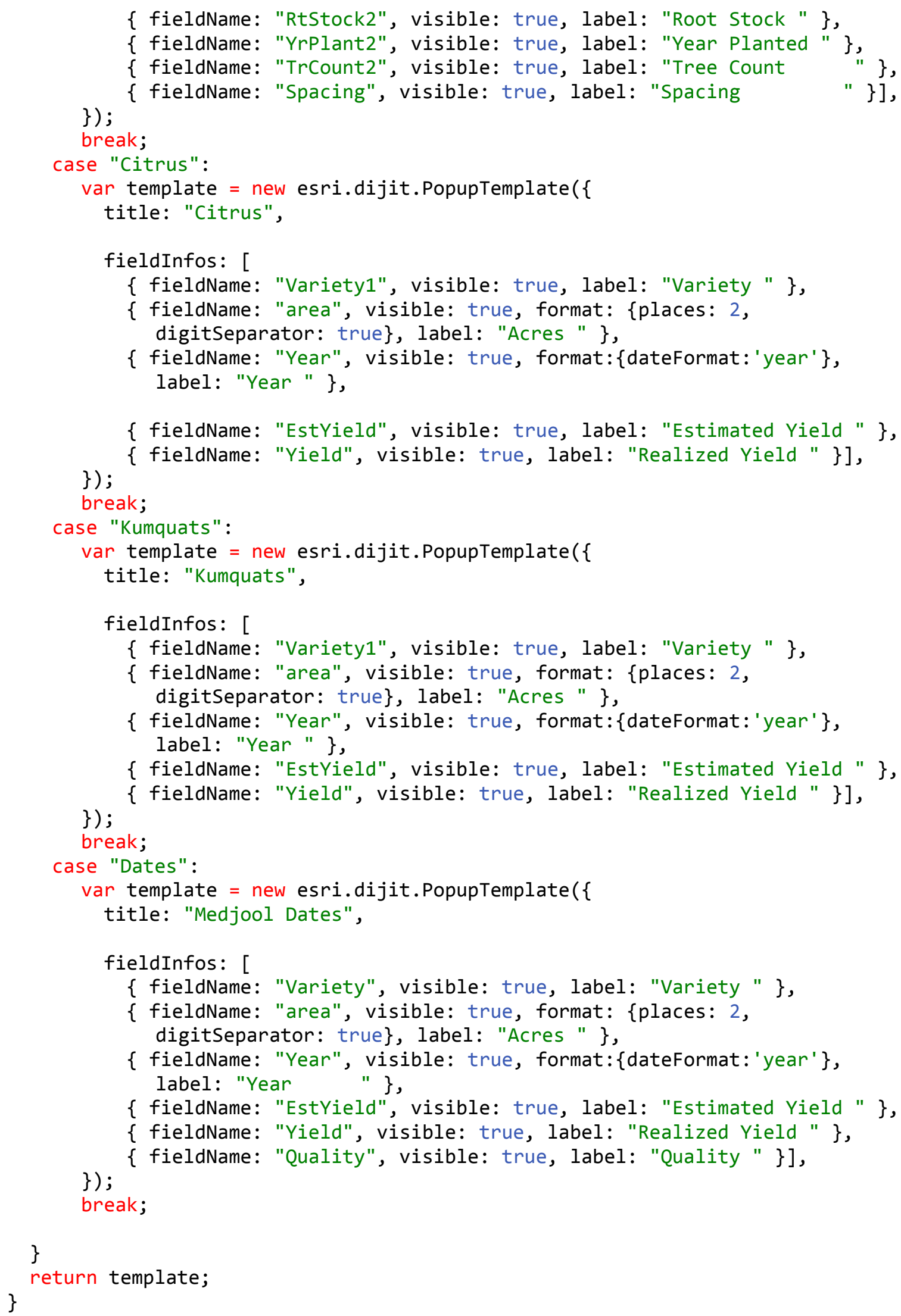


The following code contains configuration data such as the resource URLs. The code can be found in the AgolConfig.js file.

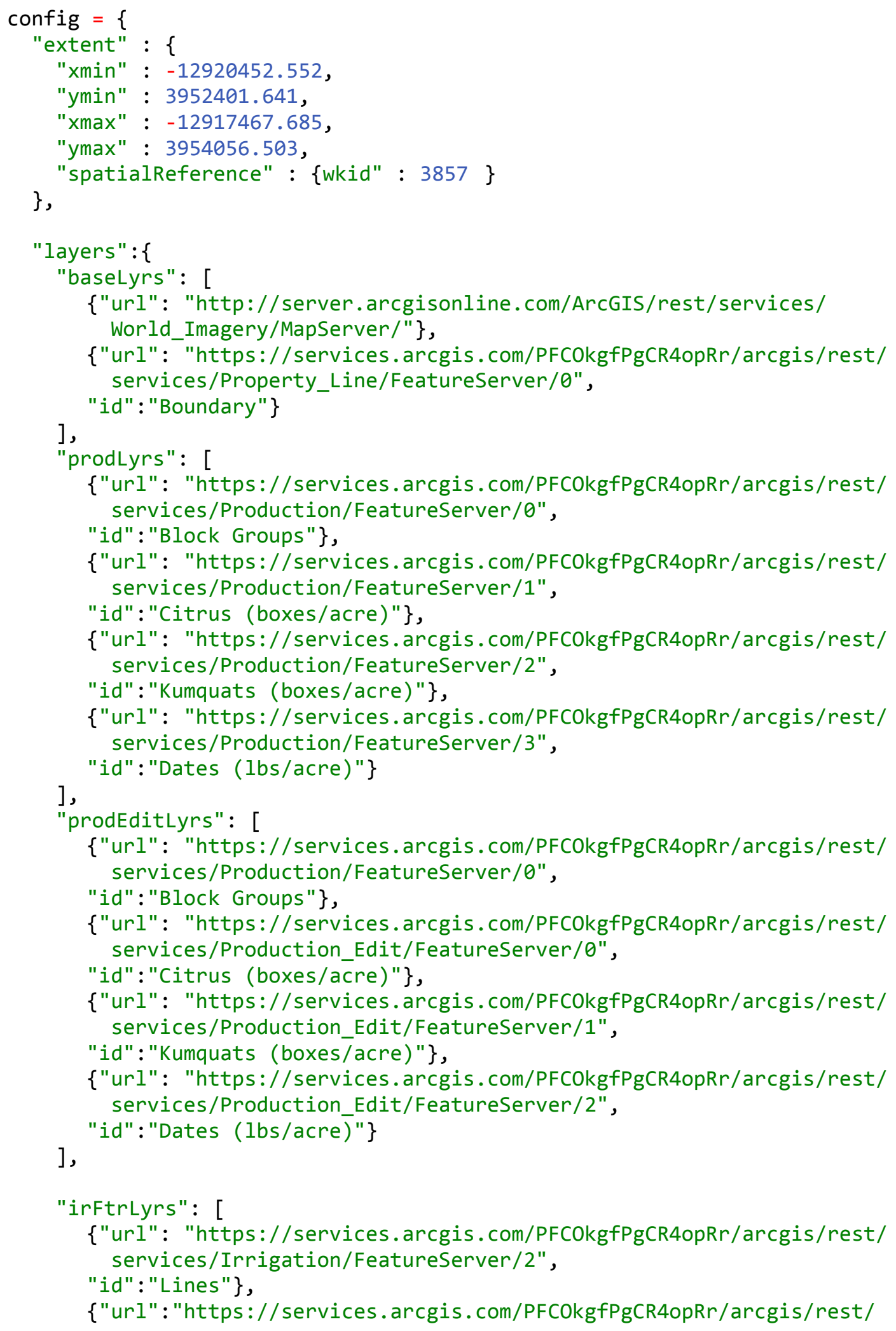




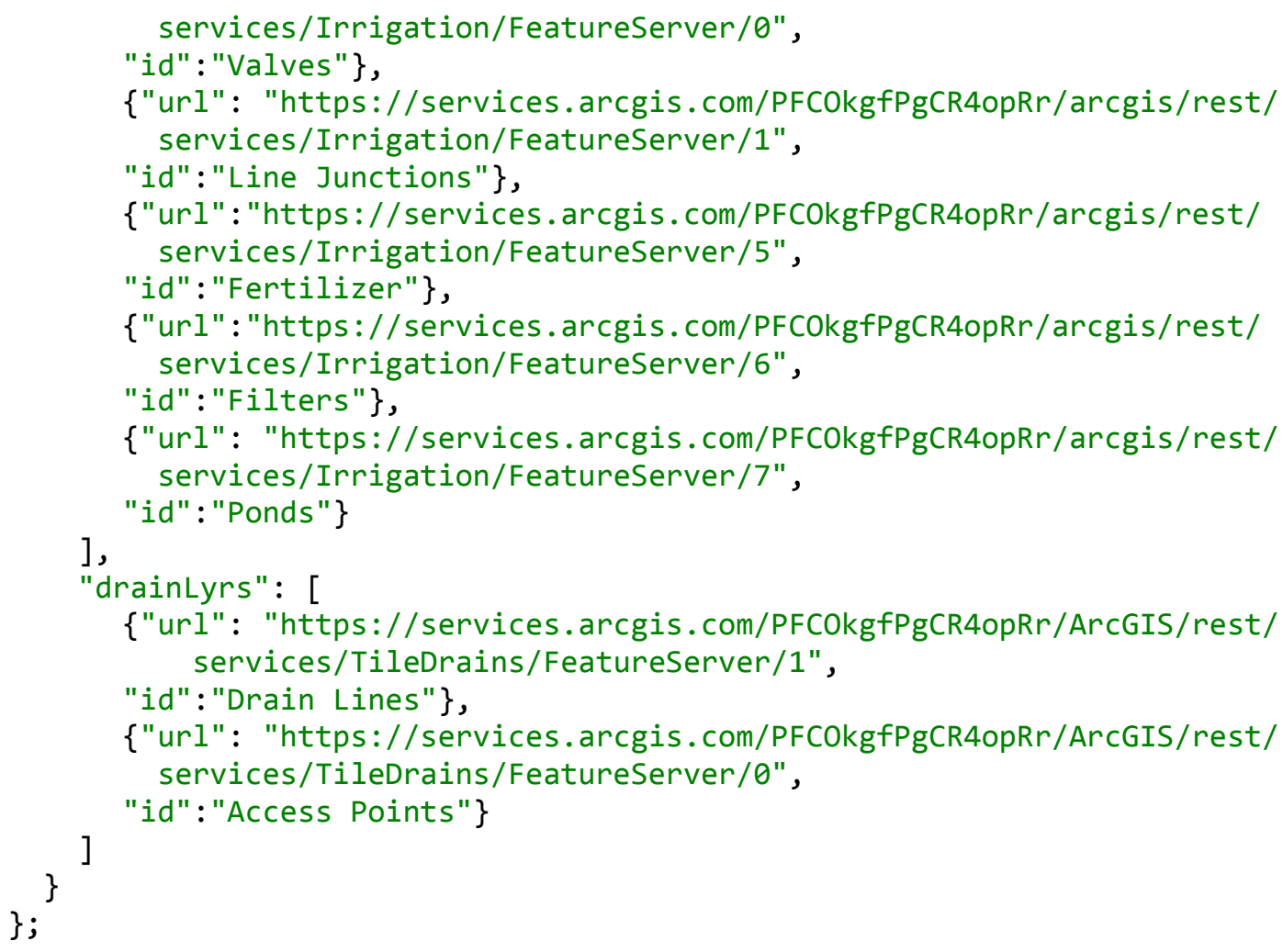

The following code contains CSS3 code that applies custom styling to the application. The code can be found in the SeaviewStyle.css file.

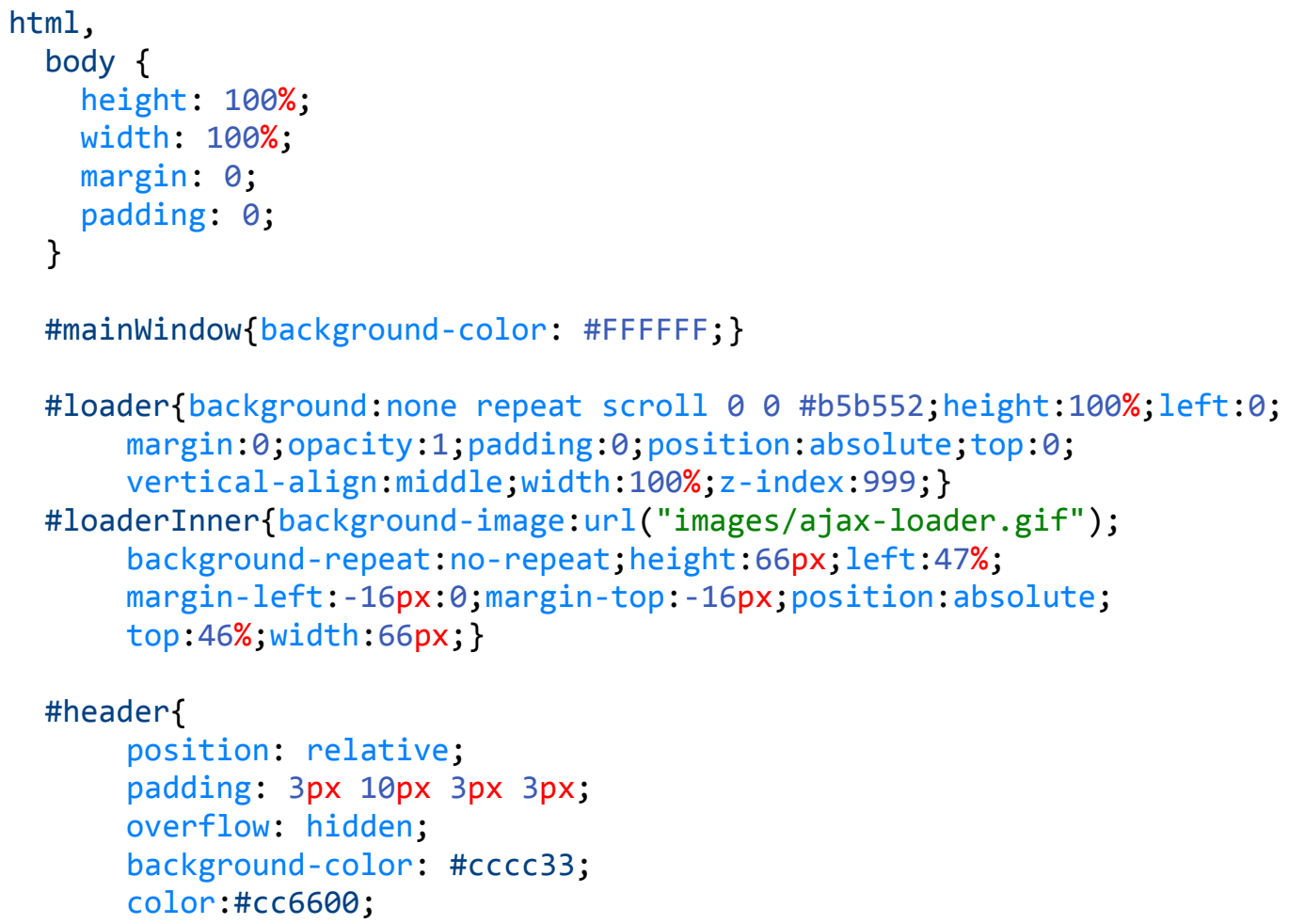




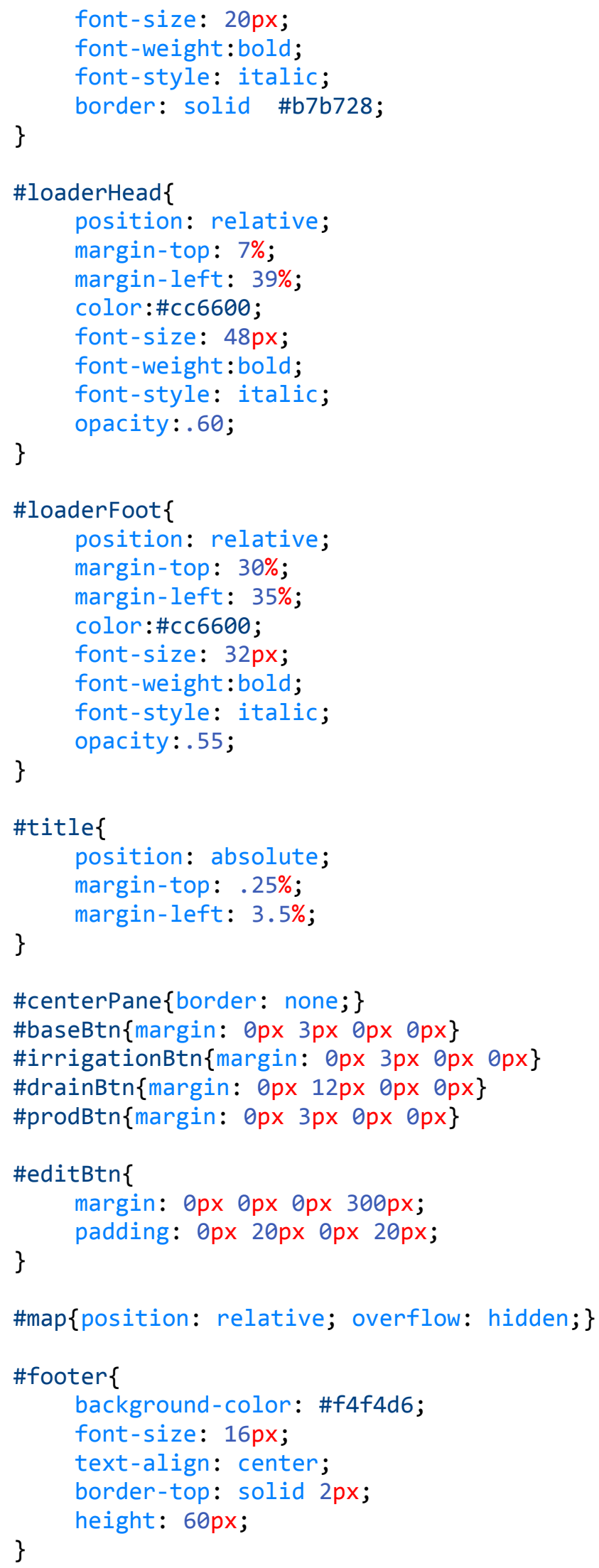


.dijitBorderContainer .dijitGutter background-color:\#CCCC33 ! important\}

.dijitTabContainer .noSidePadding\{padding: 8px, 0 ; background-color:\#f4f4d6\}

\#dijit_layout_TabContainer_0_splitter\{background-color: \#CCCC33\}

\#leftPane\{background-color:\#fafafa; color:\#80A8C1\}

. leftPaneToggle\{

background: url("images/action.png") no-repeat scroll 4px 14px

transparent !important;

background-color: \#F4F4D6 ! important;

color: \#F4F4D6;

cursor:pointer;

height: 43px;

left: $\theta$;

position: absolute;

top: $49 \%$;

width: $24 \mathrm{px}$;

z-index: 1 ;

border: solid 1px \#80a8c1;

\}

. leftPaneToggle.leftPaneToggleIn\{

background: url("images/actionRt.png") no-repeat scroll 4px 14px transparent ! important;

background-color: \#F4F4D6 ! important;

color: \#F4F4D6;

cursor:pointer;

height: 43px;

left: $\theta$;

position: absolute;

top: $49 \%$;

width: 24px;

z-index: 1 ;

border: solid 1px \#80a8c1;

\}

.leftPaneToggle:hover\{

background: url("images/action.png") no-repeat scroll 4px 14px transparent !important;

background-color: \#cccc33 ! important;

\}

color: \#cccc33;

.leftPaneToggle.leftPaneToggleIn: hover\{

background: url("images/actionRt.png") no-repeat scroll 4px 14px transparent ! important;

background-color: \#cccc33 ! important;

\}

color: \#cccc33;

.esriAttributeInspector \{height:300px

.esriAttributeInspector .atiLayerName\{display:none;

.esriLegendServiceLabel, .esriLegendLayerLabel\{font-size: .95em;\}, .esriLegendLayer\{font-size: .9em; \}

.legendBody\{color:\#3d3d3d; font-size: $0.8 \mathrm{em}$; margin:5px 00 5px\} 


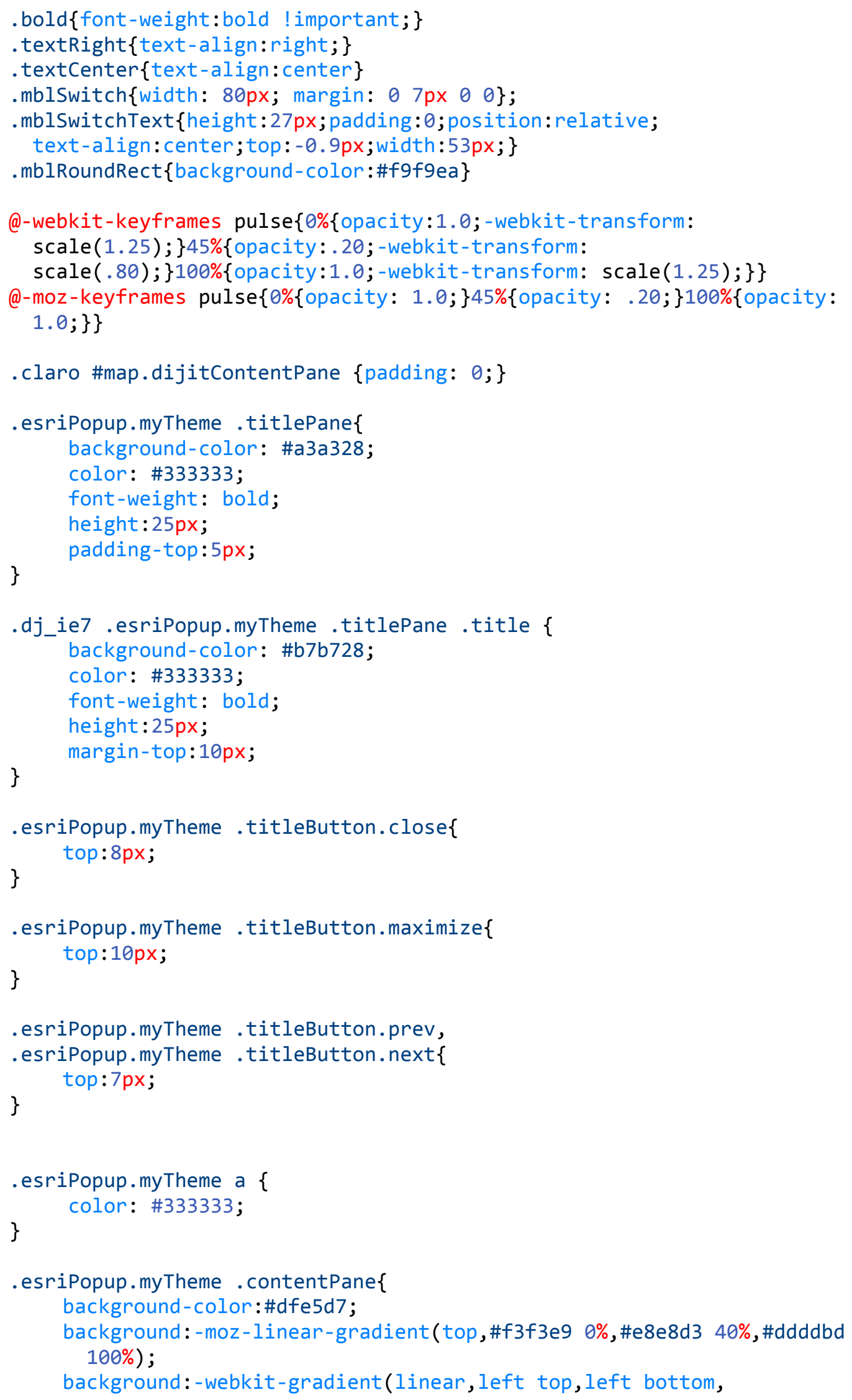




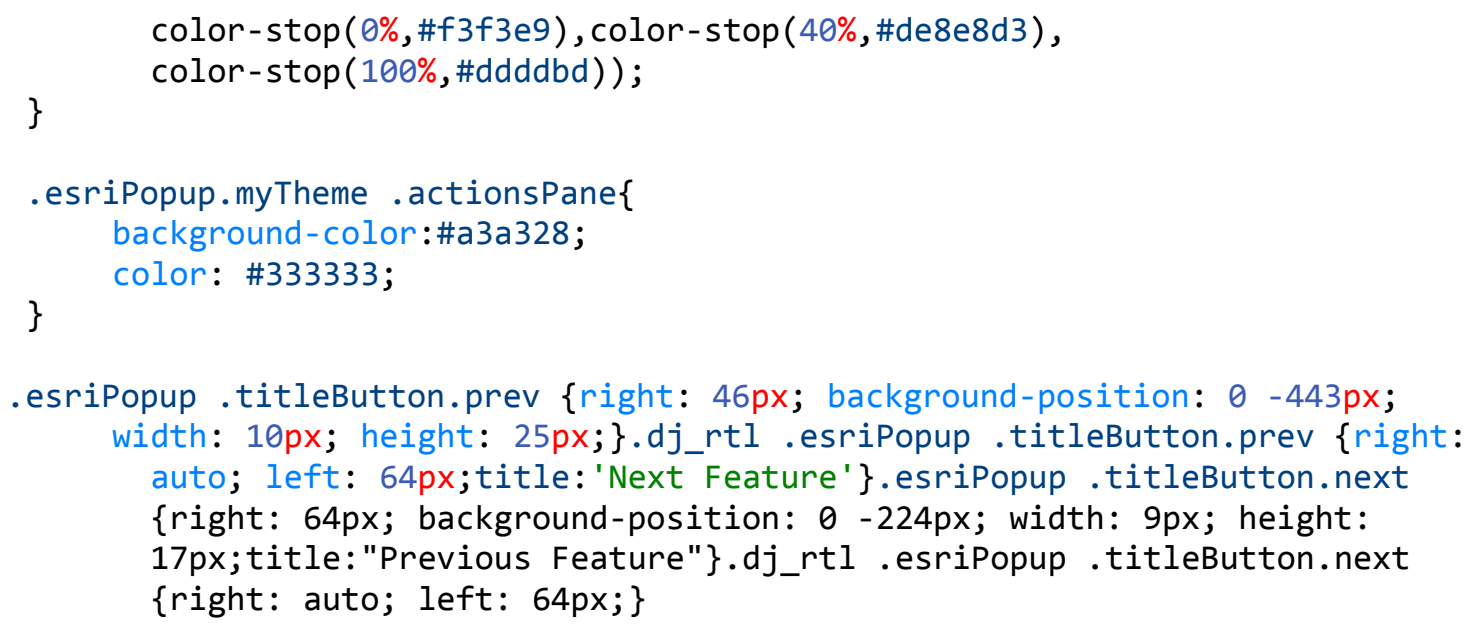

